\title{
Parkinson's disease : some pharmacotherapeutic aspects
}

Citation for published version (APA):

Jansen, E. N. H. (1994). Parkinson's disease : some pharmacotherapeutic aspects. [Doctoral Thesis, Maastricht University]. Rijksuniversiteit Limburg. https://doi.org/10.26481/dis.19940602ej

Document status and date:

Published: 01/01/1994

DOI:

10.26481/dis.19940602ej

Document Version:

Publisher's PDF, also known as Version of record

\section{Please check the document version of this publication:}

- A submitted manuscript is the version of the article upon submission and before peer-review. There can be important differences between the submitted version and the official published version of record.

People interested in the research are advised to contact the author for the final version of the publication, or visit the DOI to the publisher's website.

- The final author version and the galley proof are versions of the publication after peer review.

- The final published version features the final layout of the paper including the volume, issue and page numbers.

Link to publication

\footnotetext{
General rights rights.

- You may freely distribute the URL identifying the publication in the public portal. please follow below link for the End User Agreement:

www.umlib.nl/taverne-license

Take down policy

If you believe that this document breaches copyright please contact us at:

repository@maastrichtuniversity.nl

providing details and we will investigate your claim.
}

Copyright and moral rights for the publications made accessible in the public portal are retained by the authors and/or other copyright owners and it is a condition of accessing publications that users recognise and abide by the legal requirements associated with these

- Users may download and print one copy of any publication from the public portal for the purpose of private study or research.

- You may not further distribute the material or use it for any profit-making activity or commercial gain

If the publication is distributed under the terms of Article $25 \mathrm{fa}$ of the Dutch Copyright Act, indicated by the "Taverne" license above, 


\section{PARKINSON'S DISEASE}

SOME PHARMACOTHERAPEUTIC ASPECTS 
Ontwerp - lay out: Th.A.M.J. van Lieshout, Maastricht

Druk-en bindwerk: Drukkerij Alfa, Enschede

\section{(IP DATA KONINKLIJKE BIBLIOTHEEK, DEN HAAG}

Jansen, Ernst N.H.

Parkinson's Disease. Some pharmacotherapeutic aspects. / Ernst Nicolaas Herman Jansen. Enschede.

Proefschrift Maastricht. - met lit. opg. - Met samenvatting in het Nederlands.

ISBN 90-9007178-4

Trefw:: Parkinson's disease/pharmacotherapy/apomorphine 


\section{PARKINSON'S DISEASE}

\section{SOME PHARMACOTHERAPEUTIC ASPECTS}

\section{Proefschrift}

ter verkrijging van de graad van doctor aan de Rijksuniversiteit Limburg te Maastricht, op gezag van de Rector Magnificus, Prof.dr. H. Philipsen, volgens het besluit van het College van Dekanen,

in het openbaar te verdedigen op donderdag, 2 juni 1994 om 14.00 uur

door

Ernst Nicolaas Herman Jansen geboren te Kamperland in 1945 
Promotor: Prof.dr. J. Troost

Beoordelingscommissie:

Prof.dr. H.A.J. Struijker Boudier (voorzitter)

Dr. J. Lodder

Prof.dr. H.M. van Praag

Prof.dr. R.A.C. Roos (Rijksuniversiteit Leiden)

Prof.dr. A. Staal (Erasmus Universiteit Rotterdam) 
Ik had het leven me anders voorgesteld, meer als een spel van nauw betoomde krachten, van groote passies en vermetel trachten, de groote trek, de worstling met geweld.

\author{
J. Slauerhoff
} uit: Al dwalend 


\section{CHAPTER 1}

Diagnosis of Parkinson's disease.

CHAPTER 2

The pharmacotherapy of Parkinson's disease.

CHAPTER 3

Neuroprotection by selegiline?

CHAPTER 4

Open multicenter trial with Madopar HBS in parkinsonian patients. Preliminary assessment after short-term treatment.

CHAPTER 5

Madopar HBS in Parkinson patients with nocturnal akinesia.

CHAPTER 6

Clinical efficacy of Sinemet CR 50/200 versus

Sinemet 25/100 patients with fluctuating Parkinson's disease. An open, and a double-blind, double-dummy, multicenter treatment evaluation.

\section{CHAPTER 7}

Parlodel SRO in Parkinson's disease: A double-blind randomized comparison of Parlodel standard and Parlodel SRO. 
CHAPTER 8

$A$ "Old wine in new bottles"; therapy with subcutaneous apomorphine in Parkinson's disease.

B Pharmacokinetics of Apomorphine in Parkinson's Disease. Plasma and cerebrospinal fluid levels in relation with motor responses.

CHAPTER 9

Increase of Parkinson disability after fluoxetine medication.

CHAPTER 10

Clozapine in the treatment of tremor in Parkinson's disease.

CHAPTER 11

Concluding Remarks

CHAPTER 12

Summary

Samenvatting 
CHAPTER 1

Diagnosis of Parkinson's disease. 


\section{Definition}

Parkinson's disease (PD) is an idiopathic, relentless progressive neurologic disorder and is the most common form of parkinsonism. Parkinson's disease is considered to be a distinct clinical and neuropathologic entity, characterized clinically by bradykinesia, resting tremor, cogwheel rigidity, gait difficulty and postural reflex impairment. In addition to these cardinal signs there are many motor and non-motor manifestations of Parkinson's disease, including cognitive, sensory and autonomic disturbances. Pathologically $\mathrm{PD}$ is characterized by the loss of pigmented neurons, most prominently in the substantia nigra, with associated very specific eosinophilic cytoplasmic inclusions (Lewy bodies). ${ }^{1}$ Lewy bodies represent the typical histologic hallmark of PD. Although pigmented neurons in the substantia nigra degenerate more than the non-pigmented neurons, the other brain stem catecholaminergic neurons seem to degenerate regardless of the degree of melanin pigmentation. ${ }^{2}$

By defining PD in this way all parkinsonism of known etiology is excluded, as are all disorders with multiple system involvement or significant lesions of the striatum, such as progressive supranuclear palsy, olivopontocerebellar atrophy, Shy-Drager syndrome or striatonigral degeneration. The term 'parkinsonism' refers to any clinical syndrome in which signs typical of Parkinson's disease are prominent, regardless of the cause of the condition or its underlying pathologic substrate.

These clinical and pathological criteria, however, are too restrictive and simple, and they do not take into account the heterogenous clinical and pathologic presentations of Parkinson's disease and the overlap with other Parkinsonian disorders, each with presumably distinct etiology. In the absence of a specific biological marker for PD, the differentiation of PD from other Parkinsonian disorders rests on clinico-pathologic criteria that have yet to be rigorously tested and validated. ${ }^{3}$

\section{Diagnosis of Parkinson's disease. A changing nosological concept.}

The English physician and geologist James Parkinson provided the first clear description of the disorder that now bears his name in a brief monograph: an Essay on the Shaking Palsy, published in $1817 .^{4} \mathrm{His}$ description was based on the observation of only six patients. Three of these patients were seen by Parkinson 'at a distance', underlining that in 
clinical neurology - as it has developed later on - it is to some extent still possible to come to a 'diagnose à vue'. After this first description of PD, paralysis agitans has been defined entirely in clinical terms as a distinctive syndrome of motor dysfunction. This concept of a particular motor syndrome has remained firmly entrenched in medical literature, reinforced in our time by the discovery that the motor syndrome reflects striatal dopamine deficiency and by the dramatic success of levodopa therapy.

The nosological concept however of PD as a specific morbid entity has been undermined by the plethora of parkinsonisms and the paucity of clinicopathologic correlations. ${ }^{5}$ Is there a true PD plus many other parkinsonisms"? Is the term idiopathic parkinsonism preferable, because it avoids a firm implication of nosological specificity. ${ }^{6}$ The profusion of Parkinson syndromes has given rise to confusion and controversy.

Advances in the identification of distinct parkinsonian syndromes, like Lewy-body disease, postencephalitic parkinsonism and striatonigral degeneration, were - to a large measure - due to clinicians working closely with their colleagues in neuropathology or to clinician-pathologists such as Raymond Adams and Ludo van den Bogaerdt. The Lewy body in the substantia nigra came to be recognized as the pathologic hallmark of Parkinson's disease, the neurofibrillary tangle in the substantia nigra as typical of postencephalitic parkinsonism, the cytoplasmic argyrophilic inclusion body as highly specific for multiple system atrophy ${ }^{2}$, as are the globose neurofibrillary tangle in progressive supranuclear palsy, the corticobasal inclusion in corticodentatonigral degeneration and the argyrophilic grains in argyrophilic grain disease. ${ }^{7 a}$ Striatonigral degeneration could be separated from idiopathic parkinsonism on morphological grounds, even though clinicians could not - at that time differentiate the two conditions. Striatonigral pathology seems the most likely pathology in all non-demented patients with a pure bradykineticrigid disorder and little or no response to a sustained trial of levodopa given in a large dose. The Parkinsonian disorders were diagnosed on pathologic criteria by the neuronal morphology present in the substantia nigra pars compacta, specifically the kind of degenerative inclusion body, and by the distribution pattern of nerve cell loss elsewhere in the nervous system.

Increasing knowledge of the Lewy body in the past decade has further changed our nosological concept. A differential distribution of Lewy body pathology in the subgroups of the substantia nigra - the ventrolateral part of the substantia nigra that projects chiefly to the putamen is more affected than the dorsal part- and the pattern of distribution of Lewy 
bodies throughout the central and peripheral nervous system has led to a high degree of specificity in the pathology of $\mathrm{PD} .{ }^{8}$ In normal aging the ventral tier of the substantia nigra is not preferentially affected, and this is associated with a most prominent depletion of dopamine in the caudate nucleus. PD as a nosological entity has become synonymous with Lewy body disease, so much so that the finding of incidental Lewy body disease - in individuals who were asymptomatic in life - is believed to represent preclinical PD. The concept of idiopathic Lewy body disease arises from the notion that $\mathrm{PD}$ is a part of the spectrum of a wider degenerative process. It seems surprising but most persons harbouring Lewy bodies in the substantia nigra do not have - clinical features of Parkinson's disease. The reason for this is that Lewy bodies at this site are found in the general population with a prevalence level of $1 \%$ in persons in their $50 \mathrm{~s}$, possibly to as high as $10 \%$ in persons in their $80 \mathrm{~s} .{ }^{2}$ The demonstration of - a variable degree of - Lewy bodies in specific areas of the cerebral cortex in all patients with idiopathic Parkinson's disease (i.e. Lewy body disease features in the brainstem) has further broudened the nosological concept of clinical and pathological PD. ${ }^{3}$ It is now clear that there is a clinicopathologic spectrum extending from dementia, with absence or only few clinical Parkinson symptoms and severe cortical Lewy body involvement with coexisting brainstem Lewy body pathology, to a clinical syndrome of motor symptoms typical for idiopathic PD without cognitive decline and morphologically a brainstem Lewy body pathology with only scanty presence of Lewy bodies in the

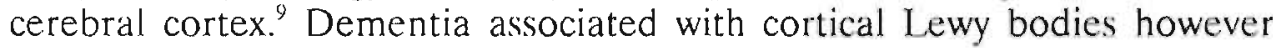
is rare in the absence of Alzheimer Type Pathology and in these cases the cortical Lewy bodies are generally believed to be exceptionally numerous.

It is not precisely known how important Lewy bodies are for Parkinson's disease. How specific are these inclusions for this particular disease and what metabolic derangements lead to their formation? ${ }^{10}$ Lewy bodies seem to signify neuronal degeneration; and nerve cell loss in PD occurs with them being found in some of these degenerating nerve cells. Recently Kremer and Bots ${ }^{1 \mathrm{i}}$ challenged the hypothesis that Lewy bodies are a sign of significant cell death.

Being aware of these pitfalls in the clinical and pathological diagnosis of PD, makes an unhesitatingly labelled diagnosis of Parkinson's disease a nearly impossible task for the neurologist. Chaos seems complete for neurologists of a former generation if we nowadays are able to recognize Lewy body disease in the absence of parkinsonism. Alzheimer Type Pathology in the basal ganglia and substantia nigra without Lewy body 
pathology, can be present in non-demented patients with a typical clinical pattern of idiopathic PD including positive response on levodopa. ${ }^{12}$ On the other hand it has been demonstrated that clinically atypical cases of PD nevertheless have typical Lewy body pathology. ${ }^{3,13}$ Clinical criteria alone, as Hughes et $\mathrm{al}^{3}$ have recently shown, do only imperfectly differentiate Lewy body parkinsonism from other degenerative disorders capable of causing parkinsonism. About $20 \%$ of patients thought to have $\mathrm{PD}$ during life are found at postmortem examination to have alternative diseases. ${ }^{3}$ Keeping in mind the frequent occurrence of dementia in PD, the loose connection of cognitive decline with the degree of coexisting cortical Lewy body pathology, cell loss in the nucleus basalis of Meynert with Lewy bodies ${ }^{70}$ and Alzheimer Type Pathology in the cerebral cortex, and the finding that one third of patients with Alzheimer's disease have Lewy bodies at autopsy ${ }^{2}$, makes a statement possible that there is a "pale body" of evidence to suggest that Parkinson's disease is a mysterious disorder.

That the neurochemical lesion in (pre)clinical PD can now be visualized using positron emission tomography (PET) scan technology ${ }^{14.15}$, brings us back to the possibility of a 'diagnose à vue' in clinical neurology. A spotPET-diagnosis irrespective of the actual presence of clinical phenomena like parkinsonism, dementia, focal dystonias and 'simple tremors'. ${ }^{16}$

\section{Diagnostic criteria for idiopathic Parkinson's disease}

The pathological entity of idiopathic PD with Lewy body formation is the most common cause for the clinical syndrome of parkinsonism. The symptom complex may also be caused by a vast number of different pathologic disorders that interfere with the function of the nigrostriatal dopaminergic system. The major categories of Parkinsonian syndromes are listed in table $\mathrm{I}$. 
Table 1. Classification of parkinsonism

1. Primary parkinsonism

\section{Secondary parkinsonism}

3. Heredodegenerative parkinsonism

4. Multiple system degenerations (parkinsonism plus)
- Parkinson's disease

- Juvenile parkinsonism.

- Infectious: postencephalitic, slow virus

- Drugs: dopamine receptor blocking drugs (antipsychotic, antiemetic drugs), reserpine, tetrabenazine, alphamethyldopa, lithium, flunarizine, cinnarizine

- Toxins: MPTP, Co, Mn, Hg, CS2. methanol, ethanol

- Vascular: multi-infarct

- Trauma: pugilistic encephalopathy

- Other: parathyroid abnormalities, hypothyroidism, hepatocerebral degeneration, brain tumour, normal pressure hydrocephalus, syringomesencephadia

- Huntington's disease

- Wilson's disease

- Hallervorden-Spatz disease.

- Olivopontocerebellar and spinocerebellar degenerations

- Familial basal ganglia calcification

- Familial parkinsonism with peripheral neuropathy

- Neuroacanthocytosis

- Progressive supranuclear palsy

- Shy-Drager syndrome

- Striatonigral degeneration

- Parkinsonism-Dementia-ALS complex

- Cortical-basal ganglionic degeneration

- Autosomal dominant Lewy body disease

- Alzheimer's disease

The percentage of etiologic categories of parkinsonism has been listed in table II. 
Table II. Etiologic categories of parkinsonism* (Joseph Jankovic)

\begin{tabular}{lcc}
\hline & $\begin{array}{l}\text { Number of } \\
\text { patients }\end{array}$ & Percentage \\
\hline & & \\
Parkinson's disease & 1595 & 77.7 \\
Parkinsonism plus & 250 & 12.2 \\
$\quad$ PSP & 154 & 7.5 \\
SDS & 35 & 1.7 \\
OPCA & 23 & 1.1 \\
CBGD & 18 & 0.9 \\
SND & 9 & 0.4 \\
PD/AD & 8 & 0.4 \\
PD/ALS & 3 & 0.1 \\
Secondary parkinsonism & 168 & 8.2 \\
Heredodegenerative parkinsonism & 12 & 0.6 \\
Unknown & 27 & 1.3 \\
\hline
\end{tabular}

* Baylor College of Medicine, Parkinson's Disease Center and Movement Disorders Clinic $(\mathrm{N}=2052)$

CBGD = Corticobasal ganglionic degeneration; $\mathrm{OPCA}=$ olivopontocerebellar atrophy; $\mathrm{PD} / \mathrm{AD}=$ parkinsonism with severe dementia; $\mathrm{PD} / \mathrm{ALS}=$ Parkinson's disease with motor neuron disease; PSP = progressive supranuclear palsy; SDS = Shy-Drager syndrome; SND = striatonigral degeneration

Idiopathic Parkinson's disease can be characterized clinically by unilateral onset of symptoms, the initial presentation of at least two of the cardinal symptoms of tremor, rigidity, bradykinesia and postural imbalance, a slowly progressive course over more than a few years before marked degrees of disability are reached, a good to excellent response to oral levodopa or subcutaneous apomorphine challenges ${ }^{17.18}$, the absence of significant changes on computed tomography (CT) scanning other than mild diffuse cortical atrophies ${ }^{19}$, normal postsynaptic D2 receptor density in the basal ganglia on [123I] IBZM SPECT-scanning ${ }^{20}$ and $60-80$ percent reduction in the density of striatal dopamine terminals with [18F] fluorodopa and [11C]-nomifensine PET scans. ${ }^{14.15}$

About $90 \%$ of patients with idiopathic PD improve on levodopa, but the response to levodopa is not helpful in accurately predicting the pathologic diagnosis. 
Table III lists the criteria used by the United Kingdom Parkinson's Disease Society Brain Bank. ${ }^{10}$

Table III. Clinical diagnostic criteria for idiopathic Parkinson's disease

Presence of at least two of:

bradykinesia

muscular rigidity

4-6 $\mathrm{Hz}$ resting tremor

postural instability (primary visual, vestibular, cerebellar or proprioceptive dysfunction excluded)

Unilateral onset

Persistent asymmetry

Abscnce of clinical exclusion criteria

Excellent response to levodopa (70)-100\%); sustained for 5 or more years

Clinical course of 10 years or more

Two major clinical subtypes of PD may be identified: one characterized by tremor and the other dominated by 'postural instability and gait difficulty'. The tremor subtype PD is associated with relative preserved mental status, earlier age at onset and slower progression of the disease. Whether these subgroups represent distinct disorders, separate from PD, is uncertain. Rajput et al. ${ }^{21}$ found Lewy bodies at autopsy only in $27 \%$ of patients with the 'postural instability - gait difficulty' form of idiopathic parkinsonism.

Table IV. Accuracy of differential diagnosis of Parkinson's disease

Alternative diagnosis on clinical grounds

$4 \%$ Progressive supranuclear palsy

$6 \%$ Olivopontocerebellar atrophy

$7 \%$ Drug-induced parkinsonism

$20 \%$ MSA

Alternative diagnosis on pathological grounds

18\% Clinical idiopathic Parkinson's disease brains

6\% Strictly defined clinical idiopathic Parkinson's disease (striatonigral degeneration, progressive supranuclear palsy )

$50 \%$ Pathologically proven striatonigral degeneration diagnosed as idiopathic Parkinson's disease in vivo 
Considerable debate exists regarding the diagnostic accuracy of clinical PD. Werner Poewe ${ }^{22}$ has summarized some studies that have addressed the difficulty to make a correct (differential) diagnosis. His findings are listed in table IV.

It has become a common procedure to establish a set of features in patients' history, neurological signs and symptoms that are incompatible with a firm diagnosis of clinical PD. These features are summarized in table $\mathrm{V}$.

Table V. Exclusion criteria for idiopathic Parkinson's disease

History of definite encephalitis

History of repeated stroke with acute onset and/or stepwise progression of signs

History of dopamine antagonist treatment prior to onset

Sustained remission

Oculogyric crises

Supranuclear gaze palsy (downward or lateral)

Cerebellar signs

Early severe dysautonomia

Early severe dementia

Babinski sign

Negative response to maximum tolerated doses of levodopa and apomorphine Incompatible findings on $\mathrm{CT} / \mathrm{MRI}$

However this list of exclusion criteria may have flaws. Gibb ${ }^{2}$ proposed that exclusion criteria for the diagnosis of PD must include also more than one affected relative. It is not uncommon for Parkinsonian patients to report other family members affected with the disease. In fact the genetics of PD have been studied extensively in the past, with generally inconclusive findings. Studies of mitochondrial dysfunction in PD (reduced mitochondrial complex I in the substantia nigra) have bolstered a growing body of evidence supporting a genetic component - with inheritance from the maternal genome. ${ }^{23}$ The non-Mendelian inheritance pattern of mitochondrial DNA would explain low concordance rates for PD in twins. ${ }^{24}$ The classic study of Ward et al. ${ }^{5}$ found no significant difference in concordance rates between monozygotic and dizygotic twins. The findings of Brooks et al. ${ }^{15}$ - by demonstrating reduced putamen [18F] dopa uptake by PET in three of six monozygotic and two of three dizygotic unaffected PD co-twins - suggest however that many of the twin pairs originally reported to be discordant for $\mathrm{PD}$, may well have been concordant if preclinical PD could have been detected. ${ }^{25}$ Golbe $^{6}$ recently 
reported a large kindred with $\mathrm{PD}$ and observed that a single abnormal genome may be capable of producing clinical and pathologic PD. It has become attractive and provocative to make a philosophy on PD as an autosomal dominant disorder. The data already available suggest the hypothesis that Lewy body Parkinson's disease is part of the clinical range of expression of an autosomal dominant disorder ${ }^{6}$ with partial age-related penetrance, long premorbid and prodromal phases and marked variability of clinical manifestations extending beyond the motor syndrome of parkinsonism, upon which our traditional concept of PD is based.

Only recently some risk factors for Parkinson's disease have been established: rural living, pesticide use, male life style, family of neurologic disease and history of depression. ${ }^{26}$

I am grateful to Roger Duvoisin and Werner Poewe for helpful comments on this chapter.

\section{References}

1. Gibb WRG, Lees AJ. The relevance of the Lewy body to the pathogenesis of idiopathic Parkinson's disease. J Neurol Neurosurg Psychiatry 1988;51:745-752.

2. Gibb WRG. The neuropathology of Parkinson disorders. In: Jankovic J, Tolosa E, eds. Parkinson's disease and Movement Disorders. Baltimore: Urban and Schwarzenberg, 1988. pp.205-233.

3a. Hughes AJ, Daniels SE, Kilford L, Lees AJ. The accuracy of the clinical diagnosis of Parkinson's disease: a clinicopathologic study of 100 cases. J Neurol Neurosurg Psychiatry 1992;55:181-184.

3b. Hughes AJ, Daniel SE, Blankson S, Lees AJ. A clinicopathologic study of 100 cases of Parkinson's disease. Arch Neurol 1993;50:140-148.

4. Parkinson J. An Essay on the Shaking Palsy. London. Whittingham and Rowland, for Sherwood, Neely and Jones, 1817.

5. Ward CD, Duvoisin RC, Ince SE, Nutt J, Eldridge R, Calne DB. Parkinson's disease in 65 pairs of twins and in a set of quadruplets. Neurology 1983;33:815824.

6a. Golbe LI, Dilorio G, Bonavita V, Miller DC, Duvoisin RC. A large kindred with autosomal dominant Parkinson's disease. Ann Neurol 1990;27:276-282

6b. Golbe LI. The genetics of Parkinson's disease. Rev Neurosci 1993;4:1-16.

7a. Braak H, Braak E. Cortical and subcortical argyrophilic grains characterize a disease associated with adult onset dementia. Neuropathol Appl Neurobiol 1989:15:13-26.

7b. Braak H, Braak E. Cognitive impairment in Parkinson's disease: amyloid plaques, neurofibrillary tangles and neuropil threads in the cerebral cortex. J Neural Transm. 1990;2:45-57.

8. Fearnley JM, Lees AJ. Aging and Parkinson's disease: substantia nigra regional 
selectivity. Brain 1991:114:2283-2301

9. Gibb WRG, Esiri MM, Lees AJ. Clinical and pathological features of diffuse cortical Lewy body disease (Lewy Body Dementia) Brain 1987;110:1131-1153.

10. Gibb WRG, Lees AJ. The significance of the Lewy body in the diagnosis of idiopathic Parkinson's disease. J Neuropathol Appl Neurobiol 1989;15:27-44

11. Kremer HPH. Bots GThAM. Lewy bodies in the lateral hypothalamus. Do they imply neuronal loss? Movement Disorders 1993;8:315-320.

12. Daniel SE, Lees AJ. Neuropathological features of Alzheimer's disease in nondemented Parkinsonian patients. J Neurol Neurosurg Psych 1991:54:972-975

13. Sage JI, Miller DC, Golbe LI, Walters A, Duvoisin RC. Clinically atypical expression of pathologically typical Lewy-body parkinsonism. Clin Neuropharmacol 1990;13:36-47.

14. Leenders KL, Salmon EP, Tyrrell $\mathbf{P}$ et al. The nigrostriatal dopaminergic system assessed in vivo by positron emission tomography in healthy volunteer subjects and patients with Parkinson's disease. Arch Neurol 1990;47:1290-1298.

15a Brooks DJ, Detection of preclinical Parkinson's disease with PET. Neurology 1991;41(suppl 2):24-27.

15b Brooks DJ, Playford ED, Ibanez V et al. Isolated tremor and disruption of the nigrostriatal dopaminergic system. Neurology 1992;42:1554-1560.

16. Frost JJ, Rosier AJ, Reich SG et al. Positron Emission Tomographic Imaging of the Dopamine Transporter with 11C-WIN 35,428 reveals marked declines in mild Parkinson's disease. Ann Neurol 1993;34:423-431.

17. Oertel WH, Gasser T, Ippisch R, Trenkwalder C, Poewe W. Apomorphine test for dopaminergic responsiveness. Lancet 1989;1:262-263.

18. Hughes AJ, Lees AJ, Stern GM. Apomorphine test to predict dopaminergic responsiveness in Parkinsonian syndromes. Lancet 1990;336:32-34.

19. Staal A, Meerwaldt JD, van Dongen KJ, Mulder PGM, Busch HFM. Nonfamilial degenerative disease and atrophy of brainstem and cerebellum. J Neurol Sci 1990;95:259-269.

20a Schwartz J, Tatsch K, Arnold G et al. [123 I]-jodobenzamide-SPECT predicts dopaminergic responsiveness in patients with de novo parkinsonism. Neurology 1092:42:556-561.

$20 \mathrm{~b}$ Verhoeff NPLG. Neuroreceptor ligand imaging by single photon emission computerized tomography (SPECT). Thesis, Rodopi, Amsterdam, 1993.

21. Rajput AH, Pahwa R, Pahwa P. Mode of onset and prognosis in Parkinson's disease. Neurology 1992;42(suppl 3):419-42.4.

22. Poewe WH. Clinical differential diagnosis of Parkinson's disease. International workshop Berlin. Medicorn 1991:174-181.

23. Shapira AHV, Cooper JM, Dexter D,Jenner P, Clark JB, Marsden CD. Mitochondrial complex I deficiency in Parkinson's disease. Lancet 1989;1:1269.

24. Parker WD, Boyson S.J, Parks JK. Abnormalities of the electron transport chain in idiopathic Parkinson's disease. Ann Neurol 1989;26:719-723.

25. Burn DJ, Mark MH, Playford ED et al. Parkinson's disease in twins studied with 18F-dopa and positron emission tomography. Neurology 1992;42:1894-1900.

26. Hubble JP, T Cao BS, Hassanein RES, Neuberger JS, Koller WC. Risk factors for Parkinson's disease. Neurology 1993;43:1693-1697. 


\section{CHAPTER 2}

The pharmacotherapy of Parkinson's disease. 


\section{Introduction}

The primary biochemical deficit in PD is the loss of dopamine in the basal ganglia, resulting from degeneration of dopamine-producing cells in the substantia nigra. The cause of the degeneration of dopaminergic containing cells and appearance of Lewy bodies in the zona compacta of the substantia nigra in patients with $\mathrm{PD}$ remains unknown. As a consequence of this dopamine loss in the striatum the neurotransmitter balance (particularly the balance between acetylcholine and dopamine) is altered and clinical symptoms emerge.

Symptomatic therapy refers to an intervention that ameliorates the clinical features of illness, but benefits are only temporary as the neurodegenerative disease progresses. Levodopa is an example of symptomatic therapy for PD: symptoms are lessened temporarily by levodopa and exacerbated upon its withdrawal (e.g. wearing-off effects)

Protective therapy represents an intervention that substantially protects the population of vulnerable neurons and thereby slows the underlying progression of neurodegeneration. Recent studies in the cause of PD have suggested that nigral damage manifestating as PD may result from either extrinsic causes such as exogenous neurotoxins similar to MPTP acting directly or indirectly via oxygen free radicals, or intrinsic causes such as free radicals and other toxins produced during the MAO-Bcatalysed breakdown of dopamine (i.e. the oxidative stress hypothesis). The antioxidative strategy of MAO-B-inhibition ${ }^{2}$ has led to a growing enthusiasm in the clinician's vocabulary for terms like neuroprotection.

Recently evidence has accumulated that the neuroprotective effect of MAO-B-inhibitors is probably not a result of MAO-B-inhibition. Selegiline does achieve neuronal rescue via activation of a 'neurotrophiclike' mechanism. ${ }^{3}$ Neuronal rescue may account for the reported slowing: of progression of $\mathrm{PD}$, reported in various clinical trials ${ }^{2,4.5}$ with the socalled MAO-B-inhibitor selegiline.

\section{Symptomatic therapy}

\section{Non-dopaminergic therapy.}

To provide symptomatic relief anticholinergics and amantadine generally are prescribed. Anticholinergics seem particularly useful in (younger) patients who are bothered by tremor, but these compounds can produce neurobehavioural side effects, such as forgetfulness. This adverse effect 
on memory has thrown discredit on anticholinergics. Amantadine has also modest anti-parkinson properties, is generally well tolerated, and thus offers a useful alternative, particularly in the elderly patients. Amantadine is recently thought to have an indirect anticholinergic effect by blocking glutamate (NMDA) receptors. ${ }^{6}$

In fact, Olney et al. $^{7}$ have proposed that NMDA-antagonists should be considered as potential antiparkinsonian drugs. These compounds reduce the overactivity in the glutamatergic cortico-striatal and subthalamic nucleus - globus pallidus tracts. It is hypothesized that the rate of progression of dopaminergic nigrostriatal degeneration coincides with a progressing functional increase of these glutamatergic pathways. These excitatory aminoacids like NMDA play a pivotal role in the 'motor loop' (=the nigrostriatal dopamine system and its striatonigral GABA-ergic counterpart) and in the 'complex loop' ( $=$ the tight connections of the basal ganglia - i.e. the ventral striatum - with the ventrolateral/ ventromedial portions of the thalamus, the limbic system and the prefrontal- and the frontal-association $\operatorname{cortex}^{8}$ ). The 'complex loop' interfaces anatomically with the 'motor loop' so that behaviourial interconnections are possible. The Dutch scientist Nauta' must be given full credit for his exciting neurobehavioural studies. Papez circuit, connecting hippocampus and anterior thalamus, has shown to be of a more complex nature. Brain areas like part of the frontal isocortex, the entorhinal cortex and septal regions are innervated by dopaminergic fibres, which mainly originate in the ventral tegmental area. Glutamatergic fibres connect cortical and limbic brain areas; and the perforant pathway - connecting the entorhinal cortex with the hippocampal sub-areas - uses glutamate as transmitter. ${ }^{8}$ Attention has therefore been focused in recent years on these regions of the brains, their dopaminergic-glutamatergic inhibitory and excitatory influences, and their involvement in psychiatric and neurobehaviourial signs and symptoms in PD and its modulation with dopamimetics, anticholinergics and glutamatergic therapies.

Whether selegiline - as a MAO-B-inhibitor - may also act on NMDA receptor modulation is uncertain at the moment. ${ }^{3}$ But the increased dopamine activity induced by selegiline - by virtue of its inhibition of dopamine enzymatic breakdown and its property to reduce dopamine reuptake - certainly gives selegiline a place in the symptomatic therapeutic modalities in PD. Especially in the early stages of the disease, while symptoms are still mild and in order to delay the introduction of levodopa. 


\section{Dopaminergic therapy}

Dopamine-precursor therapy remains the single most effective theralpy for the symptomatic treatment of PD. Its remarkable success has made it the gold standard against which all new forms of therapy need to be compared. It is the centrepiece of drugtherapy in PD. Levodopa therapy is far from perfect, however. As the number of levodopa-therapy years mount and as the underlying disease process inevitably advances, a greater share of the motor and non-motor response to levodopa becomes contaminated by response fluctuations, dyskinesias, other abnormal sensitizations to dopamine stimulation, and eventually poor responsiveness, 'tolerance', or unresponsiveness to levodopa. ${ }^{11,11,12}$ Ultimately response fluctuations become increasingly difficult to live with and complex to manage, partly because of their unpredictable timing of manifestation, and the response to levodopa itself becomes part of the disability.

Whether these levodopa-complications are more related to - the duration of - levodopa therapy or - to duration of - the disease has been debated ever since these adverse effects and response-losing first became recognized. The shortening of levodopa's half life in the striatum is probably the most important etiologic factor, as a consequence of loss of the striatum's ability to store and buffer the shifts in exogenous levodopa/dopamine concentrations, and the development of supersensitive post-synaptic dopaminereceptors. ${ }^{13}$ Strategies designed to prolong and smooth out the therapeutic plasma levels of levodopa thus have been developed. Intermittent oral levodopa administration leads to intermittent absorption with resulting fluctuations in plasma levels, which in turn leads to repeated cycles of relative dopaminergic activation and withdrawal. Other peripheral pharmacokinetic properties of levodopa contribute to fluctuations in plasma: short distribution and elimination half-lives (30 minutes and $2 \frac{1}{2}$ hours respectively), depending mainly on enzymatic decarboxylation and O-methylation. ${ }^{13}$ Although gastric emptying and the short plasma half-life of levodopa contribute greatly to response fluctuations, they do not explain individual differences in these fluctuations over the course of the illness. These phenomena only can be understood by central pharmacokinetic and pharmacodynamic factors in the handling of levodopa and dopamine.

The pathophysiology of the increasing motor complications and declining antiparkinsonian efficacy of chronically administered levodopa in patients with severe PD remains to be fully elucidated. Current observations allow the hypothesis of Thomas Chase ${ }^{14}$ to be advanced that wearing-off phenomena occur largely as a result of dopamine-terminal degeneration 
due to natural disease progression. On-off fluctuations and peak-dose dyskinesias, on the other hand, appear to reflect secondary, only partially reversible, alterations at the postsynaptic level - probably as a consequence of intermittent stimulation of normally tonically activated dopamine receptors. D1 and D2 dopamine receptor-mediated mechanisms are affected differently by the basic disease process and by dopaminomimetic therapy.

Slow release preparations of oral levodopa, such as 'Sinemet CR' and 'Madopar HBS', offer the possibility of 'smoothing out' clinical fluctuations by slowly releasing the levodopa from a special matrix. These compounds are useful in the treatment, and possibly prevention, of motor fluctuations, particularly the wearing-off phenomenon. The percentage of patients, however, with increased 'on' time without dyskinesias after these slow released preparations generally is small. Moreover a disadvantage of these compounds is the more slowly functioning in the morning. Raymund Roos et al. ${ }^{15}$ recently suggested that if the initial levodopa concentrations are not in the critical range to be effective for the patient, the advice should be to take the controlled-release levodopa preparation in a fasted condition. There are no significant differences in the clinical efficacy and adverse events of these two slow-release preparations, although there are definite differences in some of their pharmacokinetic parameters. ${ }^{16}$ Contrary to the encouraging short-term effects, long-term slow release levodopa treatment does not seem to produce long lasting benefit in most patients with response fluctuations.

Other methods currently investigated in an attempt to provide more continuous dopaminergic stimulation include duodenal infusions of levodopa. ${ }^{17} \mathrm{~A}$ continuous delivery of dopamine to the striatum can also be accomplished, experimentally, by encapsulated slow-release polymer systems which are subcutaneously implanted.

Catechol-O-methyltransferase (COMT) inhibitors added to levodopa and decarboxylase inhibitors have theoretical advantages in the management of motor symptoms of PD and possibly also in the avoidance of response fluctuations, as has been suggested by Kaakola et al. ${ }^{18 a}$ and Roberts et al. ${ }^{18 b}$

Finally one must take into account that some motor and non-motor response-fluctuations, postural disturbances and neurobehavioural symptoms are not only refractory to levodopa therapy in its own right, but may substantially limit the tolerance to standard antiparkinson medications. 


\section{Dopamine - Agonists}

These agents have the advantage of directly stimulating dopamine receptors, thereby bypassing the requirement for native decarboxylase. One can achieve a certain degree of selective stimulation of the various subtypes of dopamine receptors, and this may confer some advantage, although this is as yet not entirely clear for their clinically relevant efficacy.

Bromocriptine is the prototype dopamine agonist, has a longer duration of action than levodopa ( 4 to 6 hours) and is highly selective for D2 receptors, with a minor inhibitory activity on D1 receptors. ${ }^{19}$ Pergolide is more potent than bromocriptine, has a longer duration of action than bromocriptine (approximately 8-10 hours) and stimulates both D1 and D2 receptors. ${ }^{20}$ The potential role for $\mathrm{D} 1$ receptor stimulation in $\mathrm{PD}$ is not clear at the time - on the one hand it might increase the incidence of dyskinesias, on the other hand D1 stimulation might be necessary to modulate the D2 stimulation.

The efficacy of these two dopamine-agonists may be similar, although recent reports suggest a significant more sustained motor response with pergolide, and patients obtain new benefit when they are switched from bromocriptine to pergolide, whereas no benefit has been shown by substituting bromocriptine for pergolide. ${ }^{20}$

Dopamine-agonists stimulate presynaptic dopamine-receptors and consequently decrease dopamine turnover. This might be relevant to a reduction of oxidative stress and may provide neuroprotective properties of pergolide, as suggested by Felten et al. ${ }^{21,22}$ Another important - possibly protective - mechanism of pergolide has been an increase of superoxide dismutase (SOD) in the striatum. ${ }^{23}$ The deactivation of superoxide radicals by $S O D$, thus induced by pergolide, favour the use of pergolide early in the course of PD.

Dopamine-agonists have been used as monotherapy and seem effective in reducing the eventual development of fluctuations and dyskinesias. ${ }^{24}$ The antiparkinson potency of dopamine-agonists is, however, inadequate for any length of time. For this reason levodopa and dopamine-agonist combination therapy has proved useful for keeping the dose of levodopa low and significantly lowering the incidence of motor fluctuations and dyskinesias. Weiner et al. ${ }^{25}$ recently could not observe that early combination therapy (bromocriptine and levodopa) delayed or prevented the onset of late treatment complications, and levodopa monotherapy resulted in greater improvement in PD disability. An interim report of a Japanese study of Kondo et al. ${ }^{26}$, however, established a superior efficacy of pergolid over combination therapy as initial treatment. Pezzoli et al. ${ }^{27}$ 
recently compared the efficacy of pergolide and bromocriptine and concluded that pergolide as adjunctive therapy to levodopa is more effective than bromocriptine.

Regardless of the neuroprotective properties of pergolide, the conclusion might be drawn that dopamine-agonist therapy is highly recommended as a late adjunct to levodopa in patients already experiencing response fluctuations and dyskinesias.

Cabergoline, a potent D2 agonist, with a half life of about 65 hours (!), is currently being tested in clinical trials. The increase of dyskinesias, induced by cabergoline, seems to be a serious adverse event. ${ }^{28, b}$

Since 1987 Apomorphine, a potent D1 and D2 dopamine-agonist, has been introduced in the treatment of motor fluctuations of PD. ${ }^{29}$ Apomorphine is - to some extent - water soluble, quickly equilibrates between peripheral and central compartments, and is therefore highly suitable for intravenous, subcutaneous, sublingual and intranasal administration. ${ }^{30,31,32}$ Transdermal delivery devices for Apomorphine are being studied at the moment. Also rectal administration of Apomorphine is effective, not for a rapid-acting remedy for sudden or predictable 'freezing' episodes, but to acquire a long-duration response.

The use of Apomorphine has only been made possible by concomitant use, in the first weeks of treatment, of an anti-emetic such as domperidone. In this way it has come to a rediscovery of this first dopaminergic drug. Apomorphine is widely used as subcutaneous injection to quickly reverse the 'off period, or as subcutaneous infusion using a portable pump to achieve a continuous effect. The magnitude and other features of motor and nonmotor responses to apomorphine are similar to those produced by levodopa, only incidentally symptoms can be improved that are unresponsive to levodopa or that are to be rewarded as side-effects of levodopa therapy. ${ }^{31}$ The item of tolerance to the pharmacologic effects of Apomorphine is still a matter of debate. ${ }^{33}$ Longterm follow-up of continuous subcutaneous Apomorphine pump treatment in patients with Parkinson's disease, by Werner Poewe et al., could not substantiate a tolerance to Apomorphine. ${ }^{34}$

Long-term subcutaneous apomorphine infusions definitely are efficacious, but generally many practical, compliance, biochemical and new bizarre peak-dose dyskinesia problems have to be dealt with. In this regard subcutaneous application of Apomorphine injections are the most simple and practical procedure to use this oldest dopamine-agonist. ${ }^{35}$ 


\section{Possibly neuroprotective therapies in Parkinson's disease.}

Early detection of preclinical Parkinson's disease (greatly exceeding clinically overt PD in prevalence ${ }^{36,37,38}$ ); postmortem studies of 'incidental' Lewy body disease (10 percent of the population dying in the ninth decade of life have Lewy bodies associated with a degree of ventral tier nigral cell loss ${ }^{1}$ ); the visualization on the fluorodopa scan of neuronal loss occurring at the same rate before clinical expression of $\mathrm{PD}^{39,40}$; exposure to the neurotoxic designer drug $\mathrm{MPTP}^{41}$ (with subtle cognitive impairments found in MPTP-exposed mild cases comparable to those found in early $\left.\mathrm{PD}^{42.43,44,45}\right)$; the pivotal role of the MAO-B-inhibitor selegiline in the prevention of neurotoxicity of $\mathrm{MPTP}^{2}$ and in the inhibition of oxidative metabolism of dopamine; and the role of endogenous and exogenous hydroxyl free radicals (= oxidative stress ) for the dysfunction of mitochondrial complex I and lipid peroxidation. ${ }^{1.46}$ All these phenomena are exciting and recent findings that are very relevant to the pathogenesis of $\mathrm{PD}$ and to the development of the concept of neuroprotective therapies.

These topics have been discussed in detail in literature. ${ }^{47 a, 470}$ Bloem et al. ${ }^{44}$ hypothesized on the versatile contributions of the MPTP model to the treatment of idiopathic PD. That the result of DATATOP ${ }^{2,4 a, 5}$ was that selegiline is capable of delaying the onset of disability associated with early, otherwise untreated PD, has divided neurology in 'DATASTOPPERS' and 'DATATOBBE:RS'.

The consequence of DATATOP seems to be that, although the action of selegiline that accounts for its symptomatic or protective beneficial effects remains unclear, selegiline is worldwide adviced to be used in the early phases of PD and that dopamimetics or dopamineprecursors be added when symptoms are sufficiently severe to require it. DATATOP study learned that the time from diagnosis to need for levodopa is approximately 1 to 2 years.

Examination of the shorter-acting MAO-B-inhibitor Lazabemide, which is not metabolized to active (i.e. amphetamine) compounds may help clarify the undoubtedly beneficial action of selegiline. ${ }^{4 b}$

For etiopathogenesis of $\mathrm{PD}$ five mechanisms seem relevant:

1. MPTP induces parkinsonism by virtue of its MAO-B-transformation to $\mathrm{MPP}++$, which is a specific inhibitor of NADH-COQ-Reductase. ${ }^{49.50}$

2. Increased iron (III) and total iron content in postmortem substantia 
nigra, with a catalytic activity on the production of hydroxyl free radicals. ${ }^{4651}$ Iron's accumulation in substantia nigra is attributed to its delocalization from ferritin. 6-hydroxydopamine (6-OHDA) and Nitric Oxide (NO) are thought to owe their toxicity to release of iron bound to ferritin. NO, which can be synthesized by exitotoxic glutamatergic neurons, thus is an endogenous compound to release iron, directly interfering with complex I mitochondrial activity, and interacting with iron in the process of oxidative stress.

3. A specific nigral glutathione deficiency in $\mathrm{PD}{ }^{52}$

4. The finding of an ongoing oxidative stress in nigral cells of PD patients by dopamine metabolites (free radicals and nitric oxide), which lead to dysfunction of mitochondrial complex $I^{53,54}$

5. Disturbances in function of key enzymes that are important in endogenous metabolism, but also important for the safe metabolism of a variety of xenobiotics (S-oxidation and S-methylation reactions). Some individuals may have a genetic susceptibility to develop PD based on the reduced ability to metabolize toxins from the environment or to inactivate toxic radical species formed within the body. ${ }^{55,56}$

Neurons in the substantia nigra pars compacta are particularly vulnerable to oxidant stress because ${ }^{57}$ :

a. The metabolism of dopamine generates peroxides which in the presence of iron leads to the formation of the highly reactive hydroxyl free radical.

b. Neuromelanin within nigral neurons binds metals such as iron and aluminium, and promotes the site-specific formation of free radicals.

The increased iron, decreased glutathione and increased lipid peroxidation in the substantia nigra pars compacta support this hypothesis. The high neuromelanin content of the substantia nigra is believed to result from the auto-oxidation of dopamine.

Selegiline has many pharmacological properties, some of which are summarized here:

1. a. Dopamine re-uptake inhibition

b. Facilitation of the release of dopamine

c. Enhancement of dopamine synthesis.

2. Pharmacologic activity of the L-methamphetamine metabolite of selegiline, possibly relevant to the awakening, 'activating' or antidepressant properties of selegiline.

3. Increase of Phenylethylamine, which modulates or amplifies DA response. 
4. MAO-B-inhibition

a. relevant to symptomatic benefits of selegiline as a consequence of a dopamimetic effect.

b. Interference with the oxidative metabolism of dopamine, thereby diminishing free radical formation.

5. Neuroprotection by increased formation of SOD, catalase and suppression of formation of oxidized glutathione.

6. Acting as anti-oxidant itself. (personal communication Prof. A. Bast)

7. Neuronal Rescue ${ }^{3}$

a. (re)activation of astrocytes and trophic factors (NGi): rescue injured neurons.

b. enhancement of substantia nigra neuronal activity.

c. prevention of age related changes in the neurons of the substantia nigra.

Some of these unsuspected actions of selegiline can fully account for the reported slowing of the progression of PD in the DATATOP-study. Critical for this role of selegiline is a dosage insufficient to inhibit MAOB. William Tattons' hypothesis is that low dose selegiline rescues, and high dose selegiline kills; the so called 'kissing and killing' model of selegiline.

Seventy-one percent of dopamine in the human brain is metabolized outside the neurone by $\mathrm{MAO}-\mathrm{B}$, and four percent by $\mathrm{MAO}-\mathrm{B}$ inside the neurone. ${ }^{46}$ Twelve percent is oxidized inside the neurone by MAO-A. This raises the question whether MAO-A inhibition should also be studied in the symptomatic and protective treatment of PD.

\section{Aims of the thesis.}

1. Summarize the pitfalls in clinical diagnosis of Idiopathic Parkinson's disease.

2. Review current developments in the etiopathogenesis and pharmacotherapy in Parkinson's disease.

3. Investigate the clinical benefits of two sustained-release levodopa compounds ('Madopar HBS' and 'Sinemet CR') and one dopamineagonist ('Parlodel SRO') in pharmacotherapy of Parkinson's disease.

4. Describe some of the results of research with the dopamine-agonist Apomorphine. 
5. Report the increase of Parkinsonian disability provoked by treatment with the serotonin re-uptake inhibitor Fluoxetine.

6. Report the efficacy of Clozapine - an atypical neuroleptic agent - in the alleviation of rest-tremor in Parkinson's disease.

\section{References.}

1. Jenner P, Dexter DT, Sian J, Shapira AHV, Marsden CD. Oxidative stress as a cause of nigral cell death. in Parkinson's disease and incidental Lewy body disease. Ann Neurol 1992;S2:S82-S87.

2. Shoulson S et al. Parkinson Study Group. Effect of Deprenyl on the progression of disability in early Parkinson's disease. New Engl J Med 1989;321:1364-1371.

3. Tatton WG, Greenwood CE. Rescue of dying neurones: a new action for deprenyl in MPTP parkinsonism. J Neurosci Res 1991;30:666-672.

4a Shoulson S. The Parkinson Study Group. Effects of Tocopherol and Deprenyl on the progression of disability in early Parkinson's disease. $N$ Engl $J$ Med 1993:328:176-183.

4b Parkinson Study Group. A controlled trial of Lazabemide (R019-6327) in untreated Parkinson's Disease. Ann Neurol 1993;33:350-356.

5. Parkinson Study group. DATATOP. A multicenter clinical trial in early Parkinson's disease. Arch neurol 1989;46:1052-1060.

0. Stoof JC. Booy J. Drukarch B, Wolters ECh. The anti-parkinsonian drug amantadine inhibits the $\mathrm{N}$-methyl $\mathrm{D}$-Aspartic acid evoked release of acetylcholine from rat neostriatum. Europ J Pharmacol 1992;213:439-443.

7. Olney JW, Price MT, Labruyere J, et al. Antiparkinson agents are phencyclidine agonists and $\mathrm{N}$-methyl-aspartate antagonists. Eur J Pharmacol 1987;142:319-320.

8. De Long MR. Primate models of movement disorders of basal ganglia origin. Trends Neurosei 1990;13:281-285.

9. Nauta WJH, Smith GP, Faull FLM et al. Efferent connections and nigral efferents of the nucleus accumbens septi in the rat. Neurosci 1978;3:385-401.

10. Roos RAC, Vredevoogd $\mathrm{CB}$, van der Velde EA. Response fluctuations in Parkinson's disease. Neurology 1990;40:1344-1346.

11. De Jong GT, Meerwald JD, Schmitz PIM. Factors that influence the occurrence of response fluctuations in Parkinson's disease. Ann Neurol 1987;22:4-7.

12. Riley DE, Lang AE. The spectrum of levodopa-related fluctuations in Parkinson's disease. Neurology 1993;43:1459-1464.

13. Mouradian MM, Heuser $U$, Baronti $F$, Chase TN. Modification of central dopaminergic mechanisms by continuous levodopa therapy for advanced Parkinson's disease. Ann Neurol 1990;27:18-23.

14. Chase TN, Baronti F, Fabbrini G. Rationale for continuous dopamimetic therapy of Purkinson's disease. Neurology 1989;39(suppl.2):7-10.

15. Roos RAC, Tijssen MAJ, van der Velde EA. Breimer DD. The influence of a standard meal on Sinemet CR absorption in patients with Parkinson's disease. Clin Neurol Neurosurg 1993;95:215-219. 
16. Kleedorfer B, Poewe W. Comparative efficacy of two oral sustained-release preparations of levodopa in fluctuating Parkinson's disease: preliminary findings in 20 patients. J Neural Transm 1992;4:173-178.

17a Sage JH, Schuh L, Heikkila RE, Duvoisin RC. Long-term duodenal infusion of levodopa for motor fluctuations in parkinsonism. Ann Neurol 1988;24:87-89.

17b Kurth MC, Tetrud JW, Tanner CM, Irwin I, Stebbins GT, Goetz CA, Langston JW. Double-blind, placebo-controlled, crossover study of duodenal infusion of levodopa/carbidopa in Parkinson's disease, patients with "on-off" fluctuations. Neurology 1993;43:1698-1703.

18a Kaakola S, Wurtman T, Wurtman RJ. Effects of catechol-o-methyltransferase inhibitors and $\mathrm{L} 3,3$ dihydroxyphenylalanine with or without carbidopa extracellular dopamine in rat striatum. J Neurochem 1993;60:137-144.

$18 \mathrm{~b}$ Roberts JW, Cora-Locatelli G, Bravi D, Amantea MW, Mouradian MM, Chase TN. Catechol-O-methyltransferase inhibitor tolcapone prolongs levodopa/carbidopa action in parkinsonian patients. Neurology 1994;44:2685-2688.

19. Staal-Schreinemachers AL, Wesseling H, Kamphuis DJ, Burg W vd, Lakke JPWF. Low dose bromocriptine therapy in Parkinson's disease: double blind placebo controlled study. Neurology 1986;36:291-293.

20. Olanow CW. Pergolide/Parlodel crossover study. Neurology 1988;38:314-7.

21. Felten DL, Felten SY, Romano T, Wong D, Schmidt MJ, Clemens JA. Chronic dietary Pergolide slows aging of the nigrostriatal dopamine system in rats. Arch Neurol 1988;45:208-214.

22. Felten DL, Felten SY, Fuller RW et al. Chronic dietary Pergolide preserves nigrostriatal neuronal integrity in aged-Fischer-344 rats. J Biol Aging 1992:13:339-351.

23. Clow A, Hussain T, Glover V, Sandler M, Walker M, Dexter D. Pergolide can induce soluble superoxide dismutase in rat striata. J Netural Transm [Gen.Sect] 1992:90:27-31.

24. Rinne UK. Early combination of bromocriptine and levodopa in the treatment of Parkinson's disease: a 5-year follow up. Neurology 1987:37:826-828.

25. Weiner WJ, Factor SA, Sanchez Ramos JR et al. Early combination therapy (bromocriptine and levodopa) does not prevent motor fluctuations in Parkinson's disease. Neurology 1993;43:21-26.

26. Kondo $T$, Ando $K$, Iwata $M$. An interim report of an open-label long-term trial of Pergolide mesylate in Parkinson's disease. Movement Disorders 1993;suppl I:99.

27. Pezzoli GE, Martignoni E, Pacchetti VA. Pergolide versus Bromocriptine in Parkinson's disease: A multicenter single-blind, crossover study. Neurology 1993:43,A195.

28a Rabey JM, Nissipeanu P, Inzelberg R et al. Beneficial effect of cabergoline in the treatment of Parkinson's disease. Preliminary data. Adv Neurol 1990;53:451455.

28b Lera G, Vaamonde J, Rodriguez M, Obeso JA. Cabergoline in Parkinson's disease. Long-term follow-up. Neurology 1993;43:2587-2590.

29. Stibe $\mathrm{CMH}$, Lees AJ, Kempster PA, Stern GM. Subcutaneous apomorphine in Parkinsonian on-off oscillations. Lancet 1988;: :403-406. 
30. Pollak P, Champay AS, Hommel M, Pervet JE. Benabid AL. Subcutaneous apomorphine in Parkinson's disease. J Neurol Neurosurg Psych 1989;52:544.

31. Frankel JP, Lees AJ, Kempster PA, Stern GM. Subcutaneous apomorphine in the treatment of Parkinson's disease. J Neurol Neurosurg Psych 1990;53:96-101.

32. Poewe W, Kleedorfer B, Gerstenbrand F, Oertel WH. Subcutaneous apomorphine in Parkinson's disease. Lancet 1988,1:943.

33. Gancher ST, Nutt JG, Woodward WR. Time course of tolerance to apomorphine in parkinsonism. Clin Pharmacol Ther 1992;52:504-510.

34. Kreczy-Kleedorfer B, Wagner M, Bösch S. Poewe W. Langzeitergebnisse Kontinuierlicher subkutaner Apomorphinepumpentherapie bei Patienten mit fortgeschrittener Parkinson-krankheit. Nervenarzt 1993;64:221-225.

35. Weill E. De l'apomorphine dans certains trouble nerveux. Lyon Med $1884 ; 40: 411-419$.

36. Sawle GV.The detection of Preclinical Parkinson's disease: What is the role of positron emission tomography? Movement Disorders 1993;8:271-277.

37. Sawle GV, Wroe SJ, Lees AJ, Brooks DJ. Frackowiak RSJ. The identification of presymptomatic parkinsonism: clinical and [18F] dopa PET studies in an Irish kindred. Ann Neurol 1992;32:609-617.

38. Sawle GV. The rate of progression of Parkinson's disease. Ann Neurol 1992;31:229-233.

39. Tetrud JW. Preclinical Parkinson's disease: detection of motor and non-motor manifestations. Neurology 1991;41:69-72.

40. Sawle GV, Brooks DJ. Normal aging of the nervous system. Ann Neurol 1992:31:575-576.

41. Langston JW, Ballard P, Tetrud JW, Irwin I. Chronic parkinsonism in humans due to a product of meperidine-analog synthesis. Science 1983;219:979-980.

42. Tetrud JW, Langston JW, Garbe PL, Ruttenber AJ. Mild parkinsonism in persons exposed to MPTP. Neurology 1989;39:1483-1487.

43. Lees AJ, Smith E. Cognitive deficits in the early stages of Parkinson's disease. Brain 1983;106:257-270.

44. Poewe WH, Gerstenbrand F, Ransmayer G, et al. Premorbid personality of Parkinson patients. J Neural Transm 1983,S19;215-224.

45. Korten. JJ, Ketterings K. Anthropologische Aspekte der Parkinsonischen Krankheit. Nervenartz 1972;43:201-205.

46. Jellinger $K$, Kienzl E, Rumpelmair $G$, Riederer $P$, Stachelberger $H$, Ben Schachar D, Youdim MBH. Iron-melanin complex in substantia nigra of Parkinsonian brains, an X-ray microanalysis. J Neurochem 1992;59:1168-1171.

47a Fahn S, Cohen G. The oxidant stress hypothesis in Parkinson's disease: evidance supporting it. Ann Neurol 1992;32:2241-2250.

47b Calne DB. The free radical hypothesis in idiopathic parkinsonism: evidence against it. Ann Neurol 1992;32:799-803.

48. Bloem BR, Irwin I, Buruma OJS, et al. The MPTP model: versatile contributions to the treatment of idiopathic Parkinson's disease. J Neurol Sci 1990;97:273-293.

49. Shapira AHV, Mann VM, Cooper JM, Krige D, Jenner PJ, Marsden CD. Mitochondrial function in Parkinson's disease. Ann Neurol 1992;32:S116-S124. 
50. Mizuno Y, Suzuki K, Ohta S. Postmortem changes in mitochondrial respiratorv enzymes in brain and preliminary observation in Parkinson's disease. J Neurol Sci 1990;96:49-57.

51. Dexter DT, Wells FR, Agid F, Agid Y, Lees AJ, Jenner P, Marsden CD. Increased nigral iron content in post mortem Parkinsonian brain. Lincel 1987;II:1219-1220.

52. Sofic E, Lange KW, Jellinger K. Riederer P. Reduced and oxidized glutathionc in the substantia nigra of patients with Parkinson's disease. Neurosci Lett 1992;142:128-130.

53. Dawson TM, Dawson VL, Snyder SH. A novel neuronal messenger molecule in brain: the free radical nitric oxide. Ann Neurol 1992;32:297-311.

54. Dexter DT, Carter CJ, Wells FR. Basal lipid peroxidation in substantia nigra is increased in Parkinson's disease. J Neurochem 1989;52:381-389.

55. Roos RAC, Steenvoorde JMS, Mulder GJ, Kempen GMJ van. Acetaminıfen sulfation in patients with Parkinson's disease or Huntington's disease is not impaired. Neurology 1993;43:1373-1376.

56. Ferrari MD, Peeters EAJ, Haan J, et al. Cytochrome P-450 and Parkinson's disease. Poor parahydroxylation of phenytoin. J Neurol Sci 1990;96:153-157.

57. Olanow $\mathrm{CW}$. Oxidation reactions in Parkinson's disease. Neurology 1990;40(3):32-37. 


\section{CHAPTER 3}

Neuroprotection by selegiline? ${ }^{1}$

${ }^{1}$ Neuroprotectie door selegiline? ENH Jansen, Neef C. Pharm Weekbl 1992;127(21):571-575. 


\section{Introduction}

Parkinson's disease is characterized as a dopamine-deficiency syndrome in the nigrostriatal system. As a consequence of neuronal degeneration in the zona compacta of the substantia nigra, a loss of dopamimetic innervation of the corpus striatum (nucleus caudatus and putamen) arises reducing the concentration of dopamine in this corpus striatum. There is a correlation between this cellular loss in the substantia nigra, the loss of dopamine in the corpus striatum and the clinical phenomena of Parkinson's disease (especially the rigidity and the hypokinesia). ${ }^{12}$

Clinically Parkinson-phenomena don't come through until a cellular loss of $60 \%$ in the substantia nigra, and a loss of dopamine in the corpus striatum of $80 \%$. Also the Tyrosinehydroxylase quantity in the substantia nigra has then diminished with $80 \%$ with regard to the normal situation.

It is certain that a long period of constant neuronal degeneration precedes the clinical manifest phase of Parkinson's disease. It is supposed that there is a phase of many years of the 'presymptomatic parkinsonism'. It is the hypothesis that this neuronal degeneration results from an accelerated ageing process or from the fact that after an endogenous or exogenous damage of the cells of the substantia nigra a 'normal' ageing process brings about the degeneration. ${ }^{3,4}$

Meanwhile this presymptomatic and clinical dopamine deficiency in the striatum can be visualized and quantified ${ }^{5}$ with the positron-emission tomography (PET-scan). There has also been shown a positive correlation between the severity of the dopamine-deficiency (registered with PETscan) and the degree of clinical phenomena of Parkinson's disease. ${ }^{6}$

If there are medicines that can slow down the speed of progression of Parkinson's disease, then early diagnosis - and if possible also recognition of the presymptomatic stage - is essential in Parkinson's disease. In future this may happen with the help of 'biomarkers'.

Present-day levodopa substitution in Parkinson's disease aims at improving symptoms and during the last 25 years has led to dramatic improvement of the quality of life and increase of life-expectancy for about $70 \%$ of the idiopathical Parkinson patients. ${ }^{5-7}$ Only a part of the problems with long-term levodopatherapy is a result of levodopa itself, so that nowadays postponement of levodopatherapy is no longer considered absolute. $^{8}$ 


\section{Free radicals and neurotoxines}

The cause of cell death in the substantia nigra with Parkinson's disease is unknown, but it is taken for granted that demolition of neurones may arise by exogenous toxins and by oxygenradicals which are generated by the oxidative deamination by monoamine-oxidase-B (MAO-B) of dopamine. First the putative role of free radicals is considered; then the influence of neurotoxines is under discussion. Finally light is thrown upon the importance of MAO-B-inhibitors in the treatment of Parkinson's disease, especially with the help of the Datatop study.

\section{Free radical hypothesis}

The idea that the enzymatic oxidation of dopamine can be 'self-killing' for the nigrostriatal neurones by the formation of hydrogen peroxide and other oxygenradicals has become clearer of late years. Above all the oxidative damage of proteins, lipids and DNA has been subject of study. Free radicals and toxins damage the neurones of the substantia nigra by lipid peroxidation. In Parkinson's disease this process is increased. Then it is a question of increased oxidative stress. ${ }^{10-14}$ In consequence of this the normal detoxification of dopamine and its metabolites is disturbed. We are concerned here with the following factors:

* the dopamine-'turnover' is enhanced through which more oxygen radicals are generated. Dopamine is deaminated oxidatively by the enzyme MAO-B:

$$
\text { dopamine }+\mathrm{O}_{2 \cdots \cdots+-\mathrm{B}}^{\mathrm{MAO}} \mathrm{H}_{2} \mathrm{O}_{2}+\mathrm{O}_{2}^{-}+\text {semichinones }
$$

* The formed peroxides and superoxides can be converted via the Haber-Weiss-reaction and the Fenton-reaction into the most toxic radical, the free hydroxyl radical $(\bullet \mathrm{OH})$. Iron plays the part of catalyst in these reactions ${ }^{13}$ :

$$
\mathrm{O}_{2}+\mathrm{H}_{2} \mathrm{O}_{2} \stackrel{\mathrm{Fe}^{2+}+\cdots \mathrm{Fe}^{3+}}{\mathrm{O}} \mathrm{OH}+\mathrm{OH}+\mathrm{O}_{2}
$$

* increase of the MAO-B-activity with age and in Parkinson's disease ${ }^{10}$; 
* the iron-quantity in the substantia nigra is highly increased in Parkinson's disease ${ }^{14}$;

* the body possesses some intracellular enzymatic defense mechanisms against free radicals, namely: glutathionperoxidase, catalase and superoxide-dismutase. Also vitamin $\mathrm{E}$ (tocopherol) is intracellular active as 'scavenger' catching away the free radicals. The 'scavenger'enzymes catalase and glutathione-peroxidase are highly reduced in the substantia nigra of Parkinson-patients ${ }^{10-15}$.

As a consequence of above-mentioned factors the process of lipid peroxidation is intensified and the ultimate cell destruction in the substantia nigra is promoted.

Finally it is worth-while mentioning that an increased free radical forming can selectively bring about a damage of the complex-1 (NADHubichinon-Reductase) in the mitochondria, which decreases the synthesis of ATP-ase and the energy formation in the cell. A decreased concentration of complex- 1 was recently shown in cells of the substantia nigra in patients with Parkinson's disease. ${ }^{16-18}$

\section{Neurotoxine hypothesis}

Of late years interest has grown in the idea that one or more neurotoxines play a prominent part in neuronal degeneration, as in Parkinson's disease. This new interest has especially come into being after Langston's discovery in 1982 that methylfenyltetrahydropyridine (MPTP; or in fact the metabolite $\mathrm{MPP}^{+}$) is very selectively neurotoxic for the cells of the substantia nigra (and the locus coeruleus). It may induce a syndrome that is practically indistinguishable (not neuropathologically either) from idiopathic parkinsonism." The mechanism with which this toxicity of the substantia nigra is realised so selectively, has meanwhile been partially cleared. A noticeable experience of this research into the pathophysiology of this 'toxic-parkinsonism' was that with it a decreased complex-1-quantity was found in the mitochondria of the lesioned substantia nigra, likewise also with idiopathic parkinsonism.

The discovery of a toxic compound which can cause parkinsonism has led to a scientific concept that the origin of Parkinson's disease is possibly (also) caused by toxic compounds as they occur in our internal or external environment. Honestly speaking must be assumed that a 'MPTPlike' compound has not yet been discovered in our environment up to the present. Neuroepidemiologic research will play an important part in the 
future as far as this is concerned. This has been assumed by Barbeau in the province of Quebec (Canada) in 1986 in his attempt to correlate the prevalence of Parkinson's disease to the use of the insecticide paraquat. $^{19,20}$

Crucial in neurotoxicity of MPTP is the biotransformation to $\mathrm{MPP}^{+}$, by the MAO-B enzyme. MAO-B inhibitors are able to prevent this biotransformation completely and with it also the damage of dopaminergic cells in the substantia nigra. This is also the reason that MAO-B inhibitors have become so interesting in the causal treatment of Parkinson's disease. MAO-B inhibitors could be able to delay the process of nigrostriatal degeneration.

MAO-B, free radical-hypothesis and neurotoxine-hypothesis

Already sooner mention was made of the importance of the MAO-B in the pathogenesis of Parkinson's disease. In short it concerns the following factors:

* MAO-B is responsible for the oxidative deamination of dopamine, a process which generates free radicals;

* MAO-B realizes the biotransformation of the protoxine MPTP to the toxic $\mathrm{MPP}^{+}$;

* the MAO-B activity increases with normal ageing and also with an affection in which normal or accelerated ageing processes play a part, as with Parkinson's disease ${ }^{10}$;

* the MAO-B activity is increased in thrombocytes and in the substantia nigra of Parkinson-patients ${ }^{10}$.

\section{MAO-B-suppression (selegiline)}

The activity of selective suppression of the MAO-B enzyme can be explained two-fold:

* selegiline suppresses MAO-B, it decreases the re-uptake of dopamine. It also has an effect on the presynaptic dopamine receptors, through which the dopamine-release is facilitated. The dopamine concentration is enhanced by this. So selegiline has a dopaminergic effect. A beneficial effect on the symptoms of Parkinson's disease may be the result hereof. With selegiline it is possible to postpone the levodopatherapy as a result of this symptomatic effect or, with on-going levodopatherapy, to decrease the dosage; 
* selegiline prevents the formation of toxins (for example from protoxines like MPTP) and toxic free radicals. This antineurotoxic effect may offer protection to dopamine neurons against further demolition by the process of lipid peroxidation.

In such a case you can speak of neuroprotection.

The first beneficial effect of selegiline in Parkinson's disease was mentioned in the retrospective research of Birkmayer et al. ${ }^{21}$ They reported a longer duration of life with patients who had been treated with a combination of levodopa and selegiline, than in a group of patients that had been treated with levodopa only. Elizan et al. found a synergistic effect of the combination levodopa and selegiline. ${ }^{22}$ Already sooner these researchers had reported a weak symptomatic but not neuroprotective effect of the addition of selegiline to ongoing levodopa medication. The break-through in the research into the activity of selegiline came from the Datatop-study on-a-large-scale in the U.S.A. ${ }^{2.3}$ Datatop stands for 'Deprenyl And Tocopherol Antioxydative Therapy Of Parkinsonism'.

The Datatop-research questions the fact whether treatment with selegiline $10 \mathrm{mg}$ a day could be able to postpone the point of time, in which the Parkinson disability has become so severe that levodopa therapy is considered necessary. The primary end-point of the study had been - with so far untreated Parkinson patients - the starting point of levodopa therapy. This starting-point which had been correlated to the degree of disability, was clearly defined beforehand. The study also looked at the effect of tocopherol - 2000 I.E. a day - (vitamin E) - in combination with selegiline or otherwise, in a double-blind placebocontrolled research protocol. At present only the interim analysis is known of the data about selegiline. The complete research data won't be known until 1992. The research was prematurely broken off by the research committee of the study in 1989, because the beneficial effects of selegiline medication appeared to be so significant, that it was ethically unjustified to continue the study in unaltered form. As with every breakdown of research there was the chance that in interim analysis the extent of the effect was systematically overrated.

In the study 800 Parkinson patients were involved; 401 patients were randomized for placebo, 399 patients for selegiline. The measured therapy compliance was exceptionally high (97-99\%).

The measured interval from the beginning of medication for the reach of the end-point (necessity of levodopa) was 15 months in the placebo group and 26 months in the selegiline group (statistical significance: $\left.\mathrm{p}<10^{-10}\right)$. 
In the placebo group the end-point was reached by 176 patients, and in the selegiline group by 97 patients. This difference is statistically significant $\left(p<10^{-8}\right)$. Administration of selegiline resulted in $50 \%$ reduction of speed of disability progression, and slowed down the progression of disability itself with almost a year.

With such an obviously measured beneficial effect of selegiline the interpretation of the acquired results remains a difficult matter. Has a decreased progression of the disease been shown herewith (neuroprotection in narrower sense), or has the postponement of the levodopa therapy partly been realized by a dopaminergic and thus symptomatic effect of selegiline-medication?

In the Datatop-study a small but significant improvement was reported in the disability-score (the Unified Parkinson Disability Rating Scale; UPDRS) in the with selegiline treated group, but only after 1 and 3 months' therapy. This so-called 'wash-in'-effect suggests an initial symptomatic effect of selegiline. This effect was 1.5 point on the UPDRSscale (a total score of 125 points is possible). This small symptomatic effect of selegiline does not explain that selegiline slows down the reaching of the end-point. This was also ruled out as a consequence of measuring the disability-score at a point of time that the biological effect of selegiline had disappeared after stopping the medication. This 'washout' period lasted for a month. In the Datatop-study there seemed to be no 'wash-out'-effect at this moment of time: the disability score which was measured with the UPDRS had not deteriorated. This pleads strongly against the argument that the activity of selegiline could only be explained by a symptomatic-dopaminergic effect. At least, if a month is sufficient for the complete inactivation of biological active selegiline. That's the reason why in the U.S.A. there is a research going on into fixing the 'wash-out'-effect 2 months after stopping the selegiline medication.

This Datatop-study has not given any certainty about the question whether selegiline protects against degeneration of neurones in the substantia nigra in Parkinson's disease. But the result of this study so incontestably brought to light that selegiline can postpone the progression of disability as a consequence of Parkinson's disease, and that selegiline can so postpone the levodopa therapy, that this will have extreme consequences for the medical treatment of this disease..$^{24-28}$

The many criticisms and comments on this Datatop-study have recently been concentrated in a very critical article. ${ }^{29}$ Ample reactions were given, in such a way that the results of the Datatop-study, after having been undone from myths and misinterpretations, remained on end. ${ }^{30}$ Only as a 
consequence of a small anti-Parkinson and anti-depressive activity of selegiline the unprecedentedly high significance of the effect of selegiline on the speed-reduce of progression is unexplainable. Prescribing selegiline as soon as possible after diagnosing 'Parkinson's Disease' is therefore recommended. ${ }^{31}$

As has been reported, the final conclusions of the Datatop-study will not be published until mid 1992. Only then will definitely be reported which precisely is the part of selegiline in the medical treatment of Parkinson's disease. It does not seem unlikely that after this, additional research - if possible on even great scale as the Datatop-study as well will be necessary to make clearer the position of selegiline as neuroprotective or as dopaminergic medication.

\section{Conclusion}

The pharmacotherapy of Parkinson's disease had until recently been aimed at the treatment of the consequences of neuronal degeneration, namely levodopa substitution therapy. The results of this levodopa therapy are impressive and are not equalled by the treatment with dopamine-agonists or suchlike medications with a symptomatic dopaminergic effect.

Recent opinions in the pathophysiology in Parkinson's disease, among other things the hypothetical role of MAO-B in the production of free oxygen radicals and other toxins, have led to an important role of MAO$B$ inhibitors in the treatment of this disease. The present-day data of experimental neuro-pharmacological and clinical neurological research have led to the certainty that with selegiline the symptomatic therapy with levodopa substitution can be postponed, and that selegiline in all probability delays the progression of disability of Parkinson's disease.

In a practical sense this has the following consequences for treatment:

* selegiline medication as initial therapy in Parkinson's disease. With increasing disability are added to this (in the following order) dopamine-agonist and levodopa substitution. Levodopa is as most powerful weapon last placed in position. Selegiline medication being continued ${ }^{32}$;

* in going-on medication of levodopa and/or dopamine-agonist, selegiline is added on behalf of a levodopa-saving effect and to decrease the speed of clinical progression of the malady. Then as a rule it is possible to decrease the dosage of the on-going levodopa therapy, 
among other things to ameliorate dyskinesia or other dopaminergic side-effects $28-32$;

* in obviously progressed cases of Parkinson's disease, when moreover the motor response to levodopa therapy has been extinguished, there seems to be little room for medication with selegiline.

Parkinson patients with obvious or reasonably to be expected high degree of levodopa responsivity can derive much benefit from selegiline, especially at long-term. If by future research is confirmed that selegiline has neuroprotective qualities, then further research into presymptomatic parkinsonism is desirable. Neuroprotection with MAO-B-inhibitors should in such a case be able to reduce or delay symptomatic levodopa therapy.

Selegiline is not only an irreversible selective MAO-B-inhibitor, but it is also a reversible inhibitor of the (re)uptake of dopamimetic and MPTPlike compounds in the dopaminergic neurones.

Further research will have to make clear how these two functions of selegiline can be separated and which function is actually the most important one.

\section{References}

1. Langston JW. Current theories on the cause of Parkinsons's disease. J Neurol Neurosurg Psychiatry 1989;Suppl:13-17.

2. Hornykiewicz O, Kish Sj. Biochemical pathophysiology of Parkinson's disease. Adv Neurol 1986;45:19-34.

3. Calne DB, Langston JW. Aetiology of Parkinson's disease. Lancet 1983;2:14571461.

4. Bernheimer $\mathrm{H}$, Birkmayer W, Hornykiewicz O, Jellinger K, Seitelberger F. Brain dopamine and the syndrome of Parkinson. J Neurol Sci 1973;20:415-455.

5. Marsden CD. Movement disorders in neuropsychiatry. In: Reynolds EG, Trimble MD, red. The bridge between neurology and psychiatry. Edinburgh: Churchill Livingstone, 1989:151-158.

6. Leenders KL, Salmon EP, Tyrrel P, Perani D, Brooks DJ, Sager H, et al. The nigrostriatal dopaminerge system assessed in vivo by positron emission tomography. Arch Neurol 1990;47:1290-1298.

7. Speelman JD. Parkinson's disease and stereotactic neurosurgery (proefschrift). Amsterdam: Rodopi, 1991.

8. Horstink MWIM, Zijlmans JCM, Pasman JW, Berger HJC, Korten JJ, Van 't Hof MA. Which risk factors predict L-Dopa response in fluctuating Parkinson's disease? Ann Neurol 1990;27:537-543.

9. Langston JW, Ballard P, Tetrud JW, Irwin J. Chronic Parkinsonism in humans due to a product of meperidin-analog synthesis. Science 1983;219:979-980. 
10. Götz ME, Freyberger A, Riederer P. Oxidative stress; a role in the pathogenesis of Parkinson's disease. J Neural Transm Gen Sect 1990;29:241-249.

11. Steventon G, Humphrey C, Sturman S, Waring RH, Williams AC, Napier J. Monoamine oxidase B and Parkinson's disease. Lancet 1990;1:180.

12. Dexter DT, Carter CJ, Wells FR. Basal lipid peroxidation in substantia nigra is increased in Parkinson's disease. J Neurochem 1989;52:381-389.

13. Halliwell B. Oxidants and the central nervous system. Acta Neurol Scand 1989;126:23-33.

14. Dexter DT, Wells FR, Lees AJ, Agid F, Agid Y, Jenner P. Increased nigral iron content occurring in brain in Parkinson's disease. J Neurochem 1989;52:18301836.

15. Knoll J. The pharmacology of selegiline (Deprenyl). Acta Neurol Scand 1989; 126:83-91.

16. Shapira AHV, Cooper JM, Dexter DT, Clarke JB, Jenner P, Marsden CD. Mitochondrial complex 1 deficiency in Parkinson's disease. Lancet 1989;1:1269.

17. Parker WD Jr., Boyson SJ, Parks JK. Abnormalities of the electron transport chain in idiopathic Parkinson's disease. Ann Neurol 1989;26:719-723.

18. Mizuno Y, Suzuki K, Ohta S. Postmortem changes in mitochondrial respiratory enzymes in brain of Parkinson's disease. J Neurol Sci 1990;96:49-57.

19. Steventon GB, Heafield MTE, Waring RH, Wiliams AC, Sturman SG. Xenobiotic metabolism in Parkinson's disease. Neurology 1989;39:883-887.

20. Barbeau A, Roy M, Langston JW. Neurological consequences of industrial exposure to MPTP. Lancet 1985;1:747.

21. Birkmayer $W$, Riederer $P$, Ambroni L. Increased life-expectancy resulting from addition of deprenyl to madopar treatment in Parkinson's disease. J Neural Transm Gen Sect 1985;65:113-127.

22. Elizan TS, Moros DA, Yahr MD. Early combination of selegiline and low-dose levodopa as initial symptomatic therapy in Parkinson's disease. Arch Neurol 1991:48:31-34.

23. The Parkinson Study Group. Effect of deprenyl on the progression of disability in early Parkinson's disease. N Engl J Med 1989;321:1364-1371.

24. Cohen G, Spina HB. Deprenyl suppresses the oxidant stress associated with increased dopamine turnover. Ann Neurol 1989;26:689-690.

25. Golbe LI. Long-term efficacy and safety of selegiline in advanced Parkinson's disease. Neurology 1989;39:1109-1111.

26. Lees AJ, Shaw KJ, Stern GM, Kohout IJ, Sandler M, Youdim MBH. Deprenyl in Parkinson's disease. Lancet 1977;2:791-795.

27. Rinne JO, Roytta M, Paljarvi L, Rummakainen J, Rinne UK. Selegiline may retard death of nigral neurones in Parkinson's disease. Neurology 1991;41:859861.

28. Langston JW. Selegiline as neuroprotective therapy in Parkinson's disease. Neurology 1990;40 Supp] 13:61-66.

29. Landau WM. Clinical Neuromythology. IX. Pyramid sale in the bucket shop: Datatop bottoms out. Neurology 1990:40:1337-1339.

30. Special correspondence. Datatop and clinical neuromythology IX. Neurology 1991;41:771-777. 
31. Clough CG. Parkinson's disease: management. Lancet 1991;2:1324-1327.

32. Marsden CD. Parkinson's disease. Lancet 1990;1:948-952.

33. Langston JW. Predicting Parkinson's disease. Neurology 1990;40 Suppl 3:70-74.

34. Bloem BR, Irwin I, Buruma OJS, Haan J, Roos RAC, Tetrud JW, Langston JW. The MPTP model: versatile contributions to the treatment of idiopathic Parkinson's disease. J Neurol Sci 1990;97:273-293. 


\section{CHAPTER 4}

Open multicenter trial with Madopar HBS in parkinsonian patients. Preliminary assessment after shortterm treatment. ${ }^{2}$

${ }^{2}$ E.N.H. Jansen, J.D. Meerwaldt, Th. Heersema, J. van Manen, J.D. Speelman. Eur Neurol 1987;27(suppl. 1):88-92. 


\section{Introduction}

After some years the benefit derived from levodopa in the treatment of Parkinson's disease decreases slowly. After 6 years of levodopa therapy the initial benefit is maintained in only $30 \%$ of patients. Furthermore, in the course of several years of levodopa therapy they develop an increasing number of side effects, of which abnormal involuntary movements, response fluctuations and yo-yoing and painful off-period cramps or dystonias are the most frequent to be encountered. ${ }^{3}$ In a recent survey ${ }^{2}, 93 \%$ of patients after 10 years of levodopa therapy did exhibit the one or the other of these side effects, or a combination of them. The most problematic group of patients, however, is the one that exhibits the so-called 'drug resistant fluctuations'; about $10 \%$ of parkinsonian patients develop these fluctuations after 5 years of levodopa therapy.

The main reasons for the waning efficacy of levodopa and/or for the increasing number of side effects are: (1) relentless progression of the underlying pathology in the nigrostriatal pathway, including continued reduction of the dopamine storage capacity in the basal ganglia; (2) pharmacodynamic problems resulting in changes in receptor affinity ${ }^{3}$; (3) pharmacokinetic problems leading to a short-duration response ${ }^{4}$; and (4) formation of 3-O-methyldopa in- and outside of the brain, which reduces evidently the bioavailability of levodopa ${ }^{5}$.

Furthermore, the fluctuations in response may reflect the short half-life of the drug which, in addition, is erratically absorbed and distributed in patients who critically depend for good motor function upon adequate delivery of levodopa to their striatum. ${ }^{6}$

As the number of dyskinesias and response fluctuations are largely explained by or related to the variations in plasma levels of L-dopa, a controlled-release form of L-dopa reducing the peak levels of L-dopa in plasma and producing a steadier plasma concentration of levodopa has been developed based on the principle of the hydrodynamically balanced system of Madopar; the so-called Madopar HBS.?

We report here our preliminary results of short-term treatment with this Madopar HBS.

\section{Patients and Methods}

Twenty-three patients with idiopathic Parkinson's disease, all with some 
kind of response fluctuations, were selected for this study (table I).

Table I. Patient data (23 patients with Parkinson's disease)

\begin{tabular}{ll}
\hline Men, n & 14 \\
Women, n & 9 \\
Age, years & $52-72(61.2)$ \\
Duration of illness, years & $5-26(13.4)$ \\
Under levodopa therapy, years & $4-14(9.6)$ \\
Disability (Hoehn and Yahr scale) & \\
III, n & 12 \\
IV, n & 11 \\
Dosage standard Madopar, mg & $406-1,750(723)$ \\
Dosage bromocriptine & \\
$\quad$ (in 12 patients only), mg & $(36)$ \\
\hline
\end{tabular}

Informed consent was obtained after approval of the protocol by the hospital ethical committee. The parkinsonian signs and symptoms have been evaluated according to the Hoehn and Yahr scale ${ }^{8}$, and the Northwestern University Disability Scale (NUDS) ${ }^{9}$ and the Webster rating scale $^{10}$. The fluctuations in motor performance were scored using a list of the different types of fluctuations, scored from 0 (absent or disappeared) to 4 (extremely severe) as well as by a global assessment of these phenomena. Moreover, the patient or spouse kept a record of the times when he or she was dyskinetic, hypokinetic, or eukinetic on a card in which each quarter of an hour is one unit. The different aspects of motor behaviour have different colours: green $=$ eukinetic, yellow $=$ akinetic and red = dyskinetic or dystonic (fig. 1). With this self-rating system, designed by J.D.M., the frequency and duration of fluctuations can be monitored. This Meerwaldt patient card is filled in on 3 consecutive days. The total number of fluctuations in these 3 days is added up, and the mean of each type of fluctuations per day is calculated. Likewise, the total number of 'units' red, yellow and green per day is calculated, which yields a measure of the duration of fluctuations per day and their respective ratios. At the beginning of the study and at the end of the dose adaptation phase the Hoehn and Yahr scale, the Webster scale, the NUDS and the Meerwaldt patient card were filled out. At the end of the dose adaptation phase, the investigator also stated his personal opinion of the effects of Madopar HBS, as compared with the standard form, on the evolution of the parkinsonian symptoms, on the fluctuations in general and on the global tolerance. 


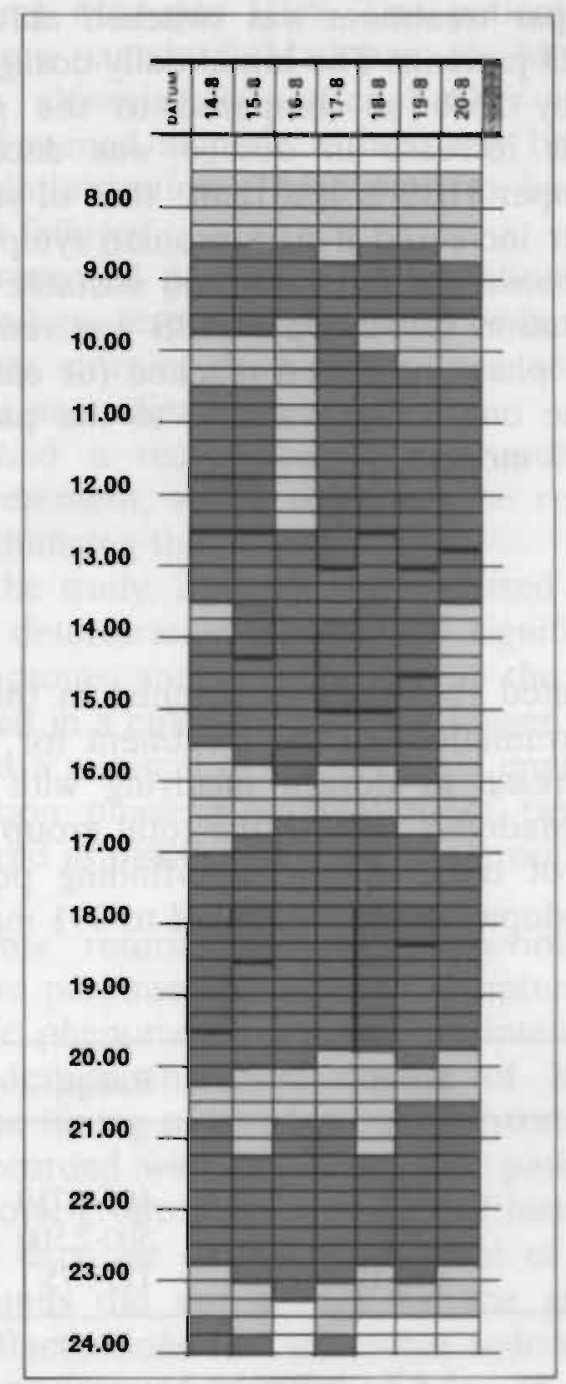

Figure 1. Model of Meerwaldt's patient card, a self-rating system of motor fluctuations. Green = eukinetic; yellow = akinetic; red $=$ dyskinetic or dystonic. 
At the same time the overall effect of this new formulation was evaluated by the investigator and the patient in order to decide whether treatment with Madopar HBS should be continued or if the previous treatment should be resumed.

The standard Madopar treatment was switched abruptly to Madopar HBS treatment in all 23 patients. The initial daily dosage of the Madopar HBS was increased by $25 \%$ as compared to the previous standard Madopar dosage. This increase in dosage was decided because the bioavailability of Madopar HBS is less than that of standard Madopar. The dosage was further increased if parkinsonian symptoms deteriorated or if the levodopa response was felt to be too unstable or too short. The frequency of administration of Madopar HBS was reduced only after a stable dose adaptation phase had been reached (or earlier if necessary). Madopar HBS was the only drug available to the patients during this dose-finding period of 3 months.

\section{Results}

All 23 patients completed the study as planned in the protocol. There were no premature terminations of the treatment for reasons unrelated to the drug. The increase in dosage incurring with the switch from standard Madopar to Madopar HBS in the total group is summarized in table II. At the end of the 3-month dose-finding period the average overall increase in levodopa dosage amounted to $391 \mathrm{mg}$ or $54 \%$.

Table II. Dosage (mg)

\begin{tabular}{lcl}
\hline & Mean & Range \\
\hline & & \\
Initial standard Madopar & 723 & $406-1,750$ \\
Madopar HBS & 1,114 & $500-2,500$ \\
Average increase & $391(54 \%)$ & $125-875$ \\
\hline
\end{tabular}

$2,500 \mathrm{mg}$ Madopar HBS $=20$ capsules $=2,000 \mathrm{mg}$ L.-dopa daily.

Three patients did not tolerate an increase in dosage of Madopar HBS as small as $125 \mathrm{mg}$; while they showed an increase in the duration of the 
'on' periods, they suffered from enhanced abnormal involuntary movements. Another 3 patients had similar problems after an increase of the dosage of Madopar HBS; they also showed an increase of abnormal involuntary movements, however, they tolerated an increase in dosage higher than $125 \mathrm{mg}$ Madopar HBS. Two patients did not tolerate the abrupt switch from standard Madopar to Madopar HBS, as they developed severe akinesia and, after further increase in dosage of Madopar HBS, remained akinetic without any beneficial response from Madopar HBS administration. These patients had to be considered as primary treatment failures.

Eight patients reported a marked prolongation of the latency of the early-morning levodopa response; this could be counteracted partly by an increase of the first morning dose of levodopa and/or by administration of the first dose at an earlier time.

Two patients had a recurrence of early-morning dystonia ${ }^{11}$ under Madopar HBS treatment, which could not be reduced by rescheduling the timing or by changing the dosage.

At the end of the study, 2 patients who started the study with a clearcut end-of-dose deterioration showed a significant improvement of parkinsonian symptoms and a reduction of the response fluctuations. They also remained in a eukinetic state for longer periods during the day. Eight patients had a minimal or questionable improvement at the end of the dose adaptation phase. Continuation of treatment with Madopar HBS was considered as justified in these two groups of patients.

Thirteen patients returned to their previous standard Madopar treatment, because parkinsonian signs or symptoms deteriorated and/or because dyskinetic phenomena increased in intensity or duration under Madopar HBS despite increased dosage of Madopar HBS and/or rescheduling of the timing of levodopa administration.

The findings recorded with the Meerwaldt patient card are shown in table III. In the total group there was a small increase in yellow units, at the expense of a decrease of the mean value of green units. The total number of red units did not change for the group as a whole. The number of daily fluctuations was somewhat reduced, i.e. the mean value of daily fluctuations dropped from 9.4 to 8.4 .

The Hoehn and Yahr scale, the Webster rating scale and the NUDS did not reveal any changes in the group as a whole after the switch from standard Madopar to Madopar HBS. The decision whether or not to continue treatment with Madopar HBS was not based on the results obtained with these rating scales. The total number of yellow units of 
Table III. Meerwaldt's patient card

\begin{tabular}{lcl}
\hline & $\begin{array}{l}\text { Standard } \\
\text { Madopar }\end{array}$ & $\begin{array}{l}\text { Madopar } \\
\text { HBS }\end{array}$ \\
\hline Yellow, units & 16.3 & 19.6 \\
Green, units & 33.8 & 30.3 \\
Red, units & 9.9 & 10.3 \\
Daily fluctuations, $\mathrm{n}$ & 9.4 & 8.4 \\
\hline
\end{tabular}

1 unit $=1$ quarter of an hour.

the Meerwaldt patient card, however, did correlate positively with the decision to stop the treatment with Madopar HBS after the dose-finding period.

\section{Discussion}

Twenty-three patients entered a study in which standard Madopar was abruptly replaced by the new galenic form Madopar HBS in an attempt to reduce fluctuations in performance and 'on-off' phenomena. After a dose-finding period of 3 months and an overall increase of levodopa dosage by $54 \%$, only 2 patients - with clear-cut end-of-dose deterioration - showed a significant improvement in response fluctuations. Thirteen patients showed no improvement or considered the change from standard Madopar to Madopar HBS as a step backwards, either with regard to response fluctuations or with regard to parkinsonian signs and symptoms. Patients with random oscillations or yo-yoing, or patients with profound diurnal swings in motor performance showed no benefit from Madopar HBS treatment.

The positive effects of Madopar HBS, i.e. the reduction of fluctuations in performance, were often obtained at the expense of the major negative effect of Madopar HBS, i.e. unacceptable delay to 'turn-on' in the morning. In patients with a 'low therapeutic index' Madopar HBS was not beneficial. Early-morning dystonia recurred in 2 patients under Madopar HBS regimen. The poor result of Madopar HBS in this study 
may be related to the bioavailability profile of the HBS compound. The relative bioavailability of Madopar HBS compared to standard Madopar is about $60 \%$. Thus, the poor results obtained with Madopar HBS in some patients in this study may have been a matter of dosage. The increase in dosage of levodopa by $54 \%$, after switch to Madopar HBS, evidently was not always sufficient to compensate for this marked reduction of bioavailability. Moreover, for a sustained response a higher plasma concentration of levodopa might be necessary than for a threshold response obtained with intravenous levodopa. ${ }^{12,13}$ Possibly, with Madopar HBS the increase in dosage might be much more substantial than the one necessary to compensate just for the reduced bioavailability.

Another reason for the relatively poor results may have been that parkinsonian patients cannot be switched to a therapeutic regimen with Madopar HBS only, i.e. they need additional standard Madopar in order to prevent the major disadvantage of this Madopar HBS: the increased latency after the first morning dose.

In a study design in which only parkinsonian patients with end-of-dose deterioration would be selected, the beneficial effects of Madopar HBS might be much more pronounced.

The patient card of Meerwaldt is an easy and reliable way of measuring frequency and intensity of fluctuations in motor performance.

\section{References}

1. Marsden CD, Parkes JD, Quinn N. Fluctuations of disability in Parkinson's disease. In: Movement disorders. Butterworth, London 1982. pp. 96-122.

2. Bergman KJ, Mendoza MR, Yahr MD. Parkinson's disease and long-term levodopa therapy. Advances in Neurology. New York: Raven Press, 1986, pp. 463-467.

3. Fahn S. 'On-off' phenomenon with levodopa therapy in parkinsonism. Neurology 1974;24:431-441.

4. Muenter MD, Sharples NS, Tyce GM, Darley FH. Patterns of dystonia in response to L-dopa therapy of Parkinson's disease. May Clin Proc 1977;52:163174.

5. Sandler $M$. The dopa effect: possible significance of transamination and tetrahydroisoquinoline formation. Adv Neurol 1973;2:255-264.

6. Nutt JG, Woodward WR. Levodopa pharmacokinetics and pharmacodynamics in fluctuating parkinsonian patients. Neurology 1986;36:739-744.

7. Sheth PR, Tossounain J. The hydrodynamically balanced system, (HBS): a novel drug delivery system for oral use. Drug Dev ind Pharm 1985;10:313-319.

8. Hoehn MM, Yahr MD. Parkinsonism: onset, progression and mortality. Neurology 1967;17:427-442. 
9. Canter GJ, de la Tore R. North Western University Disability Scale. J Nerv Ment Dis 1961;133:143-147.

10. Webster DD. Critical analyses of the disability in Parkinson's disease. Met Treat, (New York) 1968;5:257-282.

11. Melamed E. Early-morning dystonia: a late side effect of long-term levodopa therapy in Parkinson's disease. Arch Neurol 1979;36:308-310.

12. Quinn N, Marsden CD, Parkes JD. Complicated response fluctuations in Parkinson's disease: response to intravenous infusion of levodopa. Lancet 1982;i:412-415.

13. Quinn N, Parkes JD, Marsden CD. Control of 'on-off' phenomenon by continuous intravenous infusion of levodopa. Neurology 1984;34:1131-1136. 


\section{CHAPTER 5}

Madopar HBS in Parkinson patients with nocturnal akinesia. $^{3}$

${ }^{3}$ Emst N.H. Jansen and Jan D. Meerwaldt. Clinical Neurology and Neurosurgery, 1988, vol. 90-1:35-39 


\section{Introduction}

Nightly disabilities are quite common in Parkinson's disease (PD), although in the literature these nocturnal problems are only infrequently mentioned. ${ }^{1-3}$ Sleep disturbances, nocturnal immobility and frequently interrupted sleep, may be a consequence of the disease itself. Another factor, however, may also play a role: after treatment with levodopa for more than five years many patients develop a variety of dose-limiting and disabling side effects, including dyskinesias, and a complex syndrome of deterioration of drug efficacy indicating the emerging of tolerance to levodopa ${ }^{4}$, of which response fluctuations are the most troublesome. These response fluctuations may be dose-related, for instance the genuine 'wearing off' phenomenon, or occur at random and in an unpredictable manner, the 'on-off phenomenon'. The 'off'-phase does not only show the akinetic problems of Parkinson's disease itself, but may also take the form of invalidating painful 'off-period' pain, spasms and dystonia. ${ }^{5.6 .7}$

The most unpleasant and incapacitating painful 'off-period' phenomena do not only occur during the day but are also frequently registered during the night and/or the early morning. Thus Parkinson patients are not only awakened because of immobility but also because of these painful dystonic phenomena.

The pathophysiological mechanisms underlying this tolerance to levodopa are poorly understood ${ }^{8}$, but the pharmacokinetic influences seem predominant as causative factors: the short half-life of levodopa, the fluctuations of the levodopa level in the plasma and the striking influence of the duration of levodopa therapy on the development of these response fluctuations. ${ }^{9-12}$ Long-term therapy with levodopa + Dopa Decarboxylase Inhibitor (DDI) seems to provoke these phenomena earlier and more frequently than therapy with only levodopa does. ${ }^{13}$

We have carried out an open trial of a sustained-release preparation of levodopa Madopar-Hydrodynamically Balanced System (HBS) ${ }^{14,15}$ in 15 Parkinson outpatients with severe response fluctuations due to chronic levodopa treatment and suffering from severe nightly disabilities.

\section{Patients and Methods}

Fifteen outpatients with idiopathic Parkinson's disease ( 7 women and 8 men) were studied. Their mean age was 60 years (range 33 to 78 ) and the mean duration of the parkinsonian symptoms was 12 years (range 5 to 
17). The mean duration of the levodopa therapy was nine years (range 2 to 13). All patients were on levodopa, nine patients had levodopa plus a peripheral decarboxylase inhibitor (in 6 patients benserazide, in 3 patients carbidopa), and six patients had plain levodopa. The mean dosage of levodopa (calculated without the DDI part) was $785 \mathrm{mg}$ (range 531 to 1000). The number of daily doses of levodopa ranged from 4 to 16 . No patient took levodopa ante noctem, but four patients took their first levodopa at 5 a.m., either to decrease early morning dystonia or to alleviate early morning akinesia. Seven patients had additional dopamine receptor agonist therapy (bromocriptine), mean dosage $35 \mathrm{mg}$ (range 20 to 37.5). According to the Hoehn and Yahr scale ${ }^{6}$, four patients had a motor disability stage III, 10 patients stage IV and one patient stage V. All patients had response fluctuations during the day: 13 patients had a wearing-off phenomenon, the other response fluctuations are summarized in Table 1.

Table 1. Diurnal fluctuations

\begin{tabular}{lc}
\hline Symptoms & Number of patients \\
\hline peak-dose dyskinesias & 10 \\
off-period dystonias & 5 \\
end-of-dose effects & 13 \\
random on-off fluctuations & 2 \\
early morning dystonia & 1 \\
\hline
\end{tabular}

15 patients

Table 2. Night-time disabilities

\begin{tabular}{lcc}
\hline & $1^{*}$ & $2^{*}$ \\
\hline nocturnal akinesia & 15 & 2 \\
nocturnal off-period pain & 1 & 0 \\
early morning akinesia & 12 & 8 \\
early morning dystonia & 1 & 2 \\
nocturnal dyskinesia & 0 & 2 \\
\hline
\end{tabular}

15 patients

1* number of patients prior to Madopar HBS

$2^{*}$ number of patients after Madopar HBS 
All 15 patients included in this study had severe nightly disabilities, which could be divided into four groups: (1) nocturnal akinesia, and consequently frequent awakenings, micturition with problems getting to sleep afterwards; (2) painful off-period cramps (dystonia or spasms); (3) early morning dystonia and (4) early morning akinesia. The patients could be categorized in more than one group, see Table 2. Madopar HBS was administered only once a day: ante noctem, and according to the intensity of the sleep disturbances the dosage was varied from 125 to 500 mg. The daily amount of levodopa and the number of doses and their schedule were kept unchanged. After six months the assessment of the efficacy of the addition of this ante noctem Madopar HBS to the conventional levodopa regimen was based on the subjective findings of the patients in the four groups of nightly disabilities and on the global assessment of their quality of sleep.

\section{Results}

Fourteen patients completed the six-month open study on the addition of Madopar HBS ante noctem to an otherwise unchanged levodopa substitution therapy. The dosage of Madopar HBS ranged from 125 to $500 \mathrm{mg}$; 5 patients were treated with $125 \mathrm{mg}$, 1 patient with $250 \mathrm{mg}, 6$ patients with $375 \mathrm{mg}$ and the other 3 patients with $500 \mathrm{mg}$ (mean dosage $308 \mathrm{mg}$ ). Table 2 shows the overall results.

While all 15 patients had nocturnal akinesia before the institution of Madopar HBS, 13 patients had a considerable or even dramatic diminution of the akinesia; in four patients the nocturnal akinesia had completely disappeared, providing an undisturbed sleep for these patients. In eight patients the nocturnal akinesia was diminished to such an extent that they could turn around in bed again, and/or were more self-supporting in getting out of bed and walking to the toilet. The one patient with nocturnal off-period pain and cramps in the legs, which generally awakened her at 3 a.m., had a painfree sleep after $375 \mathrm{mg}$ of Madopar HBS. Further increase of the dosage to $500 \mathrm{mg}$ Madopar HBS ante noctem, provoked nocturnal dyskinesia. In an early study ${ }^{15}$ this patient had shown a reduction of diurnal off-period cramps after the administration of Madopar HBS in the daytime, at the cost of an intolerable increase of peakdose dyskinesias, which were more disabling than the off-period cramps.

Early morning akinesia, which was present in 12 patients, was only 
slightly alleviated in four, and this did not establish a functional improvement in their daily-life activities. This slight alleviation was achicved on a dosage of $125 \mathrm{mg}$ of Madopar HBS ante noctem in three patients. 'l he other patient in this group was treated with $375 \mathrm{mg}$.

Early morning dystonia was present in one patient prior to the madopar HBS therapy and disappeared after treatment with Madopar HBS. But early morning dystonia occurred in two other patients. The dosage of Madopar HBS ante noctem in these two patients was relatively high (500 $\mathrm{mg}$ ) because of very severe nocturnal akinesia. The efficacy of the Madopar HBS in these two patients on the nocturnal akinesia was quite remarkable, and as a consequence the mild early morning dystonia was taken into the bargain.

Two patients had manifestations of nocturnal dyskinesia after treatment with Madopar HBS. In one patient this could be controlled by a reduction of the dosage from 500 to $375 \mathrm{mg}$ ante noctem, without affecting the beneficial effect on nocturnal akinesia. The other patient suffered severe nocturnal dyskinesias after only $125 \mathrm{mg}$ of Madopar HBS ante noctem. Although a previously present severe nocturnal akinesia had disappeared by this small dosage of Madopar HBS, the patient and his wife could not put up with these dyskinesias and the therapy with Madopar was stopped. One patient with a regimen of $375 \mathrm{mg}$ Madopar HBS ante noctem and $600 \mathrm{mg}$ Sinemet and $25 \mathrm{mg}$ Bromocriptine in the daytime, had a slight increase in dyskinesias and longer on-periods during the day.

Adverse effects of this nocturnal Madopar HBS regimen were rare. No patients had gastrointestinal side-effects. Psychiatric complications were not seen, only one patient felt a little drowsy, which could be overcome by a reduction of the dosage of Madopar HBS from 500 to $375 \mathrm{mg}$. One other patient became restless during the day, which subsided spontaneously.

The global improvement of the sleep quality could be related to the consumption of sleeping tablets. After treatment with Madopar HBS ante noctem, sleeping pills were used regularly by only one patient, compared with eight patients who regularly took sleeping pills before the treatment with Madopar HBS.

\section{Discussion}

Patlents with idiopathic Parkinson's disease show significantly reduced 
REM sleep and more frequent and prolonged waking through the night. ${ }^{17}$ It has been suggested that this disturbed sleeping pattern is related to a reduction in brain amines. ${ }^{18,19}$

Treatment of Parkinson's disease with levodopa or a dopamine agonist is said to lead to an improvement of the quality of sleep, in accordance with the fact that the severity of disease is directly related to the impaiment of sleep. ${ }^{20}$ The sleep disturbances in PD patients consist of a light-fragmented sleep pattern, with increased muscle activity, which can be reversed by treatment with pergolide, a strong and selective $D_{2}$ agonist, in contrast to levodopa which influences the whole population of $D$ receptors ${ }^{21.22}$. Apps et $\mathrm{al}^{23}$ found reduced stages III and IV sleep only in patients in a severe state of disease (Hoehn and Yahr stages IV and V).

Long-term levodopa therapy causes a high frequency of unwanted effects, of which the wearing-off effects, dyskinesias and dystonias, and severe fluctuations in therapeutic response are the most frequently encountered..$^{24,25,26}$ In a recent study ${ }^{27} 90 \%$ of long-term levodopa-treated PD patients showed these phenomena of the 'long-term levodopa syndrome'.

At the same time it is common for PD patients to have profound nocturnal problems due to akinetic wearing-off phenomena. In their lightfragmented sleep they are frequently awake in an akinetic state, incapable of turning around in bed, or of going to the toilet. Also, many PD patients are awakened by painful off-period cramps, and dystonias. For many PD patients the night is a nightmare at the end of which only few patients have the so-called sleep benefit; they are incapacitated by early morning dystonia or early morning akinesia. For these reasons, many PD patients use sleeping pills or take their last levodopa dosage at 2 a.m. to prevent early nocturnal problems, and their first levodopa at 5 a.m. to prevent early morning problems.

In this study a new sustained-release compound - MADOPAR HBS was administered only ante noctem in a dosage of 125 to $500 \mathrm{mg}$. The very good results, related to frequency of wakening and nocturnal akinesia, verify the pharmacological sustained-release profile of this compound. The major disadvantage of Madopar HBS in daily administration, i.e. unacceptable latency of efficacy ${ }^{15}$ was not seen with the nocturnal administration of Madopar HBS and may even be an advantage in nighttime administration. The same holds true, though less pronounced, for the increase in dyskinesias. The capacity of Madopar HBS taken ante noctem to reduce the early morning akinesia or early morning dystonia is evidently too small; this is in accordance with the biopharmacological profile of this compound. 375 Milligram of Madopar 
HBS produces an adequate plateau level of plasma levodopa for only some hours. ${ }^{28}$ The occurrence of early morning dystonia in two patients in this study is in accordance herewith. The tolerance to Madopar HBS was excellent. No gastrointestinal adverse effects were registered. This is possibly related to the fact that these patients already used levodopa + DDI. No untoward effects were encountered by the use of two DDI's in some patients (carbidopa and benserazide). A sustained-release levodopa compound such as Madopar HBS seems a safe and effective method of reducing the invalidating nocturnal problems of patients with Parkinson's disease on long-term levodopa therapy.

\section{References}

1. Schmitt HS, Knopp W. Sleep in Parkinson's disease: The effects of L-Dopa. Psychophysiology 1972;9:89-97.

2. Schneider E, Maxion H, Ziegler B, Jacobi P. Das Schlaferhalten von Parkinsonkranken und seine Beeinflüssung durch L-Dopa. J Neurol 1974;207:95108.

3. Mouret J. Difference in sleep in patients with Parkinson's disease. Electroencephalogr Clin Neurophysiol 1975;38:653-657.

4. Fahn $\mathrm{S}$, Calne DB. Considerations in the management of parkinsonism. Neurology 1967:17:427-442.

5. Quinn NP, Koller WC, Lang AE, Marsden CD. Painful Parkinson's disease. Lancet 1986;1366-1369.

6. Melamed E. Initiation of Levodopa therapy in parkinsonian patients should be delayed until the advanced stages of the disease. Arch Neurol 1986;43:402-405.

7. Hoehn MM. Using Bromocriptine to manage the inadequacies of Levodopa therapy. In: Fahn S, Marsden CD (eds.). Recent developments in Parkinson's disease. Raven Press 1986;293-301.

8. Fahn S. Fluctuations of disability in Parkinson's disease: Pathophysiology. In: Marsden CD, Fahn S (eds.). Movement Disorders. Butterworth Scientific 1982; pp $123-145$.

9. Leenders KL. Palmer AJ, Quinn N, Clark JD, Marsden SD. Brain dopamine metabolism in patients with Parkinson's disease measured with positron emission tomography. $J$ Neurol Neurosurg Psychiatry 1986;49:853-860.

10. Nutt IG, Woodward. WR. Levodopa pharmacokinetics and pharmacodynamics in fluctuating parkinsonian patients. Neurology 1986;36:739-744.

11. De Jong GJ, Meerwaldt JD, Schmitz PIM. Factors that influence the occurrence of response variations in Parkinson's disease. Ann Neurology 1987;21:4-7.

12. Quinn NP, Parkes JD, Marsden CD. Control of 'on-off phenomena by continuous iniravenous infusion of Levodopa. Neurology 1984;34:1131-1136.

13. De Jong G.J, Meerwaldt JD. response variations in the treatment of Parkinson's disease. Neurology (Cleveland) 1984;34:1507-1509. 
14. Poewe WH, Lees AJ, Stern GM. Treatment of Motor Fluctuations in Parkinson's disease with an oral Sustained-Release Preparation of L-dopa: Clinical and Pharmacokinetic observations. Clinical Neuropharmacology 1986, vol. 9 no. 5:430-439.

15. Jansen ENH, Meerwaldt JD, Heersema TJ, van Manen J, Speelman JD. Open Multicenter trial with 'Madopar' HBS in Parkinson patients. In Marsden CD, Rinne UK, Koella W, Dubuis R (eds.). Eur Neurol 1987;27 (suppl 1):88-92.

16. Hoehn MM, Yahr MD. Parkinsonism: onset, progression, and mortality. Neurology (Minneap), 1967;17:427-442.

17. Kales A, Anael RD, Markham CH, Deharf MB, Tijauw Ling Tan. Sleep in patients with Parkinson's disease and normal subjects prior to and following levodopa administration. Clin Pharmacol Therapy 1971;4:397-406.

18. Jouvet M. Biogenic amines and the states of sleep. Science 1969;163:32-41.

19. Guilleminault C, Tilkian A, Lehrman K, Forno L, Dement WC. Sleep apnoea svindrome, states of sleep and autonomic dysfunction. J Neurol Neurosurg Psychiatr 1977;40:718-725.

20. Friedman A. Sleep pattern in Parkinson's disease. Acta Med Pol 1980;21:193-199.

21. Askenasy JJM, Yahr MD. Suppression of REM rebound by Pergolide. J Neurol Transmission 1984;59:151-159.

22. Askenasy JJM. Yahr MD. Reversal of sleep disturbances in PD by antiparkinsonian therapy. Neurology 1985;35:527-532.

23. Apps MCP, Sheaff PC, Ingram DA, Kennard C, Empey DW. Respiration and sleep in Parkinson's disease. J Neurol Neurosurg Psychiatr 1985;48:1240-1245.

24. Muenter MD. Should levodopa therapy be started early or late? Can J Neurol Sci 1984;11:195-199.

25. Marsden CD, Parkies JD. 'On-off' effects in patients with Parkinson's disease on chronic Jevodopa therapy. Lancet 1976;1:292-296.

26. Duvoisin RC. To treat early or to treat late. Ann Neurol 1987;21:2-3.

27. Bergman KJ, Mendoza MR, Yahr MD. Parkinson's disease and long-term levodopa therapy. In: Yahr MD and Bergman KJ eds. Advances in Neurology. New York: Raven Press, 1986, pp 463-467.

28. Crevoissier C. Hoevels B, Da Prada M. Biovailability of 'Madopar' HBS in healthy volunteers. In: Marsden CD, Rinne UK, Koella W. Dubuis R (eds.). International workshop on the on-off phenomenon in Parkinson's disease. Eur Neurol 1987;27:36-46. 


\section{CHAPTER 6}

Clinical efficacy of Sinemet CR 50/200 versus Sinemet 25/100 patients with fluctuating Parkinson's disease. An open, and a double-blind, double-dummy, multicenter treatment evaluation. ${ }^{4}$ 


\section{Introduction}

Levodopa, in combination with a peripheral dopadecarboxylase inhibitor, still constitutes the basis of therapeutic strategies in Parkinson's disease. Long-term treatment with this drug, however, is limited because of loss of levodopa responsiveness in most patients. Patients may suffer predictable wearing-off periods and/or unpredictable on-off periods with random swings in motor functioning. ${ }^{1,2}$ These motor fluctuations are said to be associated with the pharmacokinetic and pharmacodynamic properties of oral levodopa., ${ }^{3,4}$ Sustained, continuous intravenous infusions with levodopa, resulting in stable plasma levodopa levels, proved to be successful in the treatment of those fluctuations. ${ }^{3}$

Keeping plasma levodopa levels stable in this way is, however, not very practical during long-term treatment. A practical solution, in the form of controlled-release preparations with pharmacokinetic properties more or less similar to those of intravenous infusion, has been sought. A formula containing a slowly erodible polymer matrix with $50 \mathrm{mg}$ carbidopa and $200 \mathrm{mg}$ levodopa (Sinemet CR-4 = Sinemet CR), proved to be quite successful in this respect. ${ }^{5-7}$ This formula induces a sustained rise in plasma levodopa level, lasting 2-3 h longer than with Sinemet STD. ${ }^{s}$

Clinical trials with Sinemet CR showed this drug to be as safe and as well tolerated as conventional formulas. ${ }^{7-15}$ Sinemet $C R$ was found to reduce the incidence and duration of daily off-periods, with fewer doses per day, but at a higher total daily dosage of levodopa than with Sinemet STD. Open studies ${ }^{8-11}$ showed significantly improved clinical efficacy of Sinemet CR as compared with Sinemet STD, but this could not be unequivocally confirmed in double-blind studies., ${ }^{7,12-15}$

In this study we compared the efficacy and tolerability of Sinemet CR and Sinemet-STD in Parkinson's disease patients with motor fluctuations, both in an open and a double-blind fashion.

\section{Methods}

\section{Study design}

The study lasted 32 weeks and was divided into 2 phases. The first phase was an 8-week open-label dose-finding period of 4 weeks Sinemet STD (weeks 1-4) and 4 weeks Sinemet CR (weeks 5-8), in which end-readings were compared to the measurements at the start of the study (baseline-1).

The second phase was a double-blind, double-dummy period of 24 
weeks (weeks 9-32), during which period half of the patients received Sinemet CR plus placebo Sinemet STD, and the other half received Sinemet STD plus placebo Sinemet CR. Here the end-results were compared with the assessments at week 8 (baseline-2). The dosage and dose schedule for this double-blind period were established during the dose-finding periods, but investigators were allowed to alter both drug regimens (Sinemet or Sinemet CR and placebo) at the same time. Patients were randomly selected to receive therapy according to a scheme which provided equal distribution of patients concurrently receiving a stable dose of dopamine agonists in both groups. If considered necessary for the patient's welfare, drugs for other physical conditions were allowed in a stable dosage.

Physical examination and routine laboratory tests, including a complete blood cell count and electrocardiograms, were performed at commencement and at the end of the study. Safety measures included monthly recordings of adverse clinical experiences. Tolerability of the drug was recorded. Dosage and dose frequency were established based on clinical response. Evaluations of the clinical response during this study, performed at commencement and at weeks 4, 8, 12, 16, 20 and 32, included: (1) the New York University Parkinson's Disease Scale (NYUPDS) to determine clinical efficacy in terms of rigidity, tremor, bradykinesia, gait and postural stability; (2) the North-western University Disability Scale (NUDS) for the evaluation of daily activities such as walking, dressing, eating, feeding, hygiene and speech; (3) patients' diaries for the evaluation of on-off periods and sleep pattern; (4) patients' overall evaluations of early morning akinesia, dystonia, dyskinesia, and pain. Evaluations were recorded on a 5-point scale; (5) physicians' and patients' overall assessment (on a 5-point scale), including their opinion about the actual medication during the double-blind period in order to test the 'blindness' of this study.

\section{Patients}

Fifteen Dutch neurologic departments entered 84 patients with Parkinson's disease. Hoehn and Yahr stages II-IV, with motor fluctuations. A total of 15 patients withdrew during the study: 7 patients during the titration period, 8 during the double-blind period. Five of these withdrawals were due to adverse effects, of which three were Sinemet CR-related. Six withdrawals were due to insufficient therapeutic response, of which four during the Sinemet CR dose-finding period. Four patients were excluded from analysis a posteriori because of protocol violation (3), or having been lost to follow-up (1). Clinical characteristics 
of the remaining 69 patients (34 in the Sinemet STD and 35 in the Sinemet CR group) are given in Table 1. Based on statistical analysis (Student's t-test and binomial difference test), both groups were comparable at the start of the study. Of the STD-treated patients, 32 received concomitant antiparkinson therapy, such as bromocriptine, selegiline and amantadine. In the CR-treated patients this accounted for 26 persons. This concomitant therapy remained constant in all patients during the study. Pharmacologically treated conditions, other than Parkinson's disease, occurred equally in both groups: depression, insomnia, anxiety, coronary heart disease, hypertension and chronic obstructive pulmonary disease.

Statistical methods

Paired results were separately studied in both open-label and double-blind phases:

I. Open-label study: The results of all participating patients $(n=69)$ during the open-label titration phase at baseline (week 1), week 4 (end of titration period STD)

and week 8 (end of titration period CR).

\section{Double blind study.}

(1) STD-group: results of the patients treated in the double-blind phase with Sinemet STD plus placebo Sinemet CR $(n=34)$, at weeks 8 (baseline-2) and 32.

(2) CR-group: results of the patients treated in the double-blind phase with Sinemet $C R$ plus placebo Sinemet STD $(n=35)$ at weeks 8 (baseline-2) and 32 .

Student's t-test was used to discriminate between the effects on several variables. The incidence of clinically adverse experiences in the 2 treatment groups was compared during the double-blind phase by means of Student's t-test. The level of significance was reached at $P \leq 0.05$.

\section{Results}

Efficacy (Fig. 1, Table 2)

Clinical efficacy

Mean (SD) total NYUPDS scores as obtained during the open-label study in all patients at baseline $(6.9 \pm 2.7)$ and week $4(6.4 \pm 2.7)$ and 
Figure 1. Mean of total NYUPDS (upper) and NUDS (lower) scores with standard deviations (SD) in: 69 Parkinson patients at baseline-I $\left(\mathrm{BL}_{1}\right)$, week 4 (after optimal STD titration) and week 8 (after optimal CR titration); 34 patients, treated doubleblind with STD, at baseline-2 $\left(\mathrm{BL}_{2}\right.$, week 8 ) and at week 32 (end of the study); 35 patients, treated double-blind with $\mathrm{CR}$, at $\mathrm{BL}_{2}$ and week 32. NYUPDS $=$ New York University Parkinson's Disease Scale; NUDS = North-western University Disability Scale. Significance: wk 8 vs. $\mathrm{BL}_{7}$ and wk 32 vs. BL2; ${ }^{*} \mathrm{P}<0.05,{ }^{* *} \mathrm{P}<0.01$; wk 8 vs. wk $4:^{(* *)} \mathrm{P}<0.01$.

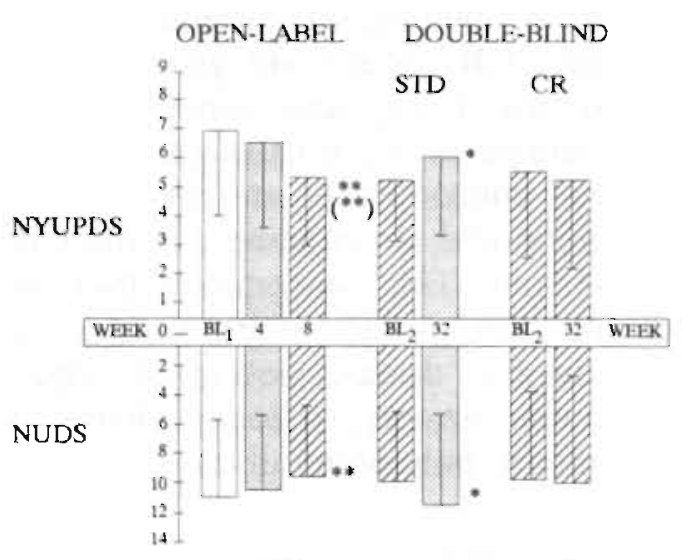

Sincmet STD

Sinemet CD

Table I Survey of clinical characteristics of the evaluated patients at start of the study

\begin{tabular}{|c|c|c|c|}
\hline & $\begin{array}{l}\text { STD }(n=34) \\
\text { Mean }(S D)\end{array}$ & $\begin{array}{l}\text { CR }(n=35) \\
\text { Mean }(S D)\end{array}$ & $\begin{array}{l}\mathrm{P} \\
\text { (STD } \\
\text { vs CR) }\end{array}$ \\
\hline Male/female & $24: 10$ & 19:16 & NS \\
\hline Age(years) & $60.8(9.3)$ & $61.6(8.4)$ & NS \\
\hline \multicolumn{4}{|l|}{ Levodopa } \\
\hline dosage (mg day) & $642(285)$ & $632(295)$ & NS \\
\hline No. of doses, day & $5.5(2.2)$ & $5.3(2.7)$ & NS \\
\hline \multicolumn{4}{|l|}{ Parkinsonian disability } \\
\hline NUDS & $11.0(4.8)$ & $10.8(5.7)$ & NS \\
\hline NYUPDS & $6.9(2.6)$ & $6.9(2.8)$ & NS \\
\hline Hoehn and Yahr stage & $2.9(0.4)$ & $2.8(0.8)$ & NS \\
\hline \multicolumn{4}{|l|}{ Duration in years of } \\
\hline Parkinson's disease & $10.6(5.2)$ & $10.4(4.6)$ & NS \\
\hline fluctuations & $4.2(2.7)$ & $3.4(2.8)$ & NS \\
\hline
\end{tabular}

STD $=$ Sinemet standard 25/100. CR $=$ Sinemet $C R$ 50/200. SD standard deviation. $\mathrm{NS}=$ not significant. NUDS $=$ North-western University Disability Scale. NYUPDS = New York University Parkinson's Disease Scale. 
week 8 (5.4 \pm 2.5$)$ showed that CR-titration induced significant improvement of the clinical condition at week 8 , as compared both with the situation at baseline and after STD-titration at week 4. There were no differences in response to STD or CR between the group ultimately assigned to STD in the double-blind portion and the group assigned to Sinemet CR. In the double-blind STD-treated patients a statistically significant increase in total NYUPDS score at week $32(6.0 \pm 2.9)$ as compared with week $8(5.3 \pm 2.2)$ was found. In the CR-treated patients, however, mean total scores showed only a small and not significant further decrease in NYUPDS scores, reflecting a stable improvement of the clinical condition at week $32(5.2 \pm 2.9)$ as compared with week 8 (5.5 \pm 2.8$)$. Rigidity and bradykinesia ameliorated, but not gait and postural instability.

\section{Disability score}

The mean (SD) total NUDS in all patients showed a statistically significant decreased disability score after CR (week 8), but not after STD-titration (week 4) compared with baseline scores (10.9 \pm 5.2 ). Scores and standard deviations decreased from $10.4 \pm 5.3$ at week 4 to $9.7 \pm 5.3$ at week 8 . In the STD-treated patients a statistically significant increase was found during the doubleblind phase, when total scores at week $8(9.9 \pm 4.7)$ were compared with those of week $32(10.9 \pm 5.7)$. In the CR-treated patients only small and not statistically significant changes in disability were established when week-8 scores $(9.3 \pm 5.3)$ were compared with the scores at week 32 (9.6 \pm 6.1$)$. Dressing and speech gave the best responses.

\section{Safety and tolerability}

There were no significant differences in laboratory values at both the start and the end of the study. No changes in ECG recordings were seen except for ischemic changes, in one STD patient, without clinical signs and/or symptoms. During the open-label phase adverse effects, not experienced earlier, were mentioned by 4 patients due to STD, and by 3 patients during the CR-titration phase, they consisted mainly of gastrointestinal complaints (5) and hyperkinesia (2). Drug-related adverse effects in the double-blind phase were also noted in both the STD-treated patients (2, one with dizziness and one with dyskinesia) and the CR-treated patients (gastrointestinal complaints (2) and hypotension (1)). 


\section{Dosage and dose frequency (Fig. 2)}

Mean (SD) total daily dosage of levodopa at baseline was $635 \pm 290 \mathrm{mg}$ in $5.3 \pm 2.5 \mathrm{mg}$ doses, at week 4 - after STD titration - $619 \pm 248 \mathrm{mg}$ in $5.7 \pm 2.5 \mathrm{mg}$ doses, and at week 8 - after CR titration - the mean daily intake was $822 \pm 344 \mathrm{mg}$ in $4.1 \pm 1.6 \mathrm{mg}$ doses. So, during the openlabel study, mean total daily levodopa intake in all patients showed a significant increase during the CR-titration period, as compared with baseline and week 4. Moreover, dose frequency declined significantly during this period. In the patients treated with STD during the double-blind period, mean daily levodopa intake (SD) and mean number of doses (SD) at week 8 were $847 \pm 325 \mathrm{mg}$ in $4.1 \pm 1.1 \mathrm{mg}$ doses, differing significantly from the figures at week $32: 663 \pm 276 \mathrm{mg}$ in $6.0 \pm$ $2.6 \mathrm{mg}$ doses. After the CR-titration period, daily dosage and doses did not show major changes during prolonged double-blind CR treatment over 24 weeks. Total levodopa intake was $797 \pm 363 \mathrm{mg}$ in $4.3 \pm 1.9 \mathrm{mg}$ doses at week 8 , and $802 \pm 345 \mathrm{mg}$ in $4.5 \pm 1.6 \mathrm{mg}$ doses at its end.

Figure 2. Mean daily levodopa dosage and dose frequency with SD in: 69 Parkinson patients at baseline-I (BL.)1,), week 4 (after optimal STD titration) and week 8 (after optimal CR titration); 34 patients. treated double-blind with STD, at baseline-2 (BL : week 8) and at week 32 (end of the study): 35 patients, treated double-blind with $C R$, at $\mathrm{BL}_{2}$ and at week 32. Significance: wk 8 vs. $\mathrm{BL}_{1}$ and wk 32 vs. $\mathrm{BL}_{2}$; ${ }^{*} \mathrm{P}<0.05,{ }^{* *} \mathrm{P}<0.01$ : wk 8 vs. wk $4:{ }^{(* *)} \mathrm{P}<0.01$.

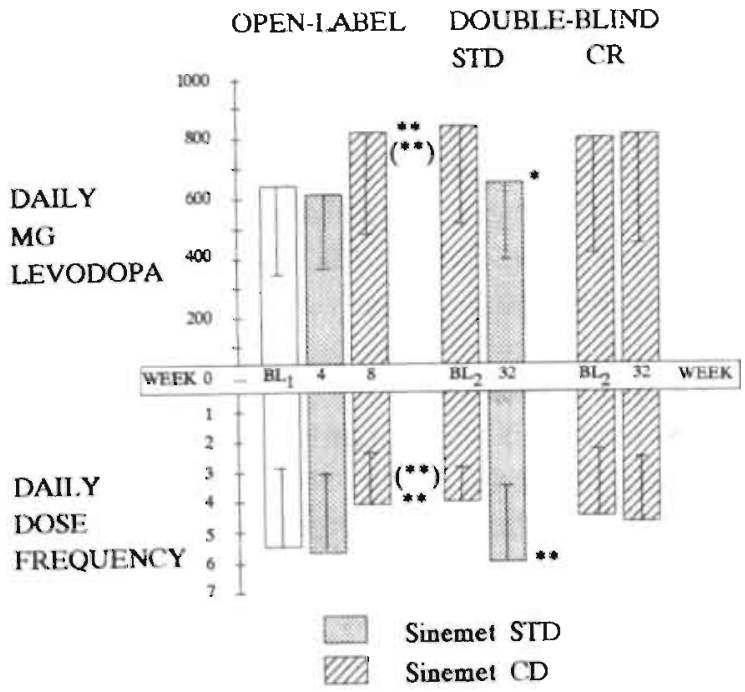

Patients' diaries (Fig. 3, Table 2) 
Figure 3. Mean total daily on and off hours and mean number of daily off periods with SD in: 69 Parkinson patients during baseline-I $\left(\mathrm{BL}_{1}\right)$, week 4 (STD titration period) and week 3 (CR titration period); 34 patients, treated double-blind with STD, during baseline-2 $\left(\mathrm{BL}_{2}\right.$ : week 8) and week 32 (end of the study): 35 patients treated double-blind with $\mathrm{CR}$, during $\mathrm{BL}_{2}$, and week 32 . Significance: wk 8 vs. $\mathrm{BL}_{1}$ and wk 32 vs. $\mathrm{BL}_{2}:{ }^{* *} \mathrm{P}$ $<0.01$ : wk 8 vs. wk 4 : ${ }^{(* *)} \mathrm{P}<0.01$.

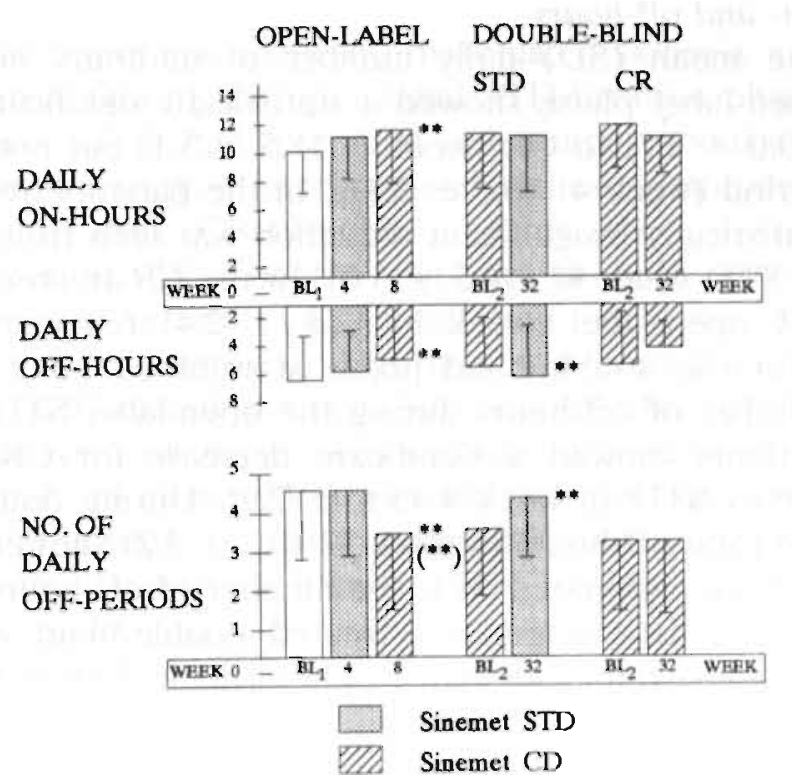

Table 2 Differences $(\Delta)$ of clinical efficacy scores (SD) during (left) open-label Sinemet-STD (STD, wk 1-4) and Sinemet CR (CR. wk 5-8) titration: $\Delta$ STD $=\Delta$ (BL1 - wk 4), $\Delta \mathrm{CR}=(\mathrm{BL1}$ - wk 8): and during (right) double-blind treatment with Sinemet-STD (STD. wk 8-32) or Sinemet CR (CR. wk 8-32): $\Delta$ STD $=\Delta$ (BL2 - wk 32), $\Delta \mathrm{CR}=\Delta(\mathrm{BL2}-$ wk 32).

Open-label

$\Delta$ STD $\Delta C R \quad \Delta S D$
$\Delta \cdot R^{i}$

\section{NYUPDS}

NUDS

Off-hours

Ofl-periods

$\begin{array}{lll}0.57 \pm 1.5^{* *} & 1.51 \pm 2.2^{* *} & * * \\ 0.46 \pm 1.5 & 1.33 \pm 2.3^{* *} & * * \\ 0.87 \pm 2.4 & 1.49 \pm 3.2^{* *} & * \\ 0.92 \pm 2.5 & 1.68 \pm 3.3^{* *} & * \\ 0.26 \pm 1.5 & 1.58 \pm 1.8^{* *} & * *\end{array}$

On-hours

${ }^{1}$ P-values indicating efficacy of Sinemet CR vi STD. Bold figures $=$ positive difference. NUDS = Nort-western University Disability Scale. NYUPIDS = New York University Parkinson's Disease Scale. ${ }^{*} \mathrm{P} \leq 0.05:{ }^{*} \mathrm{P} \leq 0.01$.
Double-blind

\begin{tabular}{|c|c|}
\hline$\triangle S^{\circ} D$ & $\triangle \mathrm{CR}$ \\
\hline
\end{tabular}

$\begin{array}{ll}0.83 \pm 2.0^{*} & 0.31 \pm 1.7 \\ 1.00 \pm 2.7^{*} & 0.31 \pm 2.7 \\ 0.70 \pm 2.4 & 0.84 \pm 2.9 \\ 1.20 \pm 2.3^{* *} & 0.59 \pm 3.2 \\ 1.10 \pm 1.2^{* *} & 0.07 \pm 1.4\end{array}$




\section{On- and off-hours}

The mean (SD) daily number of on-hours in all patients during the open-label phase showed a statistically significant increase from baseline $(10.0 \pm 2.7)$ to $\mathrm{CR}$ (week $8: 11.5 \pm 3.1)$ but not in the STD dose-finding period (week $4: 10.8 \pm 2.3$ )). In the patients treated further with STD, a statistically insignificant reduction was seen from CR week $8(11.3 \pm 3.3)$ to STD week $32(10.5 \pm 3.0)$. In the CR-treated patients, the scores with CR open-label (week 8: $11.8 \pm 2.4$ ) remained statistically unchanged after the double-blind phase at week $31(10.9 \pm 2.2)$. The mean daily number of off-hours during the open-label STD- and CR-titration in all patients showed a significant decrease for CR in week 8 (4.8 \pm 3.4$)$ versus STD in week $4(5.6 \pm 2.9)$. During double-blind STD-treatment, the total off-hours in week $32(6.2 \pm 3.2)$ showed a statistically significant increase compared with the number of off-hours with CR at week 8 (4.9 \pm 3.0 ). In the patients treated double-blind with $C R$, the number of off-hours remained statistically unchanged from $\mathrm{CR}$ week $8(4.7 \pm 3.1)$ to CR week $32(5.2 \pm 2.9)$.

\section{Off-periods}

A highly significant reduction in the daily number of off-periods was seen during open-label periods at week $8(3.3 \pm 1.8)$, compared with both baseline $(4.9 \pm 1.7)$ and week $4(4.6 \pm 1.8)$. In the STD-treated patients, a highly significant increase in off-periods was seen between week 8 ( 3.5 $\pm 1.6)$ and week $32(4.6 \pm 1.9)$. In the double-blind CR-treated patients, no change in the number of off-periods was seen at week $32(3.3 \pm 1.7)$ compared with week $8(3.3 \pm 1.8)$.

\section{Sleep pattern}

The total number of hours spent in bed at baseline was $7.6 \mathrm{~h}$ a day, and did not change significantly throughout the study, neither during STD nor during CR-treatment. At week 32 the STD-treated patients spent 7.2 $\mathrm{h}$ and the CR-treated patients $7.8 \mathrm{~h}$ in bed. Actual sleeping time, quality rating of sleep, and number of sleep interruptions did not change significantly either during the study.

\section{Delay in clinical response}

The mean delay (SD) in levodopa-induced clinical effect was significantly $(P<0.001)$ shorter after intake of Sinemet STD $(45.3 \pm 24.8 \mathrm{~min})$ than after Sinemet CR $(64.4 \pm 26.2 \mathrm{~min})$. 


\section{Patient overall evaluations}

Patient's perception of early-morning akinesia, dystonia, dyskinesia and pain was regularly registered. During the open-label STD-titration phase, perceptions showed no essential change compared to baseline. About one third of all patients indicated a marked improvement of these symptoms except for pain (13\%) - after CR-titration. After the 24-week double-blind treatment period, $33 \%$ of the patients in both groups treated with Sinemet-STD or Sinemet CR found their early morning akinesia and dyskinesia to be improved. Dystonia was found to be improved in $33 \%$ of the CR-treated patients but only in $18 \%$ of the STD-treated patients. Improvement of pain was mentioned by $15 \%$ of all patients during the double-blind phase. Most patients did not experience any improvement or deterioration of these symptoms, but some felt worse. Some STD-treated patients found their dystonia-related complaints increased during the study period after stopping their CR medication at week 8 .

\section{Physicians' and patients' overall evaluations}

An appreciable number $(80 \%)$ of 'blinded' physicians as well as participating patients (64\%), when asked for their opinion on the actual medication (STD or CR) during the double-blind phase, indicated the right drug.

\section{Discussion}

The increased clinical efficacy established according to NYUPDS and NUDS in the Sinemet CR-treated patients suggests the existence of increased intracerebral dopamine levels in the Sinemet CR patient group. However, this conclusion is contradictory to the calculated bioavailability of levodopa in both groups. Although a 33\% higher dosage of levodopa was administered with Sinemet CR than with Sinemet-STD, this higher levodopa-CR dosage required for control of parkinsonian symptoms may be attributed to its lower bioavailability $(71 \%) .{ }^{16}$ Incomplete absorption (incomplete disintegration of the polymer matrix) as well as increased first-pass decarboxylation due to slow drug release may be responsible for this decreased bioavailability. ${ }^{16}$ The major difference between the 2 dosage forms (STD and CR) appears to be that in Sinemet CR plasma concentrations fluctuate within narrower ranges as a result of a lower plasma peak and a higher end-of-dose level. ${ }^{5.16}$ The CR formula thus 
ensures a more economic way of treatment by avoiding off-periods induced by insufficient end-of-dose levels.

The improvement of efficacy was not obtained at the expense of an increase in drug-related side-effects, not experienced earlier, in the participating patients: side-effects were seen in a comparable degree in both Sinemet-STD and Sinemet CR-treated patients, and consisted mainly of gastrointestinal complaints. However. 3 patients dropped out because of intolerable drug-related side-effects caused by Sinemet CR (2 due to gastrointestinal complaints, 1 to persistent dyskinesia).

As could be expected, the number of doses per day in the Sinemet CR-treated patients decreased significantly by $28 \%$ from 5.7 to 4.1 after the 4 week open Sinemet CR-titration period and remained more or less at that level during the 24-week double-blind Sinemet CR treatment. So, CR therapy not only stabilizes plasma levodopa levels as discussed above, but also results in prolonged levodopa activity, which is more practical and convenient for the patient. This prolonged levodopa effect after Sinemet CR titration (4.1 doses at week 8) was lost during subsequent double-blind treatment with levodopa-STD, which resulted in 6.0 daily doses. The initial increase in number of daily doses during Sinemet CR and the following increase after switching to Sinemet STD moreover, shows that the difference in number of doses between Sinemet CR and Sinemet-STD is due to different levodopa formulas and not to disease factors.

The prolonged and stabilizing effects of Sinemet CR are only partially supported by the on- and off-hour scores. The total number of on-hours increased during the open-label, but not during the double-blind phase, while the number of off-hours and off-periods decreased in both phases. However, dystonia showed improvement in $\mathrm{CR}_{-}$, more than in STD-treated patients (levodopa-induced dystonia mostly occurs as end-of-dose phenomenon, its decrease should conform to an increase in on-hours). Finally, the clinical (NYUPDS and NUDS) improvement remained dependent on the type of levodopa formula administered during the entire follow-up period (see above). These facts, together with the knowledge that the number of on- and off-hours are associated with a mutually exclusive outcome of the score, would of course predict a corresponding increase in on-hours throughout the evaluation period. An explanation might be found in the fact that the CR-treated patients spent more time in bed $(7.8 \mathrm{~h}$ versus $7.2 \mathrm{~h}$ in the STD-treated group of patients).

Patients clearly noticed a delayed response (mean: $64.4 \mathrm{~min}$ ) to Sinemet $\mathrm{CR}$ as compared with Sinemet-STD (mean: $45.3 \mathrm{~min}$ ). In our experience 
patients who broke their CR tablets in half for the first morning-dose seemed to suffer less from this problem. This may be accounted for by the increase of the absorption area and the consequent faster dissolution and absorption, inducing an earlier rise to peak plasma levodopa levels. ${ }^{15}$ The delayed response was the main reason why patients and doctors quite easily guessed the correct nature of the drug during the double-blind period. Accordingly, in $80 \%$ of the doctors and $64 \%$ of the patients this study actually could not be called 'blind'! As mentioned in the introduction, open studies showed better clinical efficacy of Sinemet CR than did double-blind studies. Our findings led to the conclusion that this discrepancy is not due to the factor 'open', because nearly all of the patients could guess the code by the established delayed efficacy of a dose of Sinemet CR.

Although individual patients unequivocally recognized Sinernet CR by an increase of dyskinesia, the experience of dyskinesias was no reliable indication for the nature of the drug: in all 3 groups, namely open-label CR, double-blind CR, and double-blind STD, roughly one third of the patients experienced an increase while another third experienced a decrease in the severity of dyskinesias. As patients stated, the number of off-periods diminished during treatment with Sinemet CR. In our opinion, increase in dyskinesia during CR-treatment was noted in the more seriously affected patients, probably due to their narrow therapeutic window. Apparently, the emergence of dyskinesia depends on circumstantial and disease factors rather than on the levodopa formula. This is consistent with the findings of previous studies. ${ }^{5.8}$

This study confirmed that most efficacy variables demonstrated the effect of Sinemet CR to be superior to that of Sinemet STD (see also Table 2). It seems justified to suggest that these improved effects were not achieved at the expense of an actual increase in total daily bioavailable levodopa, nor at the expense of safety and/or tolerability. The superior effect of Sinemet CR as compared with that of Sinemet-STD was established, not only in the open-label 4-week titration period but also in the double-blind 24-week treatment period.

\section{Acknowledgements}

Statistics were performed by Evert Wattel, Amsterdam Free University. The authors are grateful for the assistance rendered by MSD, The Netherlands, especially Mrs. Carolien Doornebos, MD, and Mrs. Marleen Tesselaar, MD. 


\section{References}

1. Fahn S. On-off phenomenon with levodopa therapy in parkinsonism. Neurology 1974;24:431-441.

2. Marsden CD, Parkes JD. Success and problems of long-term levodopa therapy in Parkinson's disease. Lancet 1977;1:345-349.

3. Quinn N, Parkes JD, Marsden CD. Control of on/off phenomenon by continuous intravenous infusion of levodopa. Neurology 1984;34:1131-1136.

4. Hardie RJ, Lees AJ, Stern GM. On-off fluctuations in Parkinson's disease. A clinical and neuropharmacological study. Brain 1984;107:487-506.

5. Goetz CG, Tanner CM, Klawans HL, et al. Parkinson's disease and motor fluctuations: long acting carbidopa/levodopa (CR4-Sinemet). Neurology 1987;37:875-878.

6. Sage JL, Mark MH. Comparison of controlled-release Sinemet (CR4) and standard Sinemet (25/100) in advanced Parkinson's disease: a double-blind crossover study. Clin Neuropharmacol 1988;11:174-179.

7. Pfeiffer RF, Wilken KE, Glaeske C. Sinemet CR4 in Parkinson's disease. Neurology 1988;38 (S1):419.

8. Rondot P, Ziegler M, Aymard N, Teinturier A. Effect of controlled-release carbidopa/levodopa on motor performance in advanced Parkinson's disease. Neurology 1989;39(S2):74-77.

9. Friedman JH. An open trial of continuous release carbidopa/L-dopa (Sinemet CR) for the treatment of mild to moderate Parkinson's disease. Neurology 1988:38(S 1):180.

10. Deleu D, Jacques M, Michotte Y, Ebinger G. Controlled-release carbidopa/levodopa (CR) in parkinsonian patients with response fluctuations on standard levodopa treatment: clinical and pharmacokinetic observations. Neurology 1989;39(S2):88-92.

11. Bush DF, Liss CL, Morton A, and the Sinemet CR Multicenter Study Group. An open multicenter long-term treatment evaluation of Sinemet CR. Neurology 1989:39(S2):101-104.

12. Feldman RG, Mosbach PA, Kelly MR, Thomas CA, Saint Hilaire MH. Double-blind comparison of standard Sinemet and Sinemet $C R$ in patients with mild-to-moderate Parkinson's disease. Neurology 1989;39(S2):96-101.

13. Hutton JT, Morris JL, Gustave CR, et al. Treatment of chronic Parkinson's disease with controlled release carbidopa/levodopa. Neurology 1988;45:861-864.

14. Goetz CG, Tanner CM, Shannon KM, et al. Controlled-release carbidopa/levodopa (CR4-Sinemet) in Parkinson's disease patients with and without motor fluctuations. Neurology 1988;38:1143-1146.

15. Hutton JT, Morris JL, Bush DF, Smith ME, Liss CL, Reines S. Multicenter controlled study of Sinemet CR vs Sinemet $(25 / 100)$ in advanced Parkinson's disease. Neurology 1989;39(S2):67-72.

16. Yeh. KC, August TF, Bush DF, et al. Pharmacokinetics and bioavailability of Sinemet CR: a summary of human studies. Neurology 1989;39(S2):25-38. 


\section{CHAPTER 7}

\section{Parlodel SRO in Parkinson's disease: A double-blind randomized comparison of Parlodel standard and Parlodel SRO. ${ }^{5}$}

${ }^{5}$ ENH Jansen, A Staal-Schreinemacher, JJ van der Sande, JA Haas, JPWF Lakke. Eur Neurol 1992;32:318-320. 


\section{Introduction}

The role of dopamine agonists in the treatment of Parkinson's disease (PD) is well established ${ }^{1}$ and bromocriptine is widely used since the lirst study on bromocriptine was published by Calne et al. ${ }^{2}$ in 1974 . 'To postpone and reduce long-term adverse effects of levodopa therapy, it has become common practice to administer dopamine agonists in early stiges of PD. ${ }^{3}$ Even its efficacy in de novo patients in combination therapy with levodopa has been advocated recently. ${ }^{4}$

One of the major drawbacks of therapy with dopamine agonists is the initial intolerance, contributing to a certain percentage of withdrawal. The most frequent adverse effects are nausea, vomiting and orthostatic hypotension, not always ameliorated by adjuvant therapy with domperidone. ${ }^{5}$ These side effects might, at least in part, be due to high and rapid peak concentrations after oral administration or due to fluctuations of bromocriptine plasma levels.

Parlodel SRO (slow release oral), a slow release form of bromocriptine, has been developed in order to overcome these initial difficulties with dopamine agonist tolerance. Parlodel SRO has a relative bioavailability of $80 \%$ of the Parlodel standard (STD), but $\mathrm{C}_{\max }$ plasma levels of Parlodel SRO are $50 \%$ lower, and $\mathrm{T}_{\max }$ values are increased from $30 \mathrm{~min}$ (for Parlodel STD) to 7-8 h for Parlodel SRO. The half value duration time for Parlodel STD is $3.5 \mathrm{~h}$, and that of Parlodel SRO is $14.5 \mathrm{~h}$. Pharmacodynamic studies indicate significantly longer lasting inhibitory effects on prolactin plasma levels [Sandoz, Basle, unpubl. data].

We carried out a randomized double-blind trial to compare the tolerance and efficacy of Parlodel SRO versus Parlodel STD.

\section{Patients and Methods}

In the present study, a randomized double-blind, double-dummy design was used to compare the tolerance and efficacy of Parlodel SRO and Parlodel STD.

Thirty-four patients with idiopathic PD, who were treated with levodopa from 4 to 24 months and received a stable optimized levodopa dosage for at least 2 months prior to this study, gave informed consent. The study population consisted of 17 men and 17 women, with a mean age 64.2 years (SD 11.3). The mean Hoehn and Yahr stage was 2.72 (SD 0.63), the mean duration of PD was 4.8 years (SD 3.7 ) and the mean daily dose of levodopa $394 \mathrm{mg}$ (SD 216.8). The introduction of dopamine agonist 
therapy was considered justified as a method to improve the efficacy of anti-PD therapy without increasing the levodopa dosage. None had received a therapy with dopamine agonists previously. Excluded were patients with a levodopa dosage exceeding $1,000 \mathrm{mg}$ per day, i.e. Sinemet $1,100 \mathrm{mg}$ : levodopa $1,000 \mathrm{mg}+100 \mathrm{mg}$ carbidopa. Also excluded were PD patients with severe adverse effects to 'long-term' levodopa therapy (on-off phenomena and end-of-dose deterioration).

The patients were randomly allocated to two treatment groups: levodopa and Parlodel STD or levodopa and Parlodel SRO. The study had two phases. In the first phase, all patients were, if tolerated, titrated via a fixed dosage regimen up to $15 \mathrm{mg}$ daily of Parlodel in 6 weeks. In the second phase, the test medication of either Parlodel SRO or Parlodel STD remained constant over a period of 8 weeks. Levodopa dosage and all other anti-PD medication remained unchanged throughout both study periods. Patients were examined at 2-week intervals in the first study phase, and thereafter at 4-week intervals.

Efficacy was assessed using the Unified Parkinsonism Rating Scale (UPRS), the Hoehn and Yahr scale, and the Schwab and England Activities of Daily Living Scale. ${ }^{8}$

Global efficacy ratings and global tolerance ratings were performed at the end of both study phases, i.e. an interim overall assessment at the end of week 6 and a final overall assessment at the end of week 14. These rating scales of different items were assessed by an investigator and by patients and established a global rating of the item on a 5-point scale ranging from very poor to very good (for tolerance) and from none to very good (for efficacy). These scales were studied for statistical analysis by the Mann-Whitney and the $\chi^{2}$ test. Safety and tolerance were evaluated by clinical assessment of signs and adverse events reporting. For statistical analysis, the differences between the scores of baseline, 6- and 14-weeks assessments of Parlodel SRO and Parlodel STD treatment groups were calculated.

\section{Results}

The two groups of 17 patients each were well balanced at baseline with respect to patient characteristics and disease severity, and there were no significant differences between them. Also, the daily dose of levodopa was the same in the two treatment groups.

Thirty of the 34 patients, who entered the study completed the 14-week treatment period. 
In 4 patients, adverse events necessitated discontinuation of the trial medication. In the Parlodel STD group, 3 patients stopped Parlodel in the first phase of the study, i.e. within the 6 weeks of the dosage titration phase, because of palpitations, nausea and confusion. In the Parlodel SRO group, one patient stopped Parlodel medication because of muscle cramps. No other reasons for discontinuation were encountered.

In the 16 patients of the Parlodel SRO group completing the 14-week trial period, the mean dose of Parlodel SRO was $11.7 \mathrm{mg}$; in the other group, 14 patients ended the trial period with a mean dosage of $8.9 \mathrm{mg}$ Parlodel STD.

The magnitude of improvement from baseline in all major items of the UPRS was comparable in both groups, and there was no statistical difference between both study groups in all the tests of the UPRS (fig. 1). The UPRS items on dyskinesias after supplementing levodopa therapy with a maximum dosage of $15 \mathrm{mg}$ of Parlodel showed no appearance of or improvement in dyskinesias.

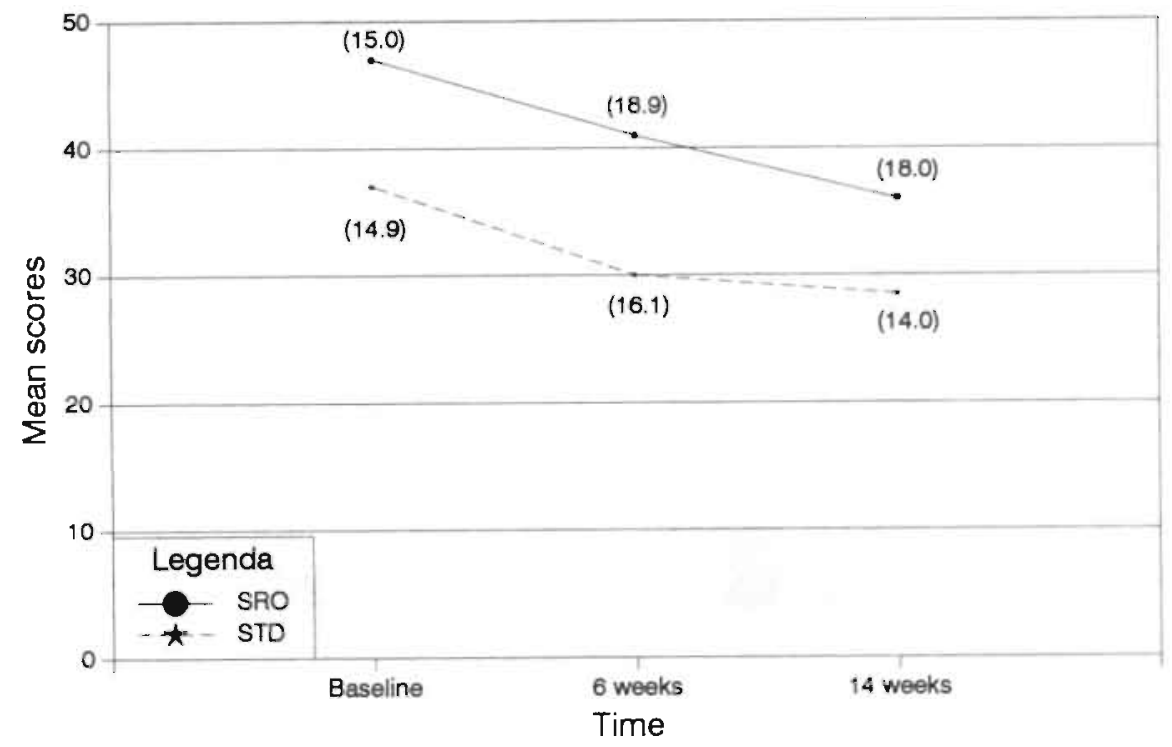

Figure 1. Mean total scores, items 1-43 summed scores of UPRS in the Parlodel STD $(---)$ and Parlodel SRO (-) groups. Standurd deviations are given in parentheses.

The Hoehn and Yahr and the Schwab and England assessment data slightly suggested a tendency in favour of the SRO group. The patients mean global ratings of efficacy had a slight trend in favour of Parlodel SRO, but this reached no statistical significance (fig. 2). 

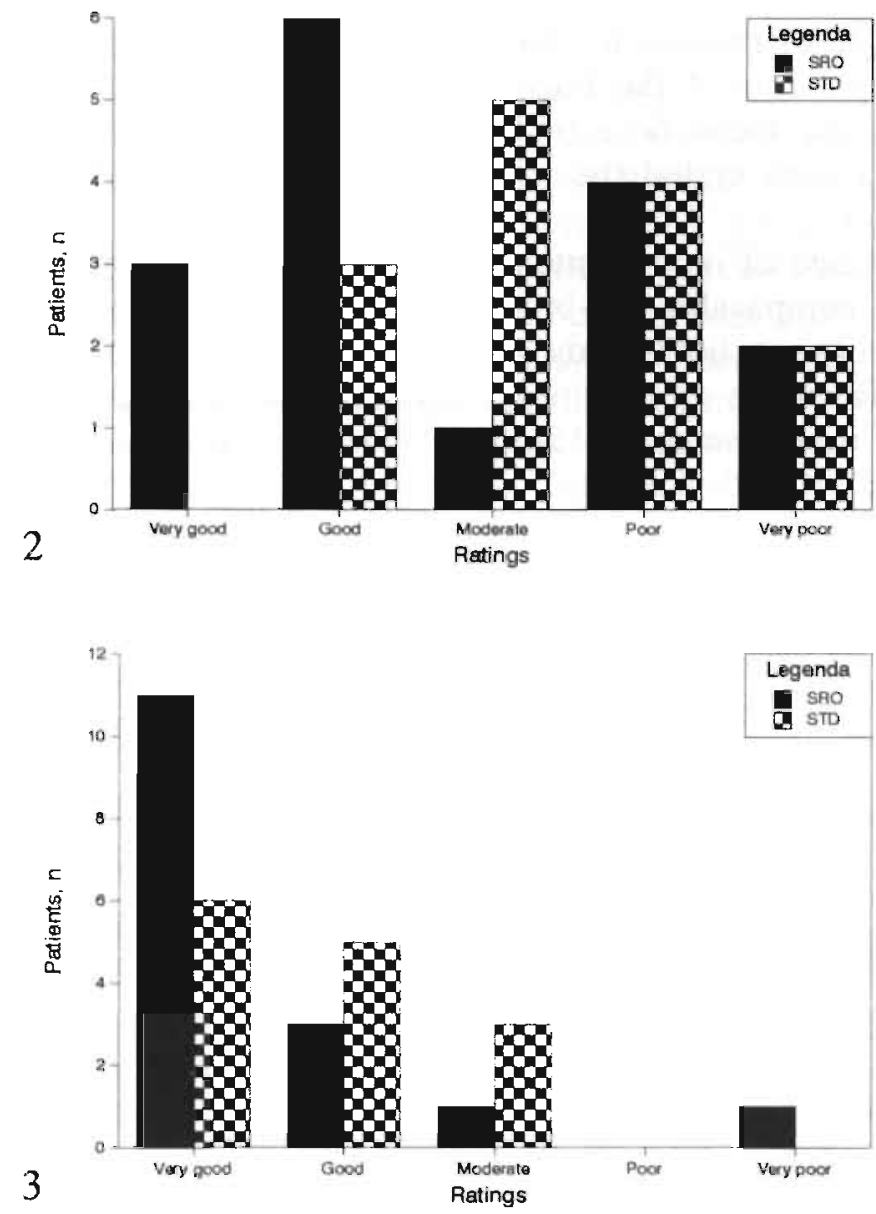

Figure 2. Global efficacy ratings (14-week assessment) by patients of Parlodel STD ( $)$ and Parlodel SRO ( ) .4 drop-outs were excluded.

Figure 3. (ilobal tolerance ratings (14-week assessment) by patients of Parlodel STD ( ) and Parlodel SRO ( ). 4 drop-outs were excluded. 
Side effects, recorded as definitely due to study medication, occurring in both groups were mainly: nausea, stomach pain, confusion, hallucinations and orthostatic hypotension. No specific side effects were occurring less frequently in the Parlodel SRO group. Statistical evaluation, however, of all comparisons by means of the Mann-Whitney test showed an overall reduction in the incidence of side effects in the Parlodel SRO group. The global tolerance ratings performed at the end of both treatment periods (6 and 14 weeks) were the other basis for assessing severity and frequency of side effects and are shown in figure 3 . The difference in the two treatment groups was not statistically significant at the 0.05 level, but the trend was in favour of the Parlodel SRO group. This trend was already reached at the 6 -week assessment of global tolerance rating and stabilized at the final 14-week assessment.

Considering efficacy and tolerance together, Parlodel SRO appeared to be significantly superior to Parlodel STD in the patient assessment $\left(\chi^{2}\right.$ : $6.58, p<0.02)$, whereas there was no significant difference in the investigator assessment.

\section{Discussion}

Our results indicate that the new galenic formulation of Parlodel, i.e. Parlodel SRO, reduces initial adverse events. This is in accordance with the peripheral pharmacokinetic profile of Parlodel SRO, by which high peak plasma concentrations after oral administration of this dopamine agonist are prevented.

The efficacy of Parlodel SRO and Parlodel STD was the same. Especially the results of the UPRS analysis showed complete comparable results, even though the relative bioavailability of Parlodel SRO is somewhat less. The patient assessment of overall efficacy and tolerance analyzed together - was significantly better in the Parlodel SRO group.

Taken together, these figures of efficacy and tolerance suggest that with Parlodel SRO more PD patients derive benefit from a drug that they are able to tolerate in an optimal dosage. One of the major drawbacks of dopamine agonist therapy can hence be reduced. As a conseguence of these results, another advantage of Parlodel SRO could be the more rapid titration to an effective dosage. In addition, the frequency of drug administration of Parlodel SRO may possibly be reduced on the basis of its pharmacokinetic profile permitting improvement in patient compliance, the willingness to continue (supplemented) therapy and at the same time a more stable clinical response. 
These improvements in the use of bromocriptine for the treatment of PD are currently being evaluated.

\section{References}

1. Poewe WH, Lees AJ, Stern GM. Low dose L-dopa therapy in Parkinson's disease: A six-year follow-up study. Neurology 1986;36:1528-1530.

2. Calne DB, Teychenne PF, Leigh PN, et al. Treatment of parkinsonism with bromocriptine. Lancet 1974;ii:1355-1358.

3. Rinne UK. Combined bromocriptine-levodopa therapy early in Parkinson's disease. Neurology 1985;35:1196-1198.

4. Rinne UK. Early combination of bromocriptine and levodopa in the treatment of Parkinson's disease: 15 -year follow-up. Neurology 1987;37:826-828.

5. Staal-Schreinemacher AL, Wesseling H, Kamphuis DJ, van den Burg W, Lakke JPWF. Low-dose bromocriptine in Parkinson's disease: double-blind-placebocontrolled study. Neurology 1986;36:291-293.

6. Fahn S. Elton RL, et al. The Unified Parkinson's Disease Rating Scale, in: Fahn S, Marscien CD, Calne DB, Goldstein M (eds): Recent Developments in Parkinson's Disease. New Jersey, Macmillan Healthcare Information, 1987, vol 2, pp 153-164.

7. Hoehn MM, Yahr MD. Parkinsonism: Onset, progression and mortality. Neurology 1967; 17:427-442.

8. England AC, Schwab RS. Postoperative evaluation of 26 selected patients with Parkinson's disease. J Am Geriatr Soc 1956;4::1219-1232. 


\section{CHAPTER 8}

A. "Old wine in new bottles"; therapy with subcutaneous apomorphine in Parkinson's disease.

B. Pharmacokinetics of apomorphine in Parkinson's disease. Plasma and cerebrospinal fluid levels in relation with motor responses. 
02 


\section{A. "Old wine in new bottles"; therapy with subcutaneous apomorphine in Parkinson's disease. ${ }^{6}$}

The medical treatment of the symptoms of Parkinson's disease has the last decennia been based on levodopa-substitution. Pharmacologically this disease can be characterized as a syndrome that arises as a consequence of dopamine-deficiency in the nigrostriatal system. The orally administered levodopa is, after resorption into the gastro-intestinal tract and after passage through the Blood Brain Barrier (BBB) transformed in the nigrostriatal neurones into the effective dopamine.

Mostly the oral levodopa is combined with a peripheral DDI which does not pass the BBB. There are indications that this combination may contribute to the late side-effects of the usually successful therapy. ${ }^{1}$ Levodopa is of late years preferably in an early phase combined with dopamine-agonists like bromocriptine and pergolide, in order to prevent complications of the levodopa therapy at long-term. These complications exist above all from dyskinesia and alternating episodes of hypokinesia and hyperkinesia, so-called response fluctuations.

Recently a method has been introduced in which dopamine-agonists are administered subcutaneously. The time-honoured and antique apomorphine appeared to be effective herein. The beneficial effects can be obtained by repeated subcutaneous injections (for example using an injection device as used with insulin therapy of diabetes mellitus) or by a continuous subcutaneous pump. Both these therapy forms are discussed in the light of case histories.

Patient A, a 56-years-old woman, has had Parkinson's disease for 10 years and has been treated with levodopa for 8 years. On account of a slow progression of the hypokinesia and a disturbed postural stability a dopamine-agonist was added to levodopa 2 years ago. As well bromocriptine as pergolide, in low dosage of respectively 15 and $1.8 \mathrm{mg}$ a day, caused the patient complaints of orthostatic dizziness and visual hallucinations. The present treatment consists of 6 tablets of levodopa with decarboxylase inhibitor, distributed over the day, with a total daily

${ }^{6}$ E.N.H. Jansen en T. van Laar. "Oude wijn in nieuwe zakken"; therapie met subcutane apomorfine bij de ziekte van Parkinson. Ned Tijdschr Geneeskd 1990;143(18):889-891. 
dosage of $350 \mathrm{mg}$. With this medication there still were a lot of problems, especially in the afternoon: increase of tardiness of movement, tremor and unsteadiness in walking, and above all starting-problems. These are so-called 'off'-phenomena, which indicate 'wearing-off' of levodopa. Besides there were dystonic phenomena at the right foot in the course of the afternoon, with cramps in the right calf, the so-called 'off-period'dystonia. These off-phenomena in the afternoon, which often appeared at irregular times and which could well last for half an hour per episode, appeared to respond excellently at subcutaneous injections with apomorphine. The injections were administered with the help of a subcutaneous injection device, such as used in insulin therapy of patients with diabetes mellitus.

Nowadays the patient's husband, formerly a textile-worker, administers the injections. The dosage of apomorphine is $2 \mathrm{mg}$ a time, solved in 0.2 $\mathrm{ml}$; the point of time of administration depends on the appearance of the off-phenomena. On an average this patient makes use of these injections twice in the afternoon or in early evening hours. The apomorphine becomes effective after about 10 minutes; the patient always feels this coming by indomitable yawning. The duration of efficacy is about 90 minutes. There are not any side-effects; at first domperidon was prescribed against nausea, but later on this did not seem to be necessary any more. The dosage of levodopa is unaltered. Patient has now been treated with apomorphine very successfully in this way for almost one year and a half and she is very satisficd with the beneficial injections. In this way apomorphine injections mean to her preservation of independence in daily life.

Patient B, a 74-years-old man, has had Parkinson's disease for 20 years now. At first only a tremor was troubling him, which was formerly diagnosed as an essential tremor, an affection that occurs in his family as appears from the anamnesis. Later on more phenomena appeared, namely a tremor combined with rigidity and starting problems. Moreover, he could no longer turn around in bed very well any more. He had been treated with $125 \mathrm{mg}$ levodopa (with decarboxylase inhibitor) 8 times a day for 6 years. The last 2 years there had been severe fluctuations in mobility: after each administration of $125 \mathrm{mg}$ levodopa a beneficial effect was no longer than one hour perceptible. Besides a striking quantity of abnormal involuntary movements was provoked rather soon after the onset of efficacy of this dosage - especially dyskinesia in the face - which usually lasted until the levodopa had become ineffective again. Such dyskinesia are called peak-dose dyskinesia, because of the presumed 
connection with the peak-level of plasma levodopa. Decrease of the dose of levodopa to $90 \mathrm{mg}$ per gift led to decrease of peak-dose dyskinesia, but at the same time reduced the duration of efficacy to half an hour and also provoked painful cramps in the calves in the next 'off-period'.

Test treatment with Madopar HBS, a compound with slow release, failed: there was an intolerable increase in intensity of the dyskinesia.

For 12 months this patient is treated with a subcutaneous pump for infusion of apomorphine in a dosage of $3 \mathrm{mg}$ per hour. The total daily dose is $25 \mathrm{mg}$. Infusion takes place from 9 a.m. to 11 p.m. The subcutaneous needle is applied by the patient's wife, a former psychiatric nurse. She had some difficulty to come to see that administration of apomorphine to her husband would not constantly provoke nausea and vomiting, as she was used to in psychiatry.

Dyskinesia have not occurred any more and the total number of 'offhours' per day has been reduced from 4 to 2 hours, with a constant dose of levodopa. During the first three weeks there was a painful itching panniculitis at the place of insertion of the subcutaneous needle for infusion, which has to be changed every 24 hours. Nausea could be effectively fought by domperidon; later on this remedy did not necessarily have to be taken any more.

Patient C, a 27-years-old man, schoolmaster of profession and a fanatic wooden-ball-shooter (in Twente called 'klootschieter') - a popular sport in the Eastern part of Holland - has suffered from Parkinson's disease for 7 years. This malady started with a tremor at his right hand and arm, and increased during the following years with severe hypokinetic-rigid phenomena at his right arm and leg. For 5 years this patient has shown an excellent beneficial response to levodopa-treatment. A beforehand discussed stereotactical - surgical procedure was unnecessary, because tremor responded so favourably to levodopa-therapy. Former amantadine primidon and propanolol had proved to be ineffective. However, after one year of levodopa therapy severe dyskinesia developed likewise in right arm and right leg, which occurred at low dosage levels: each tablet of Sinemet $62.5 \mathrm{mg}$ (50 mg levodopa and $12.5 \mathrm{mg}$ carbidopa) brought about severe dyskinesia. These generally occurred from half an hour after onset of efficacy of Sinemet until the end of efficacy. So also with this patient we can speak of peak-dose dyskinesia. The total daily dose was $562.50 \mathrm{mg}$, distributed over 9 dosages. Test-treatment with dopamineagonist pergolide (Permax) was totally ineffective on duration of response or adverse events of levodopa.

Subsequently, patient was treated with apomorphine with the use of a 
subcutaneous infusion pump. The infusion daily takes place from 7.30 a.m. to 11.30 p.m. with a constant speed of $2.5 \mathrm{mg}$ per hour. The dosage of Sinemet could subsequently be reduced to 7 times $62.5 \mathrm{mg}$ a day. The initial severe response-fluctuations with peak-dose dyskinesia provoked by levodopa therapy could thus be ameliorated by apomorphine much to the satisfaction of patient and his wife. Almost all day he was able to function unhindered. Objectively speaking, there are still some generalized involuntary choreo-athetotic movements, but these are not found to be inconvenient for the patient. His fellow wooden-ball-shooters have told him more than once that he is looking so much more cheerful and vivacious and that he takes the track in much shorter time. These involuntary movements will undoubtedly have contributed to these effects.

At the moment patient has been treated with the apomorphine pump for 1 year without side-effects.

Ladies and gentlemen, diagnosis and medical treatment of Parkinson's disease have always been matters for which special skills are necessary. The beneficial response of levodopa therapy, which can be brought about in $70 \%$ of patients with Parkinson disease makes this therapy look simple. This completely changed when it was made clear that levodopa therapy after some years is complicated by severe adverse events such as dyskinesia and response fluctuations. ${ }^{2}$ There are some strong arguments that these phenomena - at least partly - are a consequence of its own: by the short half-life of levodopa after oral administration response fluctuations and dyskinesia can be induced - considered purely pharmacokinetically. ${ }^{3,4}$ A continuous intravenous administration of levodopa has a beneficial effect on these phenomena ${ }^{5}$ and thus confirms the above mentioned pharmacokinetic mechanism. In clinical practice this intravenous administration is, however, difficult to realize. Consequently there came an interest in subcutaneous continuous application of the dopamine-agonists lisuride and apomorphine. ${ }^{6.7}$ In a technically relatively simple way the problems raised by long-term levodopa therapy can be attacked. Because the ratio between magnitude of response and adverseevents of apomorphine is considerably higher than that of lisuride, apomorphine is preferable. ${ }^{8}$

Psychiatric side-effects only seldom occur, above all in the absence of previous psychiatric history. ${ }^{7.9}$ The infrequently appearing nausea is effectively fought or prevented by domperidon. With continuous infusion of apomorphine the provocation of nausea or the stimulation of the area postrema seems to be not very substantial, at least in comparison to the 
nausea after oral application. In former days apomorphine was used as an emetic. Long-term oral administration of apomorphine can cause renal dysfunction. ${ }^{9,10}$ This side-effect is not found after subcutaneous application of apomorphine. At the simultaneous use of an oral compound against nausea such as domperidon a relatively safe combinedtreatment has been made possible.

A major problem with the subcutaneous infusion of apomorphine, however, is the panniculitis. From the fact that subcutaneous infusion with insulin is not complicated by panniculitis, can be concluded that not the infusion-needle itself, but apomorphine is responsible for this subcutaneous inflammation. Therefore, it is advisable to maximize the concentration of apomorphine in the infusion liquid to $2 \%$ (20 mg apomorphine per $\mathrm{ml}$ ). This is in accordance with the experience of others. ${ }^{6,7}$

Of the 14 patients with Parkinson's disease, thus treated with apomorphine, 2 had to be withdrawn from therapy as a consequence of this panniculitis. Treatment with apomorphine injection-pen is not complicated by this panniculitis.

Finally, we are obliged to mention the psychic stress associated with the treatment of a subcutaneous infusion pump: by the infusion the patient is, as it were, transformed into a puppet on a string. For some patients this literal lack of freedom was unacceptable or even indisputable.

The apomorphine already known for so many decades as an emetic ${ }^{11}$, can now play an essential and pivotal role as a dopamine-agonist in cases of therapy-refractory response-fluctuations in Parkinson's disease.

We are very grateful to professor Jan van Gijn, neurologist at State University of Utrecht, for this critical and so very kind comments.

\section{References}

1. Jong JG de, Meerwaldt JD, Schmitz PIM. Factors that influence the occurrence of respons variations in Parkinson's disease. Ann Neurol 1987;22:4-7.

2. Mouradian MM, Juncos JL, Fabbrini G, Chase TN. Motor fluctuations in Parkinson's disease. Ann Neurol 1988:24:372-378.

3. Kempster PA, Frankel JP, Lees AJ, Stern GM. Levodopa peripheral pharmacokinetics and duration of motor response. J Ncurol Neurosurg Psychiatry 1989;52:718-723.

4. Nutt JG, Woodward WR, Carter JH. Clinical and hiochemical studies with controlled-release levodopa/carbidopa. Neurology 1986;36:1206-1211.

5. Quinn N, Parkes JD, Marsden CD. Control of on/off phenomenon by contir:!n!ls intravenous infusion of levodopa. Neurology 1984;34:1131-1136. 
6. Stibe $\mathrm{CMH}$, Lees AJ, Kempster PA, Stern GM. Subcutaneous apomorphine in parkinsonian on-off oscillations. Lancet 1988;i:403-406.

7. Poewe W, Kleedorfer B, Wagner M, Benke T, Gasser T, Oertel W. Side effects of subcutaneous apomorphine in Parkinson's disease. Lancet 1989;i:1084-1085.

8. Hardie RJ, Lees AJ, Stern GM. On-off fluctuations in Parkinson's disease. Brain 1984;107:487-507.

9. Ruggieri S, Stocchi F, Carta A, Agnoli A. Side effects of subcutaneous apomorphine in Parkinson's disease. Lancet 1989;i:566.

10. Cotzias GC, Papavasiliou PS, Tolosa ES, et al. Treatment of Parkinson's disease with apomorphines. N Engl J Med 1976;294:567-572.

11. Nimmo WS. Apomorfine in acute poisoning. Br J Hosp Med 1985;34:176-179. 


\section{B. Pharmacokinetics of Apomorphine in Parkinson's Disease. Plasma and Cerebrospinal Fluid Levels in Relation with Motor Responses. ${ }^{7}$}

\section{Introduction}

Apomorphine is a potent dopamine agonist which is used as diagnostic tool and therapeutic drug in patients with Parkinson's Disease (PD). Therapeutically apomorphine has proved to be an effective drug in the management of motor fluctuations in PD. ${ }^{1,2,3}$ Apomorphine is used diagnostically in response tests to distinguish dopa responsive from nonresponsive patients and consequently to distinguish Idiopathic Parkinson's Disease (IPD) from Parkinsonian Plus Syndromes (PPS). ${ }^{4,5}$

In clinical practice apomorphine is given subcutaneously, sublingual or intranasal. ${ }^{2.6}$ Since apomorphine is quickly metabolized by the liver, oral administration is not sensible. Subcutaneously administered apomorphine is avoid of this high first-pass effect and has a short latency of onset (about 10 minutes) and a medium time of duration (about 90 minutes) in dopa-responsive PD patients. These features make apomorphine an extremely promising therapeutic modality as a patient-dosed drug for offperiods and severe response fluctuations in PD.

There have been several studies in which the peripheral pharmacokinetics of apomorphine have been investigated, by means of blood samples. ${ }^{1,2}$ However the central pharmacokinetics of apomorphine, up to now, are unknown. Only in a study with monkeys the central pharmacokinetics have been investigated by taking cerebral spinal fluid (CSF) samples.?

Because the plasma levels of apomorphine in humans do not correlate with the motor effects, we wanted to investigate the central pharmacokinetics of apomorphine. As has been described with levodopa, the levels in CSF might better explain the motor effects than the levels in plasma. ${ }^{8.9}$ Therefore we measured apomorphine levels in plasma and CSF samples of PD patients and correlated them with the clinical motor responses.

Our hypothesis was that a two compartment pharmacokinetic model, with a central and peripheral compartment, would better explain the clinical 52.

DJ Hofstee, C Neef, T van Laar, ENH Jansen. Clin Neuropharmacol 1994: 17:45- 
responses compared to a one compartment model. The central compartment includes the brain with CSF, whereas the peripheral compartment contains the remainder of the body.

\section{Methods}

We studied two PD patients, patient $\mathrm{A}$ is a de novo PD patient and patient $B$ is a patient with advanced $P D$. The study was approved by the Medical Ethical Committee of our hospital and both patients gave their informed consent. The characteristic data of these patients are given in table I.

Table I. Clinical data of studied PD patients.

\begin{tabular}{lll}
\hline & Patient A & Patient B \\
Age & 48 years & 64 years \\
Sex $(\mathrm{m} / \mathrm{f})$ & $\mathrm{f}$ & $\mathrm{f}$ \\
Duration PD & 1 year & 7 years \\
Hoehn \& Yahr & II (grade I-V) & V (grade I-V) \\
Webster score & $5(\max .30)$ & $20($ max. 30) \\
\hline
\end{tabular}

To prevent adverse events of apomorphine, like nausea and hypotension, domperidone $60 \mathrm{mg} /$ day was orally administered. The customary antiparkinson medication of patient B was discontinued before the dosefinding test and the pharmacokinetic test were done. Patient A did not use any anti-parkinson medication.

The day before the pharmacokinetic test an apomorphine dose-finding test was done, as described by Hughes et al. ${ }^{4}$ The patients received rising doses of apomorphine subcutaneously, until they had an optimal positive motor response. Patient A responded with $5 \mathrm{mg}$ of apomorphine and patient $\mathrm{B}$ with $3 \mathrm{mg}$ of apomorphine.

During the pharmacokinetic test blood and CSF samples were taken at $\mathrm{t}=0,10,20,30,45$ and 60 minutes after administration of the responsive dose apomorphine. For patient $\mathrm{B}$ also at $\mathrm{t}=90$ minutes samples were taken. The blood samples, $4 \mathrm{ml}$, were drawn from an intravenous canula and the CSF samples, $2 \mathrm{ml}$, from a lumbar spinal catheter. After the test the patients received an epidural blood patch to prevent post lumbar puncture complaints.

Clinical scoring of the motor responses in the dose-finding test and the 
pharmacokinetic test was based on the results of the scores of the finger tapping test during 30 seconds and of the modified Webster Rating Scale (WRS), existing of ten items. ${ }^{4}$ These scores were also taken at $\mathrm{t}=0,10$, $20,30,45,60$ and 90 minutes.

The samples of plasma and CSF were kept on ice during the test and centrifugated and frozen after the test. The levels of apomorphine in plasma and CSF were determined by a method using high-performance liquid chromatography with electrochemical detection."

The data were analysed statistically by means of the correlation formula. The level curves were fitted and analysed with the computer programs MW/PHARM and PH/EDSIM to construct a pharmacokinetic model."

\section{Results}

Clinical motor responses:

In patient $A$ with an initial WRS score of 5, extrapyramidal motor signs started to improve within 10 minutes, later her tremors and rigidity diminished completely. Her maximal improvement on the WRS was 3 points. After about 90 minutes her tremors and rigidity started to return. Patient B with an initial WRS score of 20 started to improve within 20 minutes. Rigidity decreased and the tremors diminished completely. Her maximal improvement on the WRS was 5 points. After 90 minutes the tremors started to return.

The absolute improvements on the WRS of patients $A$ and $B$ are shown in figures 1 and 2 in relation with apomorphine plasma and CSF levels.

Adverse effects:

During the test patient B had complaints of nausea but no hypotension. Patient $A$ had no adverse effects. In both patients no post lumbar puncture complaints were registered.

Plasma and CSF apomorphine levels:

In figures 1 and 2 the apomorphine levels in CSF and plasma ar: depicted for patients $\mathrm{A}$ and $\mathrm{B}$. The data points were fitted with the MW/PHARIM and PH/EDSIM programs and these calculated curves are also shown. 

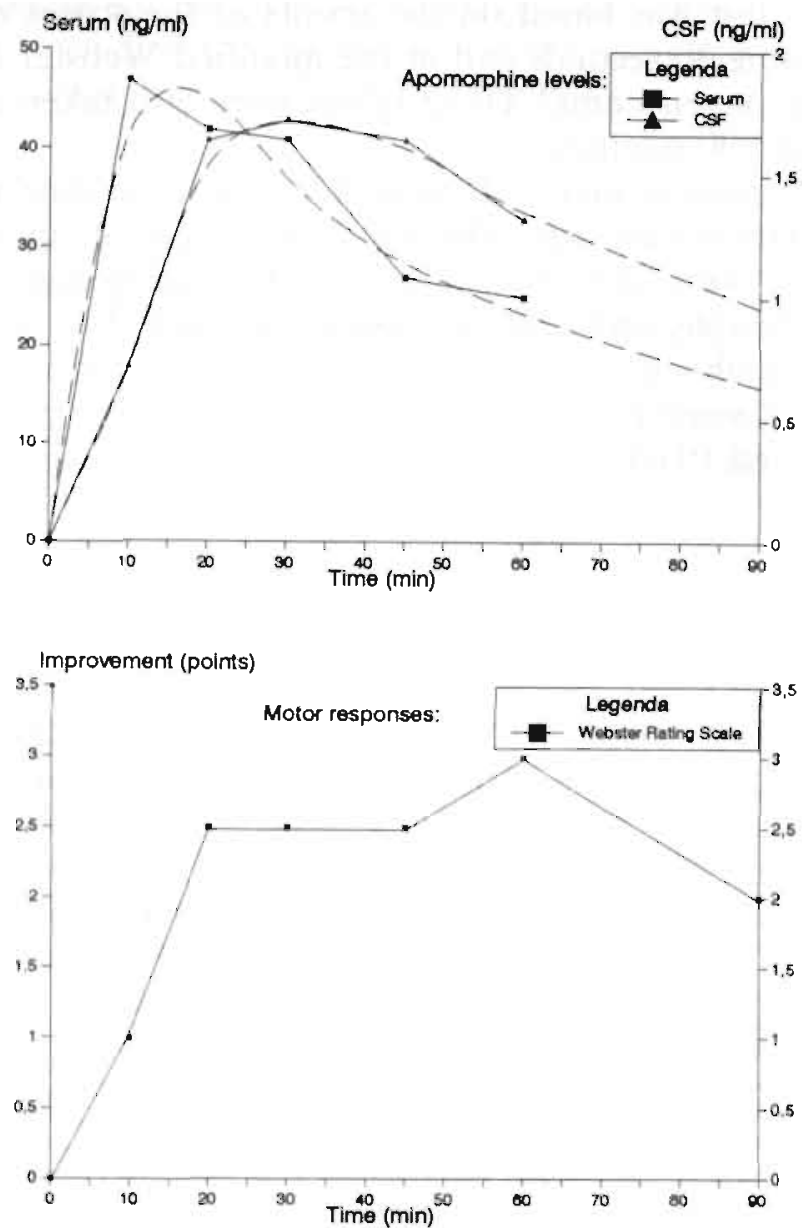

Figure 1. Clinical motor responses, CSF and plasma levels after $5 \mathrm{mg}$ apomorphine s.c. in patient $\mathrm{A}$.

Table II. Apomorphine pharmacokinetic data of studied PD patients.

\begin{tabular}{lll}
\hline & Patient A & Patient B \\
Initial ctose & $5 \mathrm{mg}$ & $3 \mathrm{mg}$ \\
$\mathrm{C}_{\max }$ plasma & $47.8 \mathrm{ng} / \mathrm{ml}$ & $21.5 \mathrm{ng} / \mathrm{ml}$ \\
$\mathrm{T}_{\max }$ plasma & $10 \mathrm{~min}$ & $20 \mathrm{nin}$ \\
AUC plasma & $640 \mathrm{ng}-\mathrm{hr} / \mathrm{ml}$ & $208 \mathrm{ng}-\mathrm{hr} / \mathrm{ml}$ \\
$\mathrm{C}_{\max }$ CSF & $1.72 \mathrm{ng} / \mathrm{ml}$ & $0.53 \mathrm{ng} / \mathrm{ml}$ \\
$\mathrm{T}_{\max }$ CSF & $30 \mathrm{~min}$ & $30 \mathrm{~min}$ \\
AUC CSF & $29.9 \mathrm{ng}-\mathrm{hr} / \mathrm{ml}$ & $17.7 \mathrm{nghr} / \mathrm{ml}$ \\
\hline
\end{tabular}


The maximal concentration $\mathrm{C}_{\max }$, the time to reach the maximal concentration $\mathrm{T}_{\max }$ and the area under the curve AUC, were calculated for the apomorphine levels in plasma and CSF. The results are shown in table II.
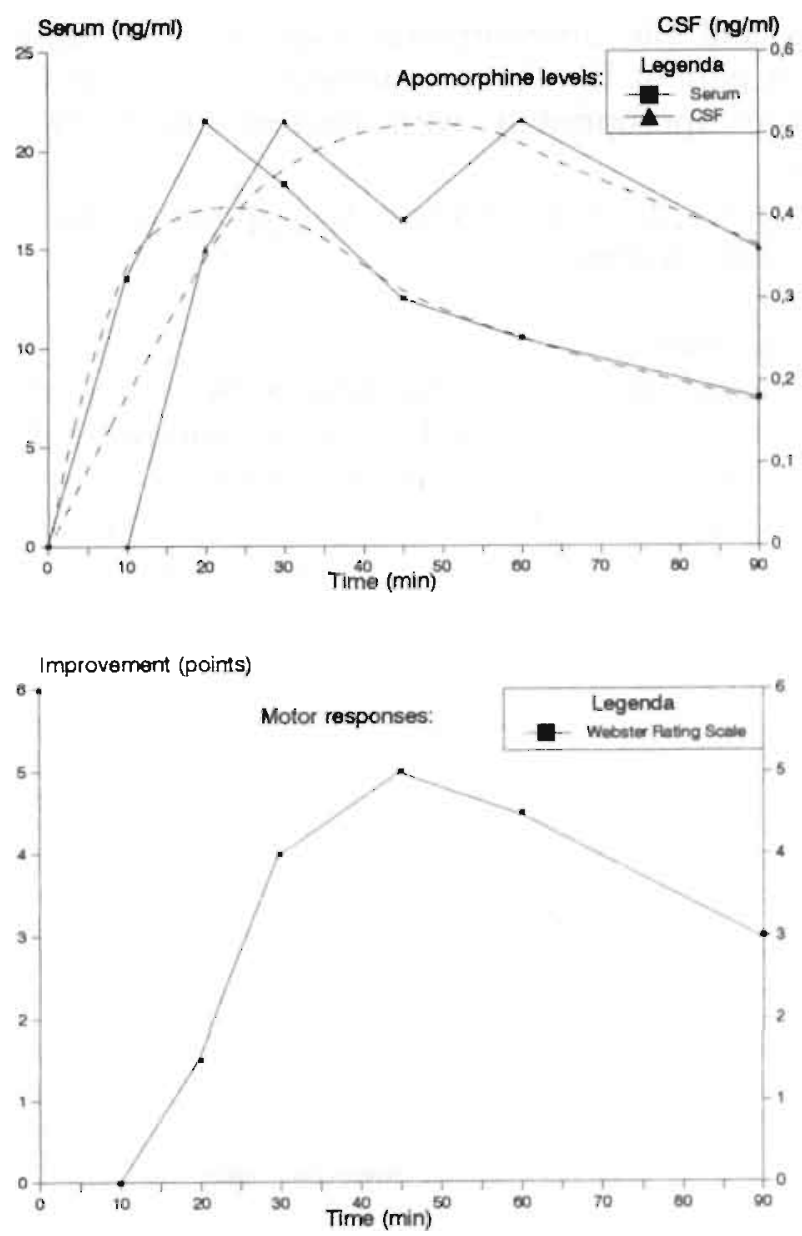

Figure 2. Clinical motor responses, CSF and plasma levels after $3 \mathrm{mg}$ apomorphine s.c. in patient $B$.

The ratio between the $\mathrm{C}_{\max }$ of apomorphine in CSF and plasma is for patient $A 0.036$ and for patient $B 0.025$. The ratio between the AUC of CSF and plasma apomorphine levels is 0.047 for patient $A$ and 0.066 for patient B.

The time lag between the $T_{\max }$ of apomorphine in plasma and in CSF was 20 minutes for patient $\mathrm{A}$ and 10 minutes for patient $\mathrm{B}$. 


\section{Correlations:}

The correlation between the clinical motor responses, WRS score improvement, and the apomorphine levels in plasma were for patient $\mathrm{A}$ +0.47 . and for patient $B+0.25$. The correlation between the clinical motor scores and the apomorphine levels in CSF were for patient A +0.93 . and for patient $B+0.89$. Apomorphine levels in CSF thus seem to correlate more appropriately with clinical effects than apomorphine plasma levels.

The tapping scores did not correlate with apomorphine plasma and CSF levels or the WRS scores.

\section{Pharmacokinetic model:}

Based on aforesaid data, a pharmacokinetic two compartment model can be constructed for patient $\mathrm{A}$ and $\mathrm{B}$. This is demonstrated in figure 3 . The first compartment characteristics are based on the plasma levels and the second compartment characteristics on the CSF levels. With the MW/PHARM and PH/EDSIM programs we calculated the values of the parameters for this model, which are shown in table III. ${ }^{11}$

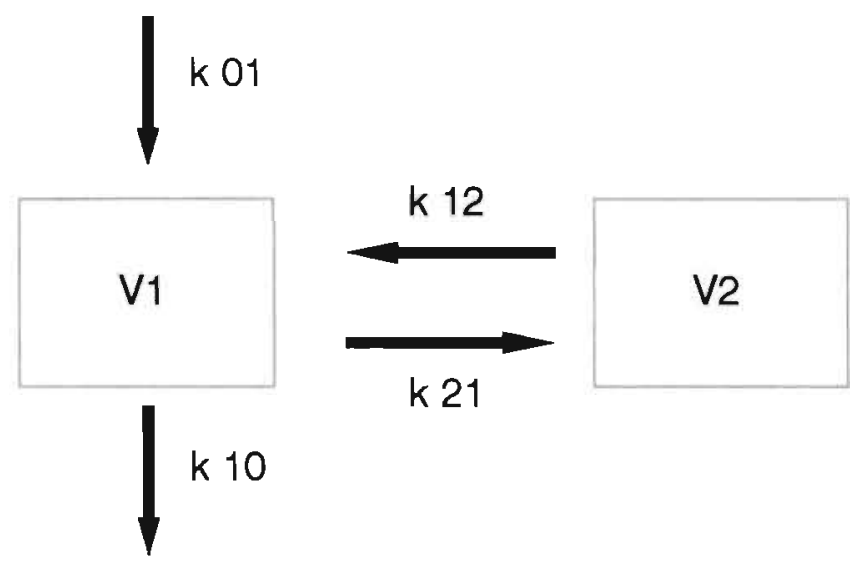

Figure 3. Two compartment pharmacokinetic model $\left(V_{1}=\right.$ compartment one, $V_{2}=$ compartment two, $\mathrm{K}_{01}, \mathrm{~K}_{10}, \mathrm{~K}_{12}, \mathrm{~K}_{21}$ = exchange constants) 
The parameters of the model are the peripheral volume of distribution (the first compartment): $V_{1}$, the central volume of distribution (the second compartment): $V_{2}$ and the exchange constants: $K_{01}, K_{10}, K_{12}$ and $\mathrm{K} 2_{21}$.

Table III. Parameters apomorphine two compartment pharmacokinetic model of studied PD patients.

\begin{tabular}{lll} 
& Patient A & Patient B \\
$\mathrm{V}_{1}$ (plasma) & $54 \mathrm{l}$ & $95 \mathrm{I}$ \\
$\mathrm{V}_{2}$ (CSF) & $711 \mathrm{l}$ & $1025 \mathrm{l}$ \\
$\mathrm{k}_{01}$ & $7.5 / \mathrm{hr}$ & $5.5 / \mathrm{hr}$ \\
$\mathrm{k}_{10}$ & $1.4 / \mathrm{hr}$ & $1.1 / \mathrm{hr}$ \\
$\mathrm{k}_{12}$ & $2.6 / \mathrm{hr}$ & $1.1 / \mathrm{hr}$ \\
$\mathrm{k}_{21}$ & $4.2 / \mathrm{hr}$ & $2.7 / \mathrm{hr}$ \\
\hline
\end{tabular}

Level - effect relation:

For these two patients we calculated the relationship between the apomorphine CSF levels and the effect, the motor response improvement as percentage of the maximal possible motor improvement on the WRS. This was done according to the Hill equation and based on the fitted apomorphine CSF level curves. The level - effect curves for patients $A$ and $\mathrm{B}$ are shown in figure 4.

\section{Discussion}

Up to row the central pharmacokinetics of apomorphine in humans were unknown. We studied the central and peripheral pharmacokinetics of apomorphine in two PD patients and measured the relationship with the clinical motor responses.

The levels of apomorphine in CSF were substantially lower than in plasma, the ratio $\mathrm{C}_{\max }(\mathrm{CSF}) / \mathrm{C}_{\max }$ (plasma) was 0.036 for patient $\mathrm{A}$ and 0.025 for patient $\mathrm{B}$. Apomorphine $\mathrm{T}_{\max }(\mathrm{CSF})$ values were 20 and 10 minutes longer than corresponding $T_{\max }$ (plasma) values in the two pitients.

The correlation between the levels of apomorphine and the motor responses (WRS improvement) was low for the plasma levels but high for the CSF levels. For patient $\mathrm{A}$ this correlation was respectively 0.47 and 0.93 and for patient B 0.25 and 0.89 . The clinical motor responses after apomorphine administration thus seem to correlate much better with 


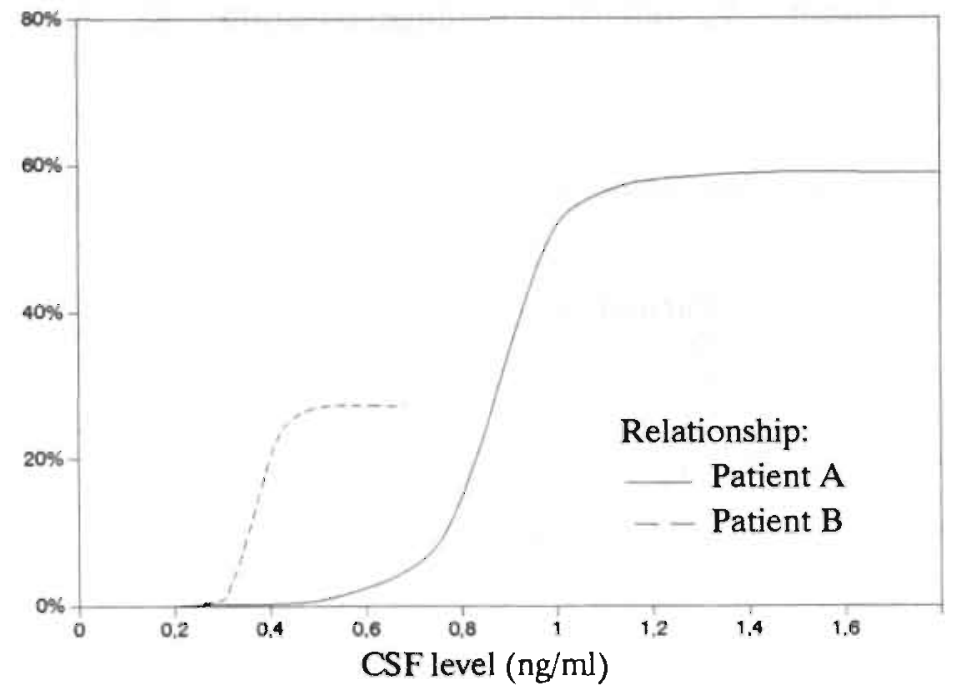

Figure 4 Relationship between the apomorphine CSF levels and the motor response improvement as percentage of the maximal improvement on the WRS.

CSF apomorphine levels than with plasma apomorphine levels.

We conclude that a two compartment pharmacokinetic model better describes the clinical effect of apomorphine than a one compartment model. This confirms our presumed hypothesis.

The timed finger tapping test scores did not correlate with apomorphine plasma or CSF levels or with WRS improvement scores. We have no obvious reasons for this lack of correlation. But it is not impossible that this test was less accurate to reflect the motor status of these two patients because of distraction of attention and patient's position with a lumbar spinal catheter in situ.

We studied the levels of apomorphine in lumbar CSF only, and consequently cannot rule out the possibility that the results of a study with ventricular CSF are different from this study. But because apomorphine appears rapidly in the lumbar CSF and the levels of apomorphine in the lumbar CSF correlate strongly with the motor responses, the difference probably will not be substantial.

To construct a pharmacokinetic model, which can be used to advice clinicians to apomorphine dose administration for PD patients, more patients need to be studied to calculate population parameters. 


\section{References}

1. Gancher ST, Woodward WR, Boucher B, et al. Peripheral Pharmacokinetics of Apomorphine in Humans. Ann Neurol 1989;26:232-238.

2. Hughes $A J$, Webster $R$, Bovingdon $M$, et al. Sublingual Apomorphine in the Treatment of Parkinson's Disease Complicated by Motor Fluctuations. Clin Neuropharmac 1991;14:556-51.

3. Jansen ENH, van Lalar T: Oude Wijn in Nieuwe Zakken. Therapie met Subcutane Apomorfine bij de Ziekte van Parkinson. Ned Tijdschr Geneesk 1990;134:889-891.

4. Hughes AJ, Lees AJ, Stern GM. Apomorphine Test to Predict Dopaminergic Responsiveness in Parkinsonian Syndromes. Lancet 1990;336:32-35.

5. D'Costa DF, Abbott RJ, Pye IF, Millac PAH. The Apomorphine Test in Parkinsonian Syndromes. J Neurol Neurosurg Psychiatry 1991;54:870-872.

6. Laar van T, Jansen ENH, Essink AWG, Neef C. Intranasal Apomorphine in Parkinsonian On-Off Fluctuations. Arch Neurol 1992;49:482-484.

7. Gancher ST, Woodward WR, Gliessman P, et al. The Short-duration Response to Apomorphine: Implications for the Mechanism of Dopaminergic Effects in Parkinsonism. Ann Neurol 1990;27:660-665.

8. Cedarbaum JM, Olanow CW. Dopaminesulphate in Ventricular Cerebrospinal Fluid and Motor Function in Parkinson's Disease; Neurology 1991;41:1567-1570.

9. Olanow CW, Gauger LI, Cedarbaum JM. Temporal Relationships between Plasma and Cerebrospinal Fluid Pharmacokinetics of Levodopa and Clinical Effect in Parkinson's Disease. Ann Neurol 1991;29:556-559.

10. Essink AWG, Lohuis CPGG, Klein Elhorst JT, Rutten WJ. Selective and Quantitative Isolation and Determination of Apomorphine in Human Plasrnit. J Chromatogr 1991;570:419-24.

11. Proost JH, Meijer DK. MW/PHARM an Integrated Software Package for Drug Dosage Regimen Calculation and Therapeutic Drug Monitoring. Comput Biol Med 1992;22:155-163. 


\section{CHAPTER 9}

Increase of Parkinson disability after fluoxetine medication. ${ }^{8}$ 


\section{Introduction}

Depressive symptoms and major depression are major clinical features of Parkinson's disease (PD). The mean value of depressive symptoms in PD is $86 \%$, and $37 \%$ for major depression. ${ }^{1}$ The pathophysiology of this affective disorder in PD is largely unknown. Dopaminergic deficiency has been postulated, with neuroanatomic representation in the dopaminergic mesolimbic pathways or a dopamine depletion in the prefrontal cortex. ${ }^{2}$ Serotonin allegedly is involved in the pathophysiology of depression, with a substantial deficiency of serotonin content and of serotinergic cells in the dorsal raphe nucleus in patients with PD and depression. ${ }^{1}$ Also, a norepiphrine depletion is found to be involved in mood and motor disorders, as well as in cognitive function impairment, demonstrated in the brainstem and particularly in the locus coeruleus. ${ }^{3}$ It is unlikely that depression in PD is reactive; the high frequency of depressive symptoms and episodes in the presymptomatic phase of PD is a solid argument against this reactive hypothesis.

Patients with PD and depressive symptoms consequently are frequently treated with antidepressants. The serotonin reuptake inhibitor fluoxetine, a relatively new antidepressive compound, seems a promising drug to overcome the affective problems in PD patients. Recently, extrapyramidal side effects of fluoxetine in psychiatric patients have been documented. ${ }^{4-6}$

We describe four patients with PD and long-standing stable levodopa therapy in whom the PD disability deteriorated during fluoxetine exposure.

Case report: Four patients with PD meeting DSM-III criteria ${ }^{7}$ for major depression had severity of depression estimated on the Hamilton Depression Rating Scale (HDRS-17 items). ${ }^{8}$ In all four patients, treatment with fluoxetine was considered justified on the basis of their scores on HDRS. Patient data are summarized in the table.

Antiparkinson medication consisted in all patients of levodopa (+D.D.I.) and amantadine. No monoamine oxidase inhibitors were used. Cognitive impairment was not present in these patients. Fluoxetine dosage was $20 \mathrm{mg} / \mathrm{d}$ in all four patients. Antiparkinson medication was kept unchanged 2 months prior to and during fluoxetine treatment. Patients were not allowed to use neuroleptics, tranquillizers, hypnotics, and/or other medication relevant to depression or PD during this observation period.

Patients tolerated fluoxetine without problems, i.e., no cardiovascular or gastrointestinal adverse effects. Patient number 2, with a prior history of 
migraine, had atypical vascular headache episodes only in the 2 nd month of fluoxetine treatment. In no patient were depressive symptoms substantially alleviated by fluoxetine (see table of scores of HDRS). Fluoxetine was given to the patients for at last 8 weeks, with a maximum of 11 weeks. Parkinson disability definitely increased, as spontaneously reported by three patients and substantiated in all four patients with the UPDRS scores (see table). Symptoms on UPDRS (part III-motor examination $)^{9}$ that were most frequently increased were tremor at rest, fingertaps, hand movements, and body bradykinesia. Patient number 4 , without prior rest tremor, developed a tremor at rest in both hands that was marked in amplitude and present most of the time. None of the four patients had an increase in action or postural tremor in the hands. The increase in the fingertap and hand movement scores was more than one point in three of the patients. Signs and symptoms of increased Parkinson disability became evident 10 to 14 days after starting fluoxetine.

Fluoxetine was withdrawn from all patients, and a return of UPDRS scores to previous values was established within 4 weeks. An analysis of variance of the HDRS ratings revealed no significant differences between the three instances of measurement $(F[2.6]=0.487 ; p=0.637)$. Before, during and after fluoxetine exposure, the mean ratings were 21.75 (SD 4.11), 20.50 (SD 3.32), and 21.25 (SD 5.85).

Despite the small number of patients, there is a significant "time" effect for the UPDRS ratings $(F[2.6]=51.92 ; p=0.0001)$. Paired $t$ tests disclosed that with fluoxetine the UPDRS ratings were significantly higher than both before and after fluoxetine exposure. The ratings of UPDRS before and after fluoxetine did not differ significantly $(\mathrm{t}[3]=$ 1.73; two-tailed, $p=0.18$ ).

In patient number 4, the severe rest tremor in both hands improved dramatically on intranasal apomorphine application $(3 \mathrm{mg}$ ). Prior to apomorphine administration, this patient was pretreated with domperidone $60 \mathrm{mg} / \mathrm{d}$. For 3 weeks, this apomorphine treatment intranasal and on demand - was realized with substantial benefit after withdrawal of fluoxetine.

In patient number 2, fasting plasma prolactin levels increased up to $1,200 \mathrm{mU} / \mathrm{I}$ after 4 weeks of fluoxetine treatment. Six weeks after fluoxetine withdrawal, the fasting prolactin level was normalized, i.e., 280 $\mathrm{mU} / \mathrm{l}$. In the other three patients, no change in plasma prolactin levels could be established. Otherwise, laboratory results in all patients were normal. 


\begin{tabular}{|c|c|c|c|c|c|c|c|c|c|c|}
\hline \multirow[b]{2}{*}{ Patient } & \multirow{2}{*}{$\begin{array}{l}\text { Age } \\
(\mathrm{yr})\end{array}$} & \multirow{2}{*}{$\begin{array}{c}\text { Duration } \\
\text { PD } \\
(\mathbf{y r})\end{array}$} & \multirow{2}{*}{$\begin{array}{l}\text { Hoehn \& } \\
\text { Yahr } \\
\text { stage }\end{array}$} & \multicolumn{3}{|c|}{ UPDRS* } & \multicolumn{3}{|c|}{ HDRS ${ }^{*}$} & \multirow{2}{*}{$\begin{array}{l}\text { Levodopa } \\
\text { dose } \\
(\mathrm{mg} / \mathrm{d})\end{array}$} \\
\hline & & & & a & b & c & a & b & c & \\
\hline 1 & 56 & 5 & III & 28 & 41 & 30 & 23 & 31 & 24 & 440 \\
\hline 2 & 61 & 7 & II & 17 & 29 & 20 & 18 & 16 & 15 & 750 \\
\hline 3 & 52 & 3 & II & 23 & 31 & 22 & 27 & 24 & 28 & 375 \\
\hline 4 & 54 & 8 & III & 11 & 19 & 13 & 19 & 21 & 18 & 990 \\
\hline Mean $+\mathrm{SD}$ & $55.57+3.86$ & $5.75+2.22$ & & & & & & & & $3.75+285.6$ \\
\hline
\end{tabular}

"Scores of UPDRS (Unified Parkinson's Disability Rating Scale-part III-motor examination) and HDRS (Hamilton Depression Rating Scale-17 items), $a=$ before, $b$ $=$ during, and $\mathrm{c}=$ after fluoxetine exposure

\section{Discussion}

PD is a striatal dopamine deficiency syndrome that can be mimicked to a very large extent by MPTP exposure. The postsynaptic dopamine depletion in the basal ganglia can also be produced by chronic neuroleptic medication.

The four patients in this report with major depression had a deterioration of Parkinson motor performance after exposure to fluoxetine. The increase of Parkinson signs and symptoms was transient in all four patients, i.e., they did not improve until after withdrawal of fluoxetine. The reversibility of this deterioration contradicts the possibility of natural progression of PD during the period of fluoxetine medication. The antidepressive efficacy of fluoxetine was not found to be substantial in these four patients. The antidepressant efficacy of fluoxetine in PD patients cannot be generalized because of the small number of patients in this study, the modest dosage of $20 \mathrm{mg} / \mathrm{d}$ of fluoxetine, and the apparent severity of depression in these four patients. The prevalence of the phenomenon of decrease of motor performance and/or improvement in depression in PD patients is not given in the literature and cannot be estimated on the basis of our small personal experience.

We are aware of the inadequacies of using HDRS in PD patients since symptoms of PD may overlap with those of depression. ${ }^{1}$ In this case report, however, the transient change in UPDRS scores was considerable and could not be attributed to other causes. The increase of Parkinson disability after fluoxetine exposure can easily be explained on the basis of a dopamine-antagonistic activity of fluoxetine. ${ }^{4}$ The increase of prolactin 
plasma levels in one patient is in accordance with this ${ }^{10}$, as is the benefit of apomorphine in another patient. We cannot rule out other possibilities for this unwanted effect of fluoxetine. ${ }^{6}$ Recently, the manifestation of Parkinson features in depressed, non-parkinsonian patients after fluoxetine exposure has been published. ${ }^{46}$ We are not apprised, however, of the striatal dopamine functioning in these patients, which could have been achieved by fluorodopa PET to exclude a presymptomatic Parkinson phase in these depressed patients. On the basis of our observations, the use of fluoxetine as a serotonin reuptake inhibiting antidepressant in Parkinson patients with depression seems to warrant some caution.

\section{Acknowledgements}

The author wishes to thank Dr. Pieternel Kölling for editorial assistance. Marie Schuil for preparing this manuscript, and Sebi Oosterloo (University Twente) for statistical analysis.

\section{References}

1. Sano M, Stern Y, Williams J. Depression and cognition in Parkinson's disease. J Clin Exp Neuropsychol 1989;11:36-51.

2. Mayberg HS, Starkstein SE, Sadzot B, et al. Selective hypometabolism in the inferior frontal lobe of depressed patients with Parkinson's disease. Ann Neurol 1990;26:57-64.

3. Chan-Pallay V, Assan E. Alterations in catecholamine neurons of the locus coeruleus in senile dementia and in Parkinson's disease with and without dementia and depression. J Comp Neurol 1989;287:373-392.

4. Brod TM. Fluoxetine and extrapyramidal side effects. Am J Psychiatry 1989:146:1352-1353.

5. Bochard RH, Pourcher E, Vincent P. Fluoxetine and extrapyramidal side effects. Am J Psychiatry 1989;146:1352-1353.

6. Tate JL. Extrapyramidal symptoms in a patient taking haloperidol and fluoxetine. Am J Psychiatry 1989;146:300-400.

7. American Psychiatric Association (APA). Diagnostic and statistical manual of mental disorders, 3rd ed revised. (DMS-III-R) Washington, DC: APA, 1987.

8. Hamilton M. A rating scale for depression. J Neurol Neurosurg Psychiatry 1960;23:56-62.

9. Fahn S, Elton RL, members of the UPDRS Development Committee. Unified Parkinson's disease. Florham Park, NJ: Macmillan Healthcare Informations, 1987:153-163.

10. Urban RJ, Veldhuis JD. A selective serotonin reuptake inhibitor, fluoxetine hydrochloride, modulates the pulsatile release of prolactin in postmenopausal women. Am J Obstet Gynecol 1991;146:147-152. 


\section{CHAPTER 10}

Clozapine in the treatment of tremor in Parkinson's disease. ${ }^{9}$ 


\section{Introduction}

Clozapine is an atypical antipsychotic drug in the dibenzodiazepine class, and has been used since 1971 in the treatment of hard to-treat schizophrenic patients. ${ }^{1}$ Clozapine is an atypical neuroleptic drug, because its propensity to provoke extrapyramidal side effects is only very weak. On the basis of this pharmacological profile Clozapine has proved to be a very effective neuroleptic agent in psychiatry. The addition of Clozapine in the treatment of psychosis in Parkinson's disease (PD) is another ideal indication for this compound. ${ }^{2,3}$

The use of Clozapine in the treatment of tremor in PD has only rarely been subject of study.,5,6

We studied the addition of Clozapine in 23 patients with PD and optimal antiparkinson medication, who all had as major disability a troublesome tremor - and investigated the antitremor efficacy and tolerability of Clozapine.

\section{Patients and Methods}

Twenty-three patients with PD and, despite optimal antiparkinson treatment, a troublesome tremor, participated in this study. All patients signed informed consent documents, in which special reference was given to agranulocytosis as the major adverse event of Clozapine.? The study was approved by the hospital's Ethical Review Board. The study was conducted in a open-label design. Capsules contained $6.25 \mathrm{mg}$. Clozapine. The dosage of Clozapine was very gradually increased: all patients started with one capsule ante noctum; further increase - if necessary - was established every third day and the daily dosage was given in the early morning and antenoctum. No upper limit of daily dosage of Clozapine was set. The study duration was 6 months. Patients with a positive effect of Clozapine on tremor scores could make a choice to proceed with Clozapine therapy.

Patients were evaluated at two weeks visits, blood counts were performed on a weekly basis. At 4 weeks intervals the UPDRS, ${ }^{8}$ motor exam score (items 18-36) was evaluated. Adverse events were recorded each second visit; special attention of adverse events was given to sedation, hypotension, epilepsy and hypersalivation. Sleep benefit and improvement of dyskinesias were also scored.

Antiparkinson medication was not changed during the whole period of study. If sedation was a major feature in the first weeks of the study - 
addition of naloxone was made possible."

PD patients with a psychosis in history or at present were excluded, as were patients with vivid dreaming. Also excluded were PD patients with overt dementia (score on Mini Mental State Exam less than 18 points), and with a history of another neuropsychiatric illness. A paired t-test was used to see whether the total scores on UPDRS after exposure to Clozapine were significantly lower than before exposure. The same analysis was reported for the tremor subscores and for the 'non-tremor' subscores on the UTPDRS. In order to detect a possible relationship between the dosage of Clozapine and the change in the (sub)scores on the UPDRS, Kendall's tau was computed.

Table 1. Summary of cases

\begin{tabular}{|c|c|c|c|c|c|c|c|c|c|c|c|}
\hline \multirow{2}{*}{$\begin{array}{l}\text { pat } \\
\text { nr }\end{array}$} & \multirow[t]{2}{*}{ Вge } & \multirow[t]{2}{*}{$n / f$} & \multirow{2}{*}{$\begin{array}{l}\text { duration } \\
\text { PD years }\end{array}$} & \multirow{2}{*}{$\begin{array}{l}\text { H\&Y } \\
\text { stage }\end{array}$} & \multirow{2}{*}{$\begin{array}{l}\text { duration } \\
\text { dopa } \\
\text { yenrs }\end{array}$} & \multirow{2}{*}{$\begin{array}{l}\text { dosage } \\
\text { lerodopa } \\
+ \text { DDI }\end{array}$} & \multirow{2}{*}{$\begin{array}{l}\text { duration } \\
\text { Clocapine } \\
\text { months }\end{array}$} & \multirow{2}{*}{$\begin{array}{l}\text { dosage } \\
\text { Clozapine } \\
\text { mg }\end{array}$} & \multicolumn{2}{|c|}{$\begin{array}{l}\text { UPDRS } \\
\text { items } 18-31^{*}\end{array}$} & $\begin{array}{l}\text { Tremor score } \\
\text { items UPDRS* }\end{array}$ \\
\hline & & & & & & & & & B & $A$ & $A$ \\
\hline
\end{tabular}

\begin{tabular}{|c|c|c|c|c|c|c|c|c|c|c|c|c|}
\hline 1 & 54 & 5 & 9 & 4 & 6 & 600 & 7 & 1.2 .5 & 40 & .35 & 17 & 11 \\
\hline 2 & 61 & $f$ & 4 & 2 & 3 & 330 & 10 & 18.75 & 49 & 39 & 21 & 9 \\
\hline 3 & 72 & $\mathrm{~m}$ & 5 & 3 & 4 & 537 & 8 & 6.25 & 54 & 47 & 23 & 18 \\
\hline 4 & 68 & f & 12 & 3 & 5 & 370 & 6 & 25.- & 49 & 51 & 14 & 14 \\
\hline 5 & 49 & $\mathrm{~m}$ & 6 & 4 & 2 & 600 & 7 & 18.75 & 56 & 49 & 6 & 2 \\
\hline 0 & 75 & nı & 18 & 4 & 10 & 940 & 6 & 18.75 & 60 & 57 & 19 & 13 \\
\hline 7 & 73 & $\mathrm{~m}$ & 11 & 3 & 8 & 760 & 6 & 31.25 & 48 & 39 & 26 & 22 \\
\hline 8 & 61 & $\mathbf{m} \mathbf{1}$ & 5 & 2 & 3 & 250 & 10 & 37.50 & 36 & 29 & $2 A$ & 16 \\
\hline 9 & 57 & r & 2 & 3 & 1 & 490 & 6 & 12.50 & 38 & 34 & 11 & 8 \\
\hline 10 & 43 & I & 4 & 1 & 2 & 250 & 3 & 12.50 & 20 & 19 & 9 & 6 \\
\hline 11 & 70 & $\mathrm{~m}$ & 12 & 3 & 8 & 570 & 9 & 18.75 & 38 & 37 & 1.7 & 1.3 \\
\hline 12 & 79 & f & I4 & 4 & 10 & 900 & 13 & 12.50 & 60 & 63 & 22 & 23 \\
\hline 13 & 54 & $\mathrm{~m}$ & 3 & I & 1 & 200 & 7 & 25.- & 20 & 13 & 22 & 1.3 \\
\hline 14 & 63 & nı & 8 & 2 & 5 & 3.30 & 16 & 31.25 & 34 & 28 & 19 & I2 \\
\hline 15 & 69 & i & 9 & 2 & 6 & 200 & 9 & 6.25 & 29 & 31 & 6 & 6 \\
\hline 16 & 58 & I & 7 & 3 & 4 & 550 & 8 & 12.50 & 51 & 44 & 8 & 4 \\
\hline 17 & 59 & $m$ & $y$ & 4 & 2 & $8 \times 0$ & $?$ & 18.75 & 65 & 61 & 6 & 3 \\
\hline 18 & 72 & $\mathbf{m}$ & 15 & 3 & 11 & 1000 & 18 & 6.25 & 52 & 52 & 4 & 1 \\
\hline 19 & 66 & f & 1.1 & 4 & 0 & 1150 & 21 & 12.50 & 75 & 73 & 9 & 3 \\
\hline 20 & 48 & $\mathbf{m}$ & 7 & 2 & 3 & 460 & 14 & 18.75 & 33 & 30 & 13 & 1.7 \\
\hline 21 & 56 & $\mathbf{m}$ & 4 & 1 & 1 & 250 & 6 & 12.50 & 12 & 13 & 8 & 8 \\
\hline 22 & 78 & r & 19 & 3 & 12 & 750 & 17 & 31.25 & 40 & 33 & 21 & 14 \\
\hline 23 & 81 & $\mathrm{~m}$ & 21 & 4 & 16 & 900 & 19) & 18.75 & 76 & 72 & 15 & 8 \\
\hline
\end{tabular}

\section{Results}

The clinical characteristics of the PD patients enroled in the trial are summarized in table 1 . Mean age was $63.5 \pm 10.7$ years, mean duration 
of PD was $9.65 \pm 5.2$ years. Mean stage Hoehn and Yahr $2.83 \pm 1.03$ points. Mean duration of levodopatherapy $5.7 \pm 4$ years, the mean daily dosage of levodopa was $576.8 \mathrm{mg}$ with SD $285.8 \mathrm{mg}$. Mean Clozapine daily dosage was $18.2 \pm 8.6 \mathrm{mg}$ and the mean duration of Clozapine therapy was 10.3 months, with a SD of 5 months. Only one patient (nr 10) discontinued the scheduled minimum period of 6 months of study because of leucopenia. All other patients wanted to proceed with Clozapine therapy after the initial 6 months study period.

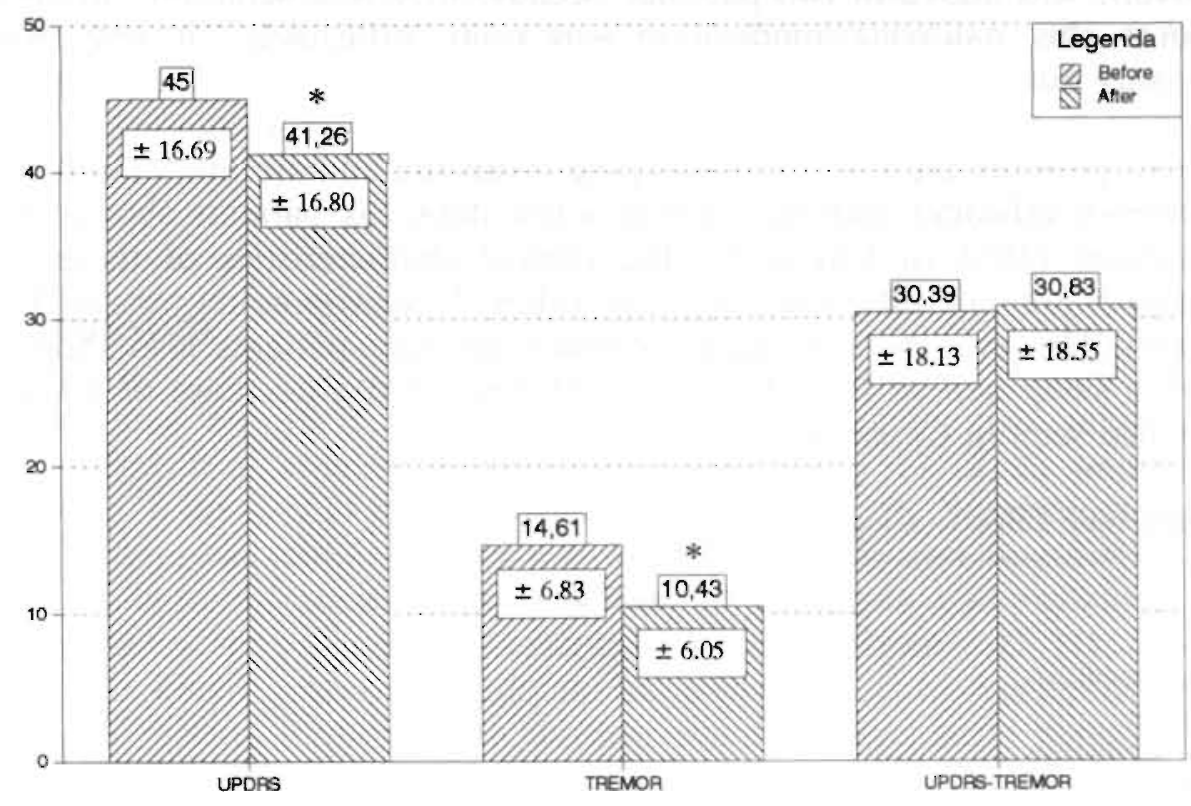

Figure 1 Effect of clozapine on unified PDRS score, Tremor score and the difference score (PDRS-Tremor). Mean score given above each bar. Standard deviation $( \pm)$ given in each bar. A star $\left({ }^{*}\right)$ indicates a significant difference $(p<0.001)$ as showed by a paired t-test.

Statistical analysis revealed that the tremor subscores before exposure were significantly higher than those after exposure to Clozapine, the means were $14.61(\mathrm{SD}=6.83)$ and $10.43(\mathrm{SD}=6.05)$ respectively $(t(22)=5.90 ; p=0.00)$. The UPDRS total scores before exposure to Clozapine also proved to be higher than those after exposure $(\mathrm{t}(22)=4.82 ; \mathrm{p}=0.00)$. (see fig. 1 )

The changes in mean UPDRS scores (before and after exposure measurements) seem completely caused by the decrease of tremor subscores. If the tremor subscores are subtracted from the UPDRS 
scores, the mean of the resulting UPDRS score is slightly higher after exposure than before (mean difference $=0.43 ; \mathrm{SD}=2.39$ ); this difference is not statistically significant however $(t(22)=-1.34 ; p>0.20)$ (see fig.1). A positive relationship was found between the change in the tremor subscore ('delta tremor') and the dosage of Clozapine administered $(n=23$; Kendall's tau $=0.33$; one-tailed $\mathrm{p}=0.01)$

In six patients hypersalivation was provoked by introduction of clozapine medication. In three patients this hypersalivation was severe.

Naloxone was added in two patients, because of severe sedation. ${ }^{9}$ In both patients this naloxone medication was quite efficacious, it only was necessary during weeks three to seven.

In most patients the effect of Clozapine (both the adverse events and the antitremor efficacy) appeared within a few days. Six patients showed no antitremor effect of Clozapine; the clinical characteristics of these six patients were not different from the other 17 clozapine-responsive PD patients. However, two of these six non-responsive patients also showed definite sleep benefit from Clozapine, and two had a decrease of nausea as is also seen in Clozapine-responsive patient.

Table 2. Side Effects - Clozapine treatment in 23 patients

total number of patients

Agranulocytosis

Sedation

Hypersalivation

Epilepsy

Decrease of nausea

Sleep benefit

Weight gain

Improvement of dyskinesias

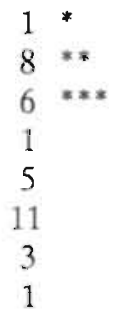

* Lowest value of leucopenia 2.3

** 2 of 8 patients requiring treatment with naloxone

$* * 3$ of 6 patients were given biperiden

The adverse events are summarized in table 2. Neutropenia occurred in one patient (n 10); the blood count returned to normal values four weeks after discontinuation of Clozapine treatment. Eleven patients encountered a sleep benefit after Clozapine medication enabling in six patients stopping their intermittent use of sleeping pills. Four of these eleven patients however, also complained of daytime sedation, although 
this was only a problem in the first 3-4 weeks of Clozapine treatment. One patient (nr 10) had a single generalized tonic-clonic seizure; in this patient anti-epileptic drugs had been stopped six years before. The same patient developed agranulocytosis.

One patient had a substantial benefit of Clozapine treatment in improvement of levodopa induced dyskinesias. These dyskinesias were bothersome for the patient and her partner, and had an orofacial distribution (especially facial grimacing).

A special side effect encountered in three patients was weight-gain during treatment with Clozapine. In one patient the weight-gain was 6 kilograms. $^{10}$

In this study symptomatic orthostatic hypotension after Clozapine was not seen.

\section{Discussion}

In previous reports ${ }^{2,3,4}$ Clozapine treated PD patients had substantial improvement of tremor. In this open label study 17 of 23 improved, resulting in an overall beneficial response rate of $73 \%$. We evaluated the tremor improvement by the scores on the UPDRS, and found that the statistically significant antitremor efficacy of Clozapine also explained the improvement on the motor examination scores (items 18-31) of the UPDRS. The effect of Clozapine on tremor is paradoxical, since in previous reports tremor as an adverse event in psychiatric patients has been described in 6 percent." The dosage of Clozapine in these psychiatric patient, however, was much higher than the Clozapine dosage used in this trial.

A low dosage of Clozapine (mean $18.2 \mathrm{mg} /$ daily) did not increase the other Parkinson disability scores of the UPDRS, as could be foreseen for a drug labelled as an atypical antipsychotic. The same holds true for the improvement - in one patient - of levodopa induced dyskinesias.

In this study one patient developed transient neutropenia which is the major adverse event of Clozapine and which may be life threatening. ${ }^{7}$

The other - minor - adverse events of Clozapine could successfully be diminished by administration of Naloxone for sedation. The exposure to Clozapine - even in this low dosage - had a substantial weight-gaining effect in some patients. ${ }^{10}$ Clozapine is related to the risk of seizures, ${ }^{12}$ and this occurred in one patient with a previous history of epilepsy.

The exact pharmacological evidence to support the efficacy of Clozapine as an atypical antipsychotic drug in psychosis and also in tremor is only 
partially understood. The selectivity of this new clinically active antipsychotic compound on the D1-D2/5HT2-receptors could account for the unique spectrum of clinical effects of Clozapine. Clozapine has shown to function more like a D1 than D2 antagonist, which could suggest a distinction between typical and atypical antipsychotic drugs. Atypical antipsychotics, like Clozapine and Fluperlapine, are potent 5HT2 and 5HT-1C antagonists, and thus may be expected to increase or modulate DA cell activity in the midbrain. Compounds like Clozapine are capable to alter the $5 \mathrm{HT} 2 / \mathrm{D} 2$ balance. ${ }^{13}$

Clozapine is the only compound to have an affinity for 5HT-1C sites that is higher than that for the D1 and D2 sites. ${ }^{14}$ The D2 blocking activity of Clozapine with a preferential binding to mesolimbic, mesocortical and hippocampal D2 receptors, and no substantial binding to striatal dopamine receptors is hold responsible for the only very weak extrapyramidal side effect profile of this compound. ${ }^{15}$ Clozapine does not increase plasma prolactin (PRL) levels nor does it block the apomorphine induced decrease in plasma PRL concentrations, these PRL results may be consistent with an increased DA release of Clozapine. ${ }^{16}$ Antagonism of D2 and 5HT2 receptors, and enhancement of DA and 5 HT release may indeed be critical not only for the antipsychotic properties of Clozapine, but also for the antitremor effect of Clozapine in PD patients. The long duration of levodopatherapy in these patients may obscure the precise mechanism of pharmacological activity of Clozapine in PD patients with tremor. Clozapine also has shown to have strong anti-noradrenergic, antihistaminergic and anticholinergic pharmacological properties.? Thus a defined theory fully accounting for the unusual pharmacologic properties of Clozapine in the treatment of psychosis and tremor still awaits further research.

On the basis of this study Clozapine seems indicated in PD patients with severe disabling tremor, otherwise refractory to treatment. Clozapine can be used safely if weekly white cell counts are - able to be - established. Future research in this field must be directed to atypical neuroleptics, with the same antitremor efficacy in PD patients, but devoid of the risk of potentially fatal agranulocytosis.

\section{References}

1. Kane J, Honigfeld G, Singer J, Meltzer HG. Clozapine for the treatmentresistant schizophrenic. Arch Gen Psych 1988;45:789-795.

2. Friedman JH, Lannon MC. Clozapine in the treatment of psychosis in Parkinson's disease. Neurology 1989;39:1219-1221 
3. Factor SA, Brown D. Clozapine prevents recurrence of psychosis in Parkinsun's Disease. Mov Disord 1992;7:125-131.

4. Pakkenberg $\mathrm{H}$, Pakkenberg B. Clozapine in the treatment of tremor. Actit Neurol Scan 1986;73:295-297.

5. Fischer PA, Baas $\mathrm{H}$ and Hefner R. Treatment of parkinsonian tremor with Clozapine. J Neur Transm 1990;2:233-238.

6. Friedman $\mathrm{JH}$, Lannon MC. Clozapine response tremor in Parkinson is I lisease. Mov Disord 1990;5:225-229.

7. Baldessarini RJ, Frankenburg F. A Vovel Antipsychotic Agent. N Eng J Med 1991;324:740-754.

8. Fahn S, Elton RL, and members of the UPDRS Development Committce. Recent developments in Parkinson's disease, Vol II, Florham Park, NJ: MacMillan, 1987:153-63.

9. Bonucelli U, Piccini P, Del Dotto $P$, et al. Naloxone partly counteracts apomorphine side effects. Clin Neuropharmacol 1991;14(5):442-449

10. Leadbetter $R$, Shutty $M$, Pavalonis $D$, et al. Clozapine-induced weight gain: Prevalence and clinical relevance. Am J Psych 1992;149:68-72.

11. Fischer PA, Cornelssen K. Fluperlapine in 104 schizophrenic patients. Drug Res 1984:34:125-130.

12. Devinsky O, Honigfeld G, Patin J. Clozapine-related seizures. Neurology 1991;41:369-371.

13. Meltzer HY. The Importance of Serotonin-Dopamine Interactions in the Action of Clozapine. Brit J Psych 1992;160(suppl2):22-29

14. Canton H, Verriele L, and Colpaert FC. Binding of typical and atypical antipsychotics to 5-HT1C and 5-HT2 sites: Clozapine potently interacts with 5HT1C sites. Eur J Pharm 1990;191:93-96.

15. Scholz E, Dichgans J. Treatment of Drug-induced Exogenous Psychosis in Parkinsonism with Clozapine and Fluperlapine. Europ Arch Psychiatr Neurol Sci 1985;235:60-64.

16. Meltzer HY. Clinical studies on the mechanism of action of Clozapine: the dopamine-serotonin hypothesis of sehizophrenia. Psychopharm 1989;99:18-27. 


\section{CHAPTER 11}

Concluding Remarks 
This thesis deals with some aspects of Parkinson's disease (PD), with special reference to recent momentous discoveries in the etiopathogenesis of PD and to new developments in the pharmacotherapy of PD.

PD is a relentless progressive disorder and is a cause of miserable disability. The discovery of selective striatal dopamine deficiency in the parkinsonian brain in the early 1960 s has improved insight in the pathophysiology of PD substantially and has consequently led to a robust decrease in the disability for the patient with PD. After the remarkable finding that striatal dopamine content was reduced by $80 \%$ or more in the brains of people with $\mathrm{PD}$, because of destruction of the pigmented nigral neurons, the disease was treated with levodopa to restore striatal dopamine levels.

In the 1960s and 1970s high dose oral levodopa therapy was established by Birkmayer, Hornykiewicz, Bernheimer and Cotzias. This is still the most effective palliative pharmacotherapy ever found for PD. PD became the first neurodegenerative disease to be treated effectively by neurotransmitter replacement therapy. The finding of dopamine deficiency in the basal ganglia of parkinsonian brains may also be seen as a serendipity: in the early 1950s the introduction of antipsychotic drugs to control schizophrenia led to the appearance of drug-induced parkinsonism. The 1950 s was the decade of the newly discovered monoamine dopamine.

The next major advance was the design of synthetic directly acting dopamine agonists, such as bromocriptine and pergolide, to stimulate a variety of dopamine receptors. Apomorphine, widely used in clinical psychiatry as a compound to provoke nausea and vomiting, was rediscovered as a dopamine agonist. Much credit must be given in this field of research to the Dutch pharmacologist Ernst.

After the discovery of dopamine and dopamine-agonists, agents were designed to enhance and prolong the duration of action of dopamine in the brain. Longer acting forms of levodopa have been introduced ('Madopar HBS', 'Sinemet CR' and 'Parlodel SRO')in the late 1980s, since many patients developed unwanted side effects of dopamine precursor therapy, response fluctuations (e.g. end of dose deterioration and dyskinesias) and eventually waning efficacy. Inhibition of the major catabolic enzyme of dopamine: monoamine-oxidase B - selegeline hydrochloride (Deprenyl) - was another major event in the 1980s. The large range of drugs available was believed to be palliative, mostly by restoring striatal dopamine levels or activity; none was thought to protect against the basic cause of PD, which was unknown. It seems reasonable to remark that the discovery of MAO-B-inhibition was taking place in the 
research-field of psychiatry (Joseph Knoll), with the intention to design a compound with anti-depressive properties. Moussa Youdim and Peter Riederer actually must be regarded as the neuropharmacologists who discovered MAO-B-inhibition as a potential drug in the treatment of P.D. At the same time a disease - specific and age-specific increase in the $\mathrm{MAO}-\mathrm{B}$-activity of the Parkinsonian brain had been established.

A pivotal role in further advance in the research of etiopathogenesis of PD was the discovery in 1983 by Bill Langston of the identification of 1 methyl-4-phenyl-1,2,3,6 tetrahydropyridine (MPTP) as a human neurotoxin that could selectively destroy the substantia nigra, induce neuropathological and neurochemical changes almost identical to those of PD, and cause a clinical illness similar to Parkinson's disease itself. MPTP is a pro-toxin, it must be converted to MPP +, in the glia by the fore-mentioned MAO-B enzyme. MPP+, the active neurotoxin, is a substrate for the active dopamine neuronal uptake. MPP + is thus concentrated into dopaminergic neurons where it binds to neuromelanin a byproduct of dopamine synthesis found in nigral cells. The intraneuronally accumulated MPP + is taken up and concentrated in mitochondria, where it poisons NADH-linked components of complex I of mitochondrial encrgy metabolism. MPP + also may induce the formation of free radical species, imposing oxidative stress with consequent lipid membrane peroxidation. MPP + may also poison mitochondrial complex I activity as a result of free radical damage. Thus a number of biochemical abnormalities, which appear to be playing a role in the nigral cell death in PD, have been disclosed in recent years:

1. Mitochondrial complex I deficiency in the substantia nigra, in the nigral melanin-containing and tyrosine-hydroxylase positive dopamine neurons.

Similar but less severe changes have also been found in the aging substantia nigra. Mizuno found an increase in deleted mtDNA in PD patients.

2. Iron accumulation. Iron content in substantia nigra is signilicantly increased in PD. Iron will react with hydrogen peroxide to form hydroxyl radicals in the presence of $\mathrm{Fe}^{2+}$, and thus may induce oxidative damage to nigral cells.

Moreover iron itself is cytotoxic: it directly decreases the number of tyrosine-hydroxylase neurons.

3. Oxygen free radicals. An increase in lipid peroxidation has been reported in PD suggesting reactive oxygen production. Free radical theory and iron theory are closely related.

4. Neurotoxin. Some of the derivatives of tetrahydroisoquinolines and B- 
carbolines are MPTP-analogues, and are toxic to mitochondrial respiratory complexes.

5. Cytochrome P 450. Recent reports have established poor metabolizers of debrisoquine hydroxilation or acetaminophen - sulphation, with an increased risk for acquiring Parkinson's disease. In such cases even a weak toxin may induce nigral damage.The reverse may also be relevant: a genetically arranged metabolic make up of increased $\mathrm{N}$ methylation of tetrahydroisoquinolines putatively may be associated with increased risk for acquiring Parkinson's disease.

All these mechanisms in the pathogenesis of nigral cell death in PD will eventually lead to alterations in the therapeutic management of Parkinson's disease, early diagnosis of $\mathrm{PD}$, detection of the preclinical phase of PD, and establishment of the most effective use of neuroprotective agents. Neuronal rescue is the most recent finding in the 'post MPTP' period providing evidence that non-MAO-B-inhibition or low dosage selegiline may activate a 'neurotrophic-like' mechanism. This 'neuronal rescue' is very important in the research on neurotransplantation or brain grafting of fetal substantia nigra into the striatum, especially the survival of such grafts and the potency for regeneration. But the 'neuronal rescue', of course, might also be very important for alleviation of the actual degeneration of nerve cells in the substantia nigra of the parkinsonian brain.

The agents related to neuronal rescue and neuroprotection have immense implications for substantially influencing the underlying pathology of PD, and possibly also other primary degenerative neurological disorders, like Alzheimer's disease and Motor Neuron Disease.

Confined to Parkinson's disease the major implications are:

1. All newly diagnosed cases of PD should be started on a drug that has shown neuroprotective or neuronal rescue properties.

2. Methods of diagnosing the illness at its earliest stage (or even before motor and non-motor symptoms are present) should be developed.

3. Neuroprotection and Neuronal Rescue can postpone or delay palliative pharmacotherapy with dopamine-precursors and dopamine-agonists. Pharmacotherapy with these agents has many adverse events and may have only a temporary benefit.

4. Treatment of Parkinson's disease by implantation procedures will be critically dependent on these neuroprotective and neuronal rescue procedures. 
As to the present therapeutic management of symptoms of PD the observations made in this study justify some global conclusions.

* Selegiline should be considered among the available therapeutic options for the initial treatment of PD.

* Sustained release levodopa and dopamine-agonists compounds are beneficial in the palliative treatment of PD, and in the short-term treatment of response fluctuations.

* Apomorphine has shown to be very effective in parkinsonian patients with severe response fluctuations.

* Pharmacological modelling of $\mathrm{D} 1 / \mathrm{D} 2$ agonism and antagonism in combination with activity on a variety of $5 \mathrm{HT}$ receptors may be beneficial in the treatment of neurobehaviourial, cognitive and dopaunresponsive symptoms in patients with $\mathrm{PD}$, with or without longstanding levodopa and/or dopamine-agonists therapy

Parkinson's disease is much more than a dopamine deficiency in the basal ganglia, and also is much more than a pure motor disorder. We all await the second Wartenberg-lecture of David Marsden "The mysterious nonmotor function of the basal ganglia". 


\section{CHAPTER 12}

SUMMARY and SAMENVATTING 


\section{Summary}

This thesis deals with pharmacotherapy in Parkinson's disease. General aspects of the pathogenesis and medical treatment of Parkinson's disease are discussed, and some particular aspects of the treatment and the complications of treatment are dealt with in more detail.

Chapter 1 is a general introduction and describes the clinicopathologic features of Parkinson's disease, the problems with diagnostic criteria of idiopathic Parkinson's disease and Parkinsonism. The new classification criteria of the United Kingdom Parkinson's disease Society Brain Bank facilitate a more reliable diagnosis, mainly based on inclusion and exclusion criteria. The accuracy of the clinical diagnosis of idiopathic Parkinson's disease is debated, establishing that about 25 percent of patients with a clinical diagnosis of Parkinson's disease actually have other causes of parkinsonism. Clinical heterogeneity is common even in patients unquestionably diagnosed as having Parkinson's disease. Changing concepts of Parkinson's disease with respect to both the clinical and the pathological spectra also hamper a definite answer to the genetic etiologic factors in Parkinson's disease.

Chapter 2 gives a review on the rationale of pharmacotherapy in Parkinson's disease. Symptomatic therapy with dopamineprecursors is discussed, which is based on the deficiency of nigrostriatal dopamine and tries to enhance dopaminergic transmission in the basal ganglia. Levodopatherapy is the backbone of pharmacotherapy in Parkinson's disease. Slow-release levodopa preparations and dopamine agonists are mainly used to alleviate or prevent the levodopa and disease related response-losing and response-fluctuations. Special attention has been given in this chapter to recent insight in the possibility of neuroprotection and neuronal rescue, referring to a growing interest in slowing progression of PD by protecting surviving neurons. Bill Langston's finding that MPTP can induce Parkinsonism and that deprenyl prevents MPTPinduced Parkinsonism, has played a pivotal role in the stimulated interest in anti-oxidative therapy. Recently the MAO-B-inhibiting property of deprenyl has been extended to MAO-B independent actions of deprenyl, based on the hypothesis that deprenyl increases trophic support to damaged neurons by adjacent reactive astrocytes. 
Chapter 3 describes the topic of neuroprotection by the MAO-B-inhibitor selegiline in some detail. Although the primary cause of Parkinson's disease remains unknown, four theories assign an essential role in the putative mechanisms leading to cell death in the zona compacta of substantia nigra. These theories are discussed:

1. Iron $\left(\mathrm{Fe}^{2+}\right)$ is cytotoxic and leads eventually to decrease of striatal dopamine.

2. Environmental neurotoxins (like MPTP) imitate idiopathic Parkinson's disease extremely closely; the ultimate mechanism of cell killing is presumably mitochondrial complex I poisoning.

3. Endogenous MAO-B mediated (auto-)oxidation of dopamine leads to the production of toxic oxygen free radicals with potential for nigral degeneration.

4. Inherited variations in handling of xenobiotics and endogenous toxins could lead to increased susceptibility to Parkinson's disease.

The results of the DATATOP trial are discussed. These deprenyl studies of patients in early stages of Parkinson's disease support a recommendation for treating these patients with deprenyl $10 \mathrm{mg} /$ day. It has proven unlikely that these studies will provide conclusive data regarding the mechanism of Deprenyl's benefit in Parkinson's disease.

Chapter 4 describes the results of a multicenter study on the potency of the oral slow-release levodopa preparation Madopar HBS to alleviate response fluctuations. Patients with clear-cut 'wearing-off' type of response fluctuations seem particular good candidates for the treatment of these newly developed levodopa preparations. Random oscillations and freezing-episodes were found to be resistant to slow-release levodopa oral administration regimes. Especially in severely disabled patients the therapeutic response to the first morning dose of Madopar HBS appeared too slowly, and therefore a combination with standard Madopar still seems necessary.

Chapter 5 describes a study in co-operation with the late Jan Meerwaldt, of the use of Madopar HBS in Parkinsonian patients with nocturnal and carly-morning disabilities. Although James Parkinson in his Essay on the Shaking Palsy observed that sleep came as a merciful release to sufferers of the malady, for many individuals with Parkinson's disease the night brings with anguish. pain and a crippling despair. In an attempt to combat some of the areas of nocturnal difficulty, patients in this study took Madopar HBS before retiring. This anti-noctum levodopa regimen 
did lead to a considerable diminution in nocturnal akinesia and in the frequency of waking-up. The results provoked by Madopar HBS on these nocturnal akinetic wearing-off phenomena are in agreement with the pharmacokinetic profile of this preparation.

Chapter 6 reports the results of a national multicenter study ( by the Dutch Sinemet Study Group ) on the experiences of the clinical efficacy of Sinemet CR versus standard Sinemet in patients with fluctuating Parkinson's disease. The fourth generation of controlled-re]ease carbidopa/levodopa, termed Sinemet $C R$, is formulated as a slowly erodible matrix containing carbidopa and levodopa. In this double-blind randomized study Sinemet CR showed to be superior in efficacy: reduction in fluctuations in motor performance. The results in this study on the short-term beneficial effect of slow-release levodopa preparations are a consequence of more constant levodopa plasma levels, and thus confirm the hypothesis that response fluctuations may in part be attributed to the pharmacokinetic properties of oral levodopa, a quickrelease formulation with a short plasma half-life.

Chapter 7 describes the results of a national double blind randomized study comparing the efficacy and tolerability of standard bromocriptine versus sustained-release bromocriptine. The introduction of therapy with standard bromocriptine is frequently complicated by peripheral adverse events, mainly concerning orthostasis and nausea. These unwanted effects prevent reaching an effective dosage of bromocriptine. Parlodel SRO was superior compared to standard Parlodel in tolerance, and thus it is seems possible for more Parkinson patients to be treated with this dopamine agonist in effective dosages.

Chapter 8 describes some results of the research group of the Neuropharmacology department in Medisch Spectrum Twente in Enschede with that oldest dopamine-agonist: Apomorphine. The rediscovery of Apomorphine, which is active at both D-1 and D-2 receptors, has essentially been achieved by the Middlesex Hospital Research Group in London (Andrew Lees, Gerald Stern and Merton Sandler). Enschede was able to take the position of a 'satellite' research unit. Apomorphine is used in the search for D2 receptor status in the diagnostic phase of Parkinson's disease. Apomorphine is extremely efficacious in the treatment of 'off' periods, by subcutaneous injections, and in the continuous treatment by subcutaneous infusion using portable pumps. As an alternative to subcutaneous injections, intranasal 
administration of Apomorphine is also quite an efficacious and reliable method to overcome 'off' status. Also reported is an original study of the pharmacokinetics of Apomorphine levels in cerebrospinal fluid and plasma. This research indicated that Apomorphine levels in the cerebrospinal fluid reflect the pharmacologic motor effects of Apomorphine administration in Parkinson patients more accurately than the conventional estimation of Apomorphine plasma levels.

Chapter 9 reports an unsuspected adverse event of anti-depressant treatment in Parkinson's disease. Depression is only recently a major focus of study in $\mathrm{PD}$, although there is little controversy regarding the frequency of depression in Parkinson's disease.

Nearly half of the patients with Parkinson's disease are depressed, the most frequent forms of which are major depression and dysthymic disorders. Especially depression with psychomotor retardation seems to be more or less specific for a neurologic disorder with dopamine deficiency in the basal ganglia. The report describes the increase of Purkinson disability after fluoxetine medication, underlining indirect dopamine-antagonistic properties of this serotonin re-uptake inhibitor and the intimate link between serotonin and dopamine in the pathogenesis of signs and symptoms of Parkinson's disease.

Chapter 10 also deals with the dopamine and serotonin interplay in the symptomatology of Parkinson's disease. Atypical neuroleptics, like Clozapine, combine pharmacological actions on dopamine and serotonin receptors, and confirm the serotonin and dopamine interactions in the nigrostriatal and mesolimbic pathway. Although the relevance of dopaminergic deficiency for the pathophysiology of tremor in PD is at least questionable, the ratio of serotonin and dopamine affinity may be critical for the role of Clozapine in alleviating tremor in Parkinson's disease. The potentially fatal agranulocytosis provoked by Clozapine in a frequency of $1 \%$ is a caution, of course, against gratuitous use of this compound in neuro-psychiatry.

Chapter 11 - concluding remarks - gives a historical review of momentous discoveries in the neuropharmacology of PD, and summarizes some implications for pharmacotherapy in PD.

Chapter 12 summarizes our findings, and reviews the conclusions of the separate chapters. 
All chapters have been published or are accepted for publication. These separate papers consequently are more or less repetitious, which does give resemblance to scientific papers in general. 


\section{Samenvatting}

In dit proefschrift worden enkele aspecten van farmacotherapie bij de Ziekte van Parkinson besproken. Een overzicht wordt gegeven van de conventionele en de meer recente inzichten in de pathogenese en de medicamenteuze therapie bij de Ziekte van Parkinson. Ook enkele bijzondere behandelingsmodaliteiten worden beknopt of zelfs anekdotisch beschreven.

Hoofdstuk 1 is bedoeld als inleiding in de kliniek, de pathofysiologie en de differentiaal diagnostiek van de Ziekte van Parkinson. Inclusie- en exclusie-criteria voor het stellen van de diagnose 'Ziekte van Parkinson' worden beschreven, o.a. aan de hand van de meer recente classificaticcriteria van de Engelse 'Parkinson's disease Society Brain Bank'. Er zijn veel aanwijzingen - vooral gebaseerd op studies tot stand gekomen door een hechte samenwerking van klinisch neuroloog en neuropatholoog - dat de nosologische entiteit 'De Ziekte van Parkinson' niet zo duidelijk omschreven kan worden. Het is derhalve wellicht zinvol termen als Idiopathisch Parkinsonisme, Syndroom van Parkinson of L.ewy Body Disease te gebruiken. Klinisch neurologische en neuropathologische diagnostische criteria kunnen bovendien weinig gebruikt en g('waardeerd worden indien - zoals toenemend wordt beschreven en herkend - er een overlapping is van verschillende neurologische degeneratieve ziektebeelden als Ziekte van Parkinson, Ziekte van Alzheimer en Amyotrofische Lateraalsclerose. Voor het parkinsonisme is dan wellicht typisch de hyperactiviteit van dopaminerge neuronen (o.a. in de substantia nigra) die tot eerdere celsterfte aanleiding geeft. Een typisch 'wear and tear' gebeurtenis dus.

Hoofdstuk 2 geeft een overzicht in de medicamenteuze therapie bij de Ziekte van Parkinson. De symptomatische palli ttieve behandeling met levodopa wordt uitvoerig besproken: tengevolge van degeneratieve afwijkingen in de substantia nigra ontstaat een min of meer selectief defect van het enzym tyrosine hydroxylase, het exogeen toegediende levodopa kan het al langdurig aanwezige dopamine tekort in de basale ganglien 'overwinnen' en de postsynaptische dopamine transmissie 'weer ain de gang krijgen' met alle klinisch-functionele gevolgen van dien.

Levodopamedicatie bij de Ziekte van Parkinson is nog steeds de meest succesvolle therapie - ook op de lange termijn. Een afgeleide van de levodopatherapie is de levodopa met vertraagde afgifte in het 
maagdarmkanaal. Tengevolge van de farmacokinetische eigenschappen en beperkingen van levodopa en dopamine kunnen Madopar HBS en Sinemet CR de 'eb en vloed' mechanismen van conventioneel oraal levodopa verminderen en een meer continue stroom van levodopa en dopamine aan de basale ganglien toeleveren. Dopamine-agonisten vooral indien voorzien van een lange halfwaardetijd - kunnen een zelfde effect te weeg brengen.

Behalve deze symptomatische medicamenteuze behandeling van $d e$ Ziekte van Parkinson, zijn er recent ook argumenten om neuroprotectieve medicamenten voor te schrijven. Neuroprotectie is gebaseerd op de hypothese dat de verschillende pathogenetische mechanismen die een rol spelen bij de Ziekte van Parkinson (oxydatieve stress, defecte mitochondriale complex I activiteit, en excessieve belasting met 'excitatory amino acids") een continue beschadigende factor vormen voor de dopaminerge neuronen, en dat met medicamenten als MAO-Bremmers de resterende (door compensatie overactieve) dopaminerge neuronen verdere beschadiging kan worden verminderd of zelfs voorkomen. Cruciaal in dit opzicht was de ontdekking dat MPTP, een aan heroïne verwante stof, parkinsonisme kan veroorzaken en dat MAOB-remmers deze selectieve toxiciteit van de dopaminerge neuronen in de substantia nigra door MPTP kan voorkomen. Wellicht zijn het de neurotrofische eigenschappen van deze preparaten die een zodanige beschermende werking tot stand brengen (de zogenaamde 'neuronal rescue'). Het 'occam's razor' geldt dan dus ook voor de dosering van een preparaat dan ten onrechte een 'MAO-B-remmer' wordt genoemd.

Hoofdstuk 3 behandelt in meer uitgebreide zin het onderwerp van neuroprotectie zoals dat mogelijk wordt gerealiseerd door de MAO-Bremmer Selegiline. Met neuroprotectie wordt dan uitdrukking gegeven aan een bescherming van de zona compacta cellen in de substantia nigra tegen vier schadelijke factoren.

1. IJzer $\left(\mathrm{Fe}_{2_{+}}\right)$is schadelijk voor de cel en er zijn argumenten voor een overbelasting aan ijzer voor de genoemde dopaminerge cellen.

2. Neurotoxines, zoals MPTP, kunnen selectief de dopaminerge neuronen beschadigen, en als zodanig parkinsonverschijnselen - zowel klinisch als neuropathologisch - doen ontstaan.

Metabolieten van het MPTP zijn zeer toxisch voor het complex I gedeelte van de mitochondriën in de neuronen en kunnen op deze manier celsterfte bewerkstelligen.

3. Auto-oxydatie van het endogene dopamine door het overvloedig aanwezige MAO-B-enzym kan toxische zuurstofradicalen genereren die 
direct (lipidenperoxydatie) of indirect (complex I) de celdegeneratie veroorzaken.

4. Erfelijke factoren die de snelheid en de effectiviteit van detoxificatie van endogene of exogene toxines bepalen.

In dit hoofdstuk worden de resultaten van de DATATOP studie besproken. Deprenyl (Selegiline) therapie bij de-novo Parkinson patiënten kan de therapie met levodopa uitstellen. Hoewel de interpretatie van de resultaten van deze DATATOP studie niet eenduidig is en kan worden, heeft een en ander er wel toe geleid dat Deprenyl wordt voorgeschreven als eerste keuze preparaat bij de medicamenteuze behandeling van de Ziekte van Parkinson.

Hoofdstuk 4 behandelt de resultaten van een Nederlandse multicenter studie met het preparaat Madopar HBS, een levodopa met vertraagde afgifte, bij de behandeling van Parkinson patiënten met responsfluctuaties. Patiënten met voorspelbare schommelingen in motoor prestatieniveau bleken gunstig te reageren op Madopar HBS. Dit bleek niet het geval met andersoortige responsfluctuaties. Een nadeel van het Madopar HBS, namelijk de verlaging van Cmax en de verlenging van de Tmax, veroorzaakt veelal echter verminderde werkzaamheid vooral 's morgens. Monotherapie met Madopar HBS blijkt dan ook in het geval van al aanwezige responsfluctuaties niet goed mogelijk.

Hoofdstuk 5 is een artikel over de effectiviteit van Madopar HBS bij de nachtelijke problemen zoals door veel patiënten met de Ziekte van Parkinson worden ervaren. Er zijn wel aanwijzingen dat er bij de Ziekte van Parkinson slaapstoornissen in engere zin zijn, maar zeker worden vele Parkinson patiënten in hun slaap gestoord door effecten van levodo$\mathrm{pa}$, zoals 'wearing-off' fenomeen in de nacht en onrustige slaap ('vivid dreams'). Madopar HBS had een gunstig effect bij veel patiënten in de studie op de nachtelijke problemen. Deze studie was een gevolg van de zeer gewaardeerde samenwerking met Dr. Jan Meerwaldt.

Hoofdstuk 6 is het artikel van de GSSH (Gemengde Studie Sinemet Holland). Het bevat de resultaten van een studie met Sinemet CR en standaard Sinemet bij Parkinson patiënten met responsfluctuaties. Sinemet CR geeft door langzame erosie van zijn matrix in niet-zuurmilieu een vertraagde afgifte van carbidopa en levodopa. In vergelijking met standaard Sinemet was er een significante vermindering van het aantal fluctuaties in motoor prestatieniveau. De betrouwbaarheid van de Parkinson patiënt en zijn partner bij het registreren van respons- 
fluctuaties werd nog eens bevestigd, evenals de moeilijkheid om een dubbelblinde onderzoeking te verrichten met twee zo verschillende levodopapreparaten.

Hoofdstuk 7 is een weergave van de Nederlandse multicentrische studie met standaard Parlodel en Parlodel SRO. Het betreft een vergelijkende dubbelblinde studi: naar de effectiviteit en de tolerantie van deze twee dopamine-agonisten. Met name werd gekeken of bij gelijkblijvende effectiviteit een verbeterde tolerantie kan worden gerealiseerd met behulp van Parlodel SRO. Dit bleek inderdaad het geval. Vooral misselijkheid en orthostase kwamen minder voor in de met Parlodel SRO behandelde groep van patiënten. Daardoor kan een eenvoudige en betere introductie van deze dopamine-agonist worden bereikt bij een groter aantal Parkinson patiënten.

Hoofdstuk 8 is een weergave van enkele studies met de dopamine-agonist apomorphine, zoals deze konden plaatsvinden in de werkgroep neurofarmacologie van het ziekenhuis Medisch Spectrum Twente in Enschede. Apomorphine is onstabiel, moeilijk oplosbaar en lokaal toxisch, maar bij gebruik parenteraal onstaat een bijna wonderlijke en snelle antiparkinsonwerking; een verbetering die in veel opzichten gelijkt - ook in snelheid - op de verbetering van myasthenie symptomen na Tensilon injectie.

Hoofdstuk 9 beschrijft een onverwachte bijwerking van antidepressieve medicamenteuze behandeling bij enkele Parkinson patiënten. Na gebruik van Fluoxetine medicatie ontstond cen toename van Parkinsonverschijnselen, mogelijk veroorzaakt door indirecte dopamineantagonistische eigenschappen van deze serotonine re-uptake remmer. Deze casuïstische mededeling bevestigt de sterke koppeling tussen de neurotransmitters Serotonine en Dopamine bij de pathogenese van klachten en verschijnselen van de Ziekte van Parkinson.

Hoofdstuk 10 beschrijft de gunstige effecten van een lage dosering van het atypische neurolepticum Clozapine bij de tremor van Parkinson patiënten. Clozapine heeft een D1/D2 ratio die hoger is dan bij de conventionele neuroleptica en in combinatie met aangetoonde serotonerge eigenschappen van dit preparaat is wellicht een verklaring te vinden voor het zo bijzondere antitremor effect. Clozapine kan echter een fatale agranulocytose veroorzaken, zodat het voorschrijven van dit preparaat aan strikte regels, voor wat betreft laboratorium-controles onder verantwoordelijkheid van de voorschrijvende arts, is gebonden. 
Hoofdstuk 11 geeft een historisch overzicht van de neurofarmacologische ontwikkelingen bij de Ziekte van Parkinson en geeft de consequenties voor de farmacotherapie bij deze ziekte in grote lijnen aan.

De hoofdstukken 12 en 13 geven een samenvatting van de verschillende pathogenetische en neurofarmacologische ontwikkelingen.

Ieder hoofdstuk is een weergave van een publicatie. Het geheel van artikelen dat aldus door bundeling is ontstaan, probeert meer inzicht tt verschaffen in het enigma dat de Ziekte van Parkinson is. 


\section{Selected Publications}

1. Deficiency of Acetylcholine Receptors in a Case of End-Plate Acetyl-Cholinesterase Deficiency. Frans G.I. Jennekens, Laura F.G.M. Hesselmans, Henk Veldman, Ernst N.H. Jansen, Frank Spaans and Peter C. Molenaar. Muscle \& Nerve 1992;15:63-72.

2. Falling Spells in Normal Pressure Hydrocephalus, A Favourable Prognostic Sign? Joost Haan, Ernst N.H. Jansen, Jan Oostrom and Raymund Roos. Eur Neurol 1987;27:216-220.

3. Von Recklinghausen Neurofibromatosis and Pregnancy. Jelis Boiten, Ernst N.H. Jansen and Ron de Graaf. Clin Neurol Neurosurg 1987;89:181-184.

4. Bromocriptine in levo-dopa response losing Parkinsonism, A double blind study. Ernst N.H. Jansen. Eur Neurol 1978;17:92-99.

5. Madopar HBS in Parkinson patients with nocturnal and carlymorning akinesia. Ernst N.H. Jansen and Jan D. Mererwaldt. Adv Neurol 1987; $48: 52-55$.

6. Neurolues anno 1988, een serologische diagnose? Rini Frijns en Ernst N.H. Jansen. Ned Tijdschr Geneeskd 1988;132:2225-2228.

7. Komen de MAO-remmers terug? Ernst N.H. Jansen and Jan D. Meerwaldt. Ned Tijdschr Geneeskd 1988;132:487-488.

8. Ischialgia caused by a malignant Triton tumour of the lumbo-sacral plexus. Rini Frijns and Ernst N.H. Jansen. Clin Neurol Neurosurg 1989;91:177-180.

9. Long Term Treatment with High Dosage Bromocriptine in Advanced Parkinson's disease. Ernst N.H. Jansen and Jan D. Meerwaldt. Adv Neurol 1986;45:539-542.

10. Familial alternating Bell's Palsy with Dominant Inheritance. Gerard Hageman, Elly Ippel, Ernst N.H. Jansen and Fred Rozeboom. Eur Neurol 1990;30:310-313.

11. Normal Pressure Hydrocephalus in rheumatic patients, a diagnostic pitfall. Hans Rasker, Ernst N.H. Jansen, Joost Haan and Jan Oostrom. N Engl J Med 1985;312:1239-1241.

12. Een vloeistofchromatografische bepaling van levodopa en 3-0methyldopa in plasma. Paul G.L.C. Krugers Dagneaux, Henk Mouw, Jan T. Klein Elhorst and Ernst N.H. Jansen. Ziekenhuisfarmacie 1993;9:104-107.

13. Madopar in Nocturnal symptoms of patients with Parkinson's Disease. Ernst N.H. Jansen and Jan D. Meerwaldt. Advances in Neurology 1990;53:527-531. 
14. Dementie en de Ziekte van Parkinson, "Lewy Body Disease" of Ziekte van Alzheimer. Ernst N.H. Jansen and Rob A.I. de Vos. Ned Tijdschr Geneeskd 1994, 138. 


\section{Acknowledgements}

I am grateful for the generous help of many persons, who supported the scientific work leading to this thesis. Without the help and willingness of many patients with Parkinson's disease and their partners, any study on pharmacotherapy in this disease would have been impossible.

As James Parkinson stated so clearly in the final paragraphs of his own preface "I shall think myself fully rewarded by my friends to humanity and medical science by having excited the attention of those, who may point out the most appropriate means of relieving a tedious and most distressing malady".

Although I have been engaged for many years in active neurological practice, by virtue of my upbringing and education I could so difficultly detach myself from some scientific work, and I have been led - as in compulsive behaviour - by professional ardour and the dictates of duty. Parkinson's disease is such a ubiquitous disease of the central nervous system, that is was actually not such a difficult task to start with research on some issues of this disease in the little extrapyramidal side striut which was apparently Enschede.

Prof.dr. A. Kemp introduced me to clinical neurology and clearly had a personality and scientific charisma appropriate for me to embark on neurology.

Prof.dr. A. Staal was the genius in Rotterdam "Dijkzigt" to educate me in clinical neurology. I have always been impressed by his constructive and enthusiastic criticism, his directness, his stature, and his energetic intelligent expression of countenance. Prof.dr. $H$. van Crevel and Prof.dr. J. van Gijn helped to create that stimulating and sometimes amicable atmosphere in the department of neurology. When Jos Snoek wrote his thesis "Het denken van de neuroloog" he must have been thinking of Arthur Staal's brain processing.

Prof.dr. J.P.W.F. Lakke regularly called my attention to the possibility of making a thesis. He supported me throughout my subsequent scientific and personal adventures.

Dr. Jan Meerwaldt was my best comrade in extrapyramidal research, and made an everlasting impression by his honesty, friendship and collegiality. He was "small and beautiful".

Dr. W. Beck deserves my gratitude for accepting me as a neurologist in "Beck's" practice in Enschede. He could have been my father, and accepted most of my many characteristical failures as many fathers do. 
Dr. Johannes Lycklama à Nijeholt can create an atmosphere in which research and humour can flourish. Our discussions were often heated but generally fruitful.

The other colleagues of the department of neurology in Enschede have been helpful in tolerating me, with my hardly bearable waste of time in research on Parkinson's disease.

Mrs. Marie Schuil-Friskus provided excellent secretarial help during many years; prepared my texts with devotion, silence and skill.

I am much indebted to my colleagues in the clinical neuropharmacology research group in the MST Hospital Enschede (in alphabetical order) Guus Essink, Dik Hofstee, Teus van Laar and Cees Neef. Apomorphine can be as addictive and toxic as morphine.

Prof.dr. J. Troost kindly suggested me the possibility to make a collection of my scientific public affairs. As a consequence of his move to Maastricht he has shown the relative truth of the saying: a near neighbour is better than a distant cousin.

Many thanks are due to Thera van Lieshout. She seems to be a microsoft computrain, a word perfect with bright windows, and with a compassion for work. A Tulip in Maastricht.

Dr. R. de Vos, neuropathologist, infected me with his enthusiasm on the detection of Lewy bodies in Enschede. The magnificent staining of those ubiquitous Lewy bodies in his "Streeklaboratorium voor Pathologie" made us sing so frequently happily and simultaneously "There is no body like Lewy body". 


\section{Curriculum Vitae}

\section{Ernst N.H. Jansen}

geboren 24 oktober 1945 te Kamperland (Zeeland)

1951 - 1957 Lagere school "Park Rozenburg" te Rotterdam

1957 - 1962 Middelbare school "Libanon Lyceum" te Rotterdam

1962 - 1964 Studie Tandheelkunde, Rijksuniversiteit Utrecht

1964 - 1971 Studie Geneeskunde, Rijksuniversiteit Utrecht

197] - 1972 Officier Koninklijke Luchtmacht - Vliegbasis Ypenburg

1972 - 1978 Opleiding Neurologie en Klinische Neurofysiologie, Afdeling Neurologie, Academisch Ziekenhuis Rotterdam "Dijkzigt" (opleiders: Arthur Staal, Hans van Crevel, Herman Busch, Christa Loonen, Frans van Harskamp, Jan van Gijn en Marinus de Vlieger)

1978 - 1994 Neuroloog Medisch Spectrum Twente te Enschede

1980 - 1985 "Movement Fellow" werkgroep bewegingsstoornissen, Academisch Ziekenhuis Groningen (Prof. Hans Lakke) 

